

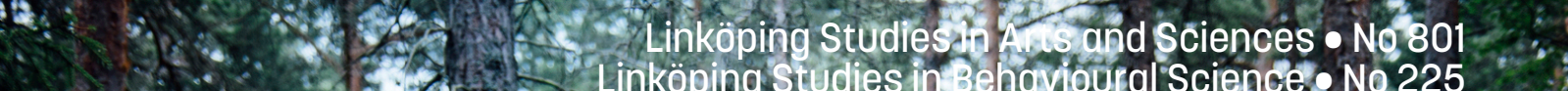



i. 10.9

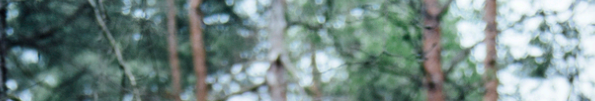




If 17

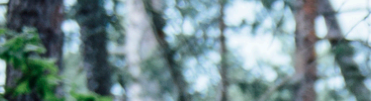

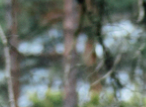

Learning how to recover from st ess-related cisorders viaintemetbasedinter ventions

Rober Pessoin Asplond

D INKOPING 



\title{
Learning how to recover from stress-related disorders via internet-based interventions
}

\author{
Robert Persson Asplund
}

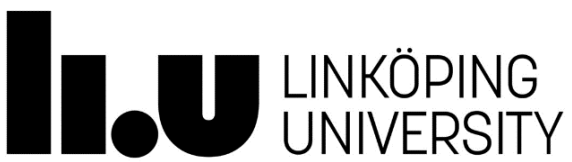

Linköping Studies in Arts and Sciences • No 801

Linköping Studies in Behavioural Science • No 225

Faculty of Arts and Sciences

Linköping 2021 
Linköping Studies in Arts and Sciences $\bullet$ No 801

Linköping Studies in Behavioural Sciences • No 225

At the Faculty of Arts and Sciences at Linköping University, research and doctoral studies are carried out within broad problem areas. Research is organized in interdisciplinary research environments and doctoral studies mainly in graduate schools. Jointly, they publish the series Linköping Studies in Arts and Sciences. This thesis comes from Division of Psychology at the Department of Behavioural Sciences and Learning.

Distributed by:

Department of Behavioural Sciences and Learning

Linköping University

58183 Linköping, Sweden

Robert Persson Asplund

Learning how to recover from stress-related disorders via internet-based interventions

Edition 1:1

ISBN 978-91-7929-722-0

ISSN 0282-9800

ISSN 1653-2029

(c) EY-No This work is licensed under a Creative Commons Attribution-

NonCommercial 4.0 International License.

https://creativecommons.org/licenses/by-nc/4.0/

(C) Robert Persson Asplund

Department of Behavioural Sciences and Learning, 2021

Cover by: Malin Mörner via Johnér Bildbyrå $A B$

Printed by: LiU-tryck, Linköping 2021 
Till Mia, Maja och Ellen

"Om du tänker positivt varje dag, arbetar hårt, strävar efter att bli den bästa versionen av dig själv, omger dig med inspirerande människor och aldrig ger upp, så finns det inga gränser, för hur utbränd du kan bli”

Svend Brinkmann, professor i psykologi (Aalborgs universitet) 


\section{ACKNOWLEDGEMENTS}

I would like to start by thanking all participants included in the studies of the present thesis. Without your participation, this research would never have been possible. I would also like to extend my warmest gratitude to...

Gerhard Andersson, my main supervisor. We first met at Uppsala university in 19992000, when I was a student looking for a scientific project in psychology. From that day on, you have always shown such kindness and openness to new ideas. Your supervision has been very wise and gentle, pushing me when I need to, and generously and trustfully letting me explore and grow as a researcher. And thank you for all the laughs and mischievous pranks (mixing up signs, titles, roles, mugs etcetera). To my delight, I have also noticed that you have picked up some recovery activities during these years.

Brjánn Ljótsson, my co-supervisor. I am very grateful for all your valuable support and encouragement during these years. You have really inspired me in testing and applying various statistical methods. And thank you for sharing your experiences and knowledge on becoming a $\mathrm{PhD}$.

George Vlaescu (a.k.a. G or Speedy), IT-System developer. Thank you for your quick, invaluable and sometimes crucial support regarding the IT-platform iterapy. Without your quick and methodical work, this research would not have been possible.

Per Carlbring, professor and fellow grant applicant. Thank you for your enthusiastic, and super quick responses, and for your helpful and thorough comments on our studies.

Master level psychology students and psychotherapy students. Without your commitment and hard work, this would never have been possible. I have enjoyed reading all the comments from grateful participants regarding the importance of your guidance in their treatment. Study I, Ida Fjellström, Linnea Niemi, Katja Hansson, Forough Zeraati and Masha Ziuzina. Study II, Anna Jäderlind and Isabel Höijer Björk. Study III, Sofia Asplund, Helene von Buxhoeveden, Hanna Delby, Karin Eriksson, Maurits Gerhardsson, Joachim Palm, Thea Skyttberg and Julia Torstensson. Study IV, Fernanda Carvallo, Hanna Christensson, Elin Videsäter and Annakarin Häggman.

Current and former colleagues in the research group at Linköping university, thank you for your inspiration, knowledge and ideas at research meetings, conferences and lunches (at the disgusting restaurant Blåmesen). Jesper Dagöö, for starting this journey together with me back in 2011. Kristin Silfvernagel, for introducing me in all the necessities in the world of academia, and at IBL in particular. Ali Sarkohi, for your warm support and for 
letting me co-author your book. Lise Bergman Nordgren for all the sick jokes and hilarious laughs. Naira Topooco for our shared interest in beautiful old houses (we almost bid on the same house). Kristoffer Vernmark and Hoa Ly for inspirational conversations on internet-based interventions in various formats and settings. Also, thanks to Matilda Berg, Anton Käll, Thomas Lindegaard, Mats Dahlin, Hugo Hesser, Robert Johansson, Peter Molander and Stefan Blomberg for interesting and cheerful conversations.

Britt-Marie Alfredsson and Anette Larsson, for your continuous administrative support and endless patience over my delayed submissions. Maria Jannert, for your help in recruiting students.

Avonova Health $A B$, current and former colleagues, for years of generous support and encouragement, and for making this research possible. I am especially grateful to my former boss and foremost friend, Stefan Persson, for always believing in me and for your warmth, mischievous humour, wisdom and unconditional support.

Jens Högström, Benjamin Bohman and Kristoffer NT Månsson. Thank you for our "doktorandluncher", with the perfect mix of hilarious jokes, gossip and serious talks.

Elin Lindsäter, my former colleague and friend from Gustavsbergs vårdcentral, where my interest in stress started. I am very grateful for your valuable and helpful comments on my studies at the final seminar. And, for sharing the nerdy interest in interventions for stress-related disorders.

Swedish Council for Working and Life Research (FORTE) and Sweden's Municipalities and Regions (SKR) for generous sponsorship and grants over nine years.

Suzanne E Lagerveld, Utrecht and Amsterdam University, and Roland W B Blonk, TNO, for sharing their work on work-focused CBT.

To my parents, Britt-Marie and Christer, and my sister Karin for your encouragement and support.

And finally, my family, thank you Mia, Maja and Ellen, for your unconditional love and support, and for always reminding me of what is really important in life and for teaching me how to recover from stress. 


\section{ABSTRACT}

Stress has become one of the major challenges of modern society, especially within the working population, causing significant costs and personal problems. Notwithstanding the well-known health implications of stress and the benefits of mental health interventions, access to treatment is still relatively limited. Internet provides new options for broad dissemination and a growing body of evidence suggest that internet-based interventions for stress might be effective. However few studies have examined the efficacy in clinical samples or how participants actually experience these treatment delivery formats. Further, only a limited number of studies have evaluated if recovery has the potential in stress prevention and the efficacy of work-focused stress interventions on work-related outcomes (e.g., absenteeism).

The overall aim of Study I, III and IV was to evaluate the efficacy of internetbased interventions targeting employees and managers with stress-related disorders. In Study II, the aim was to investigate the participants experiences of an internet-delivered and work-focused intervention for stress-related disorders and how the intervention could be improved to further enhance the efficacy and utilization in the target population.

In Study I, managers $(\mathrm{n}=117)$, II $(\mathrm{n}=9)$, III $(\mathrm{n}=182)$ and IV $(\mathrm{n}=69)$, employees, who fulfilled the ICD-10 criteria for a stress-related disorder were recruited nationally via an open requitement strategy. Participants in Study I were randomized to an eight-week internet-based stress and positive management program or attention control (AC). In Study II, participants were recruited for interviews from an independent controlled pilot trial. In Studies III participants were randomized to either a ten-week work-focused and internetbased intervention for stress-related disorders or a generic version (excluding the work-related aspects) or a waitlist control group (WLC). Study IV was a controlled pilot trial evaluating a brief five-week recovery training intervention, compared to a WLC-group. Main outcomes in Studies I, II and IV were perceived stress, burnout, exhaustion, recovery experiences and work-related outcomes (e.g., absenteeism). In Study II, semi-structured interviews were used for data collection and interviews were transcribed and then analysed with thematic analysis.

Results of Studies I, III and IV indicated that, compared to controls, all interventions were effective in reducing chronic stress and mental health-related symptoms with sustained effects until a six-months follow-up. In Study II, participants found the work-focused stress intervention to be feasible and reported positive experiences on stress, mental health and well-being in both life and at work. Finally, preliminary results from Study III suggests that, compared to controls, the work-focused and internet-based intervention was effective in improving work ability and reducing sickness absence. 
In the studies of the present thesis internet-based interventions, designed to reduce symptoms of stress and increase participation at work, were found be effective. If implemented, these relatively brief and accessible interventions could be a feasible way to increase access to treatment and learning distressed employees and others how to prevent and recover from stress-related disorders. The results motivate further evaluation within different populations, including mediating treatment mechanisms and further integration within the workplace. 


\section{LIST OF SCIENTIFIC PAPERS}

I. Persson Asplund, R., Dagöö, J., Fjellström, I., Niemi, L., Hansson, K., Zeraati, F., Ziuzina, M., Geraedts, A., Ljótsson, B., Carlbring, P., \& Andersson, G. (2018). Internet-based stress management for distressed managers: Results from a randomised controlled trial. Journal of Occupational and Environmental Medicine, 75, 105-113.

II. Persson Asplund, R., Jäderlind, A., Björk, I. H., Ljótsson, B., Carlbring, P., \& Andersson, G. (2019). Experiences of internet-delivered and workfocused cognitive behavioural therapy for stress: A qualitative study. Internet Interventions, 18, 100282.

III. Persson Asplund, R., Asplund, S., Carvallo, F., Christensson, H., Häggman, A.K., Johansson, T., Videsäter, E., Ljótsson, B., Carlbring, C., \& Andersson, G., (2021). Work-focused versus generic internet-based interventions for stress-related disorders: A randomized controlled trial. Unpublished manuscript.

IV. Persson Asplund, R., Delby, H., Eriksson, K., Gerhardsson, M., Johansson, T., Palm, J., Torstensson, J., von Buxhoeveden, H., Ljótsson, B., Carlbring, C., \& Andersson, G., (2021). Learning how to recover from stress: Results from an internet-based randomized controlled pilot trial. Unpublished manuscript. 


\title{
ABBREVIATIONS
}

\author{
ANCOVA Analysis of covariance \\ ANOVA Analysis of variance \\ $\mathrm{AD} \quad$ Adjustment disorder \\ CBT Cognitive behavioural therapy \\ CMD Common mental disorder \\ DSM Diagnostic and Statistical Manual of Mental Disorders \\ ED Exhaustion disorder \\ iCBT Internet-based cognitive behavioural therapy \\ ICD International Statistical Classification of Diseases and Related \\ Health Problems \\ PSS Perceived Stress Scale \\ RCT Randomized controlled trial \\ RTW Return-to-work \\ SMBQ Shirom-Melamed Burnout Questionnaire \\ WLC Waitlist control condition \\ W-iCBT Work-focused and internet-based cognitive behavioural therapy
}




\section{CONTENTS}



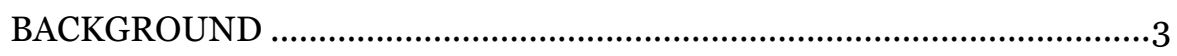

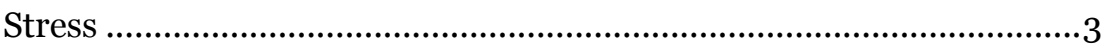

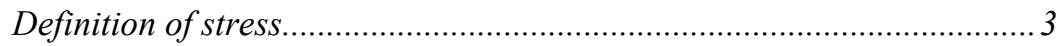

Stress and disease …….....................................................................

Cardiovascular disease .................................................................... 7

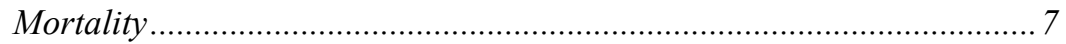



Neurobiological correlates and cognitive impairments........................... 8

Immune system ………............................................................... 8

Absenteeism, presentism and long-term sick leave .................................. 8

Stress-related disorders....................................................................... 9

Potential risk- and protective factors ................................................. 14

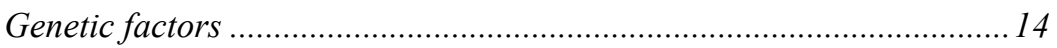

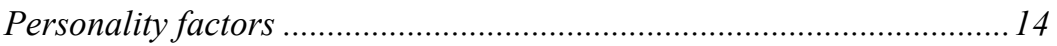

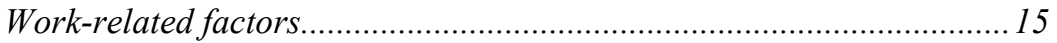



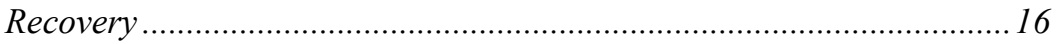



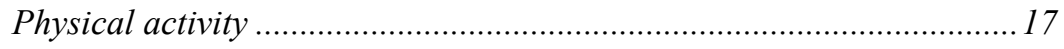

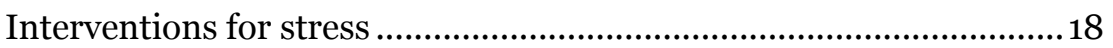



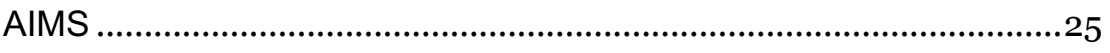



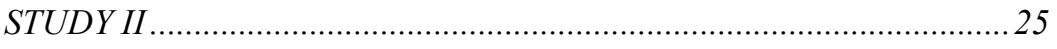

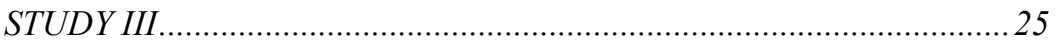

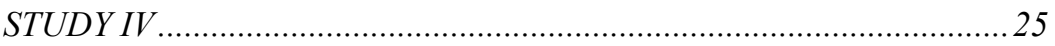



Study I: Internet-based stress management for distressed managers: results from a randomised controlled trial.............................................27 


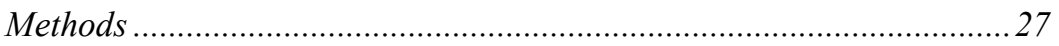



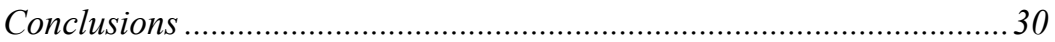

Study II: Experiences of internet-delivered and work-focused cognitive behavioural therapy for stress: A qualitative study .............. 31

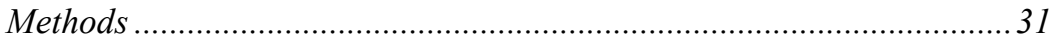

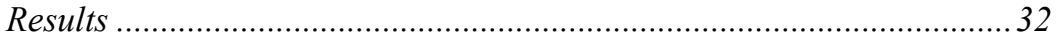

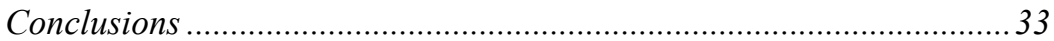

Study III: Work-focused versus generic internet-based interventions for employees with stress-related disorders: a randomized controlled

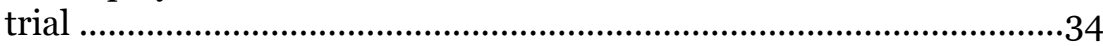

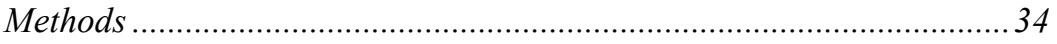

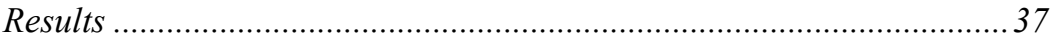

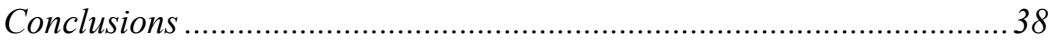

Study IV: Learning how to recover from stress: results from an Internet-based, randomized, controlled pilot trial...............................39

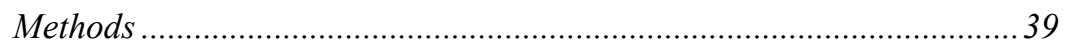

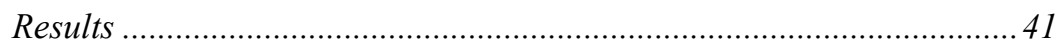

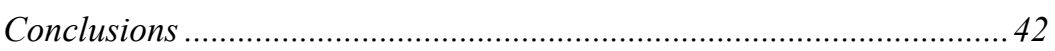

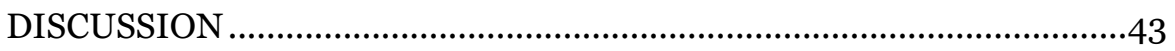

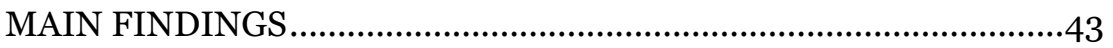

Effects of internet-based cognitive behavioural stress management

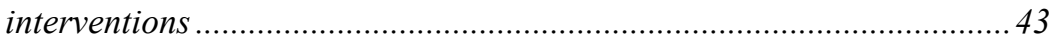

Effects of internet-based and work-focused stress interventions ............. 45

Effects of internet-based preventive stress interventions .........................46

Experiences of internet-based stress interventions .................................. 47

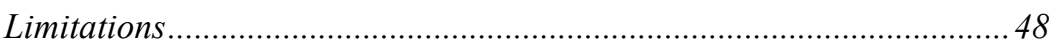

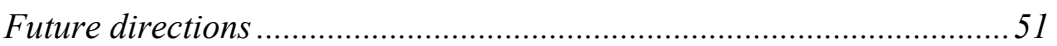

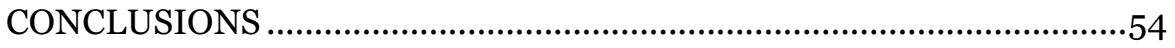

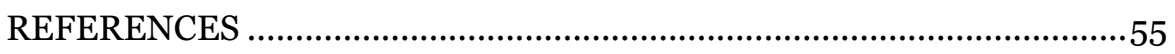

LINKÖPING STUDIES IN BEHAVIOURAL SCIENCE............................ 84 


\section{INTRODUCTION}

Within two decades, globalization and advancements in technology, automatization and digitalization, has led to a major shift in how we live, work and interact. We have rapidly moved from physical to mental strain. Consequently, stress has increasingly been recognized as a significant health problem, especially within the working population (Atroszko et al., 2020).

Stress is not a disease in itself. It helps us overcome everyday stressors and plays an important role in our survival as a species. However, stress becomes a problem when our body is forced to mobilize energy for an extended period of time without sufficient recovery. Long-term exposure to stress can lead to a dysregulation in the allostatic system, "allostatic load", which constitutes the fundamental features in the development of chronic stress and stress-related disorders (Sterling \& Eyer, 1988). Chronic stress has been associated with wellknown health implications, e.g., coronary artery disease, mortality, metabolic syndrome, cognitive impairments, lowered immune functioning, anxiety, depression and insomnia ( $\AA$ kerstedt, 2006; Grossi et al., 2015; Kiecolt-Glaser et al., 2002; Kivimäki et al., 2006; Melchior et al., 2007).

In addition, chronic stress has been associated with impaired work functioning and problems in work participation such as sickness absence and long-term sick leave (Joyce et al., 2016; Kessler et al., 2006; Sanderson \& Andrews, 2006). Decreased work participation is problematic as it has direct effects on people's well-being and leads to immense costs for society (Goetzel et al., 2003; Hassard et al., 2018). Given these rising costs, it is not surprising that many policy makers view stress as a major public health issue and are seeking advice on the types of interventions that may be effective (World Health Organization, 2008).

Despite the comprehensive knowledge regarding stress and although evidence suggests that interventions are effective in increasing our psychological resources and resilience to stress (Richardson \& Rothstein, 2008), we are still struggling with the mission to provide effective treatment to those who are suffering from chronic stress (Hilton et al., 2008). Internet, smartphones, and innovations in technology provide new options for broad dissemination of interventions and change the way we experience treatment (Andersson, Titov, et al., 2019). During the last two decades, a growing body of literature has documented the efficacy of internet based stress management interventions (Heber et al., 2017).

Given the rapidly accumulating evidence, we are still lacking knowledge regarding the efficacy in clinical samples and the effects of work-focused stress 
interventions on work-related outcomes (e.g., absenteeism), and how participants actually experience these new treatment delivery formats.

The present thesis will introduce different perspectives on stress and research on interventions for stress-related disorders. A summary of the four empirical studies will be presented. In the final section, I will discuss the key findings, future remarks and to what extent the present thesis adds to accumulating evidence on the efficacy and experiences of internet-based interventions for stress-related disorders. 


\section{BACKGROUND}

\section{Stress}

\section{Definition of stress}

The concept of stress originates from the study of physics and has been used for centuries to describe the elasticity of various materials. Walter Cannon followed by Hans Selye was the first to use the concept in the medical, social and psychological sciences (Cannon, 1915; Selye, 1936). In the 1930s Selye discovered that animals displayed similar physiological reactions when exposed to different stressful stimuli, e.g. cold, surgical wounds and vigorous physical activity (Selye, 1936). Within days he found changes in the animal's spleen, thymus, liver and adrenal glands, where the stress hormones adrenaline and cortisol are produced. Selye defined these reactions as, "the nonspecific response of the body to any demand made upon it" (Selye, 1936).

Although Selye mainly focused on physiological stress reactions he was also interested in the factors that can cause stress. These factors have been termed stressors. A stressor is any factor that contributes to a physical and/or mental stress reaction and requires a person to adapt their behaviours (Carr \& Umberson, 2013).

Since the early studies of Walter Cannon and Hans Selye, stress has been defined and studied within various disciplines and across different populations, using different terminology and outcomes, ending up in a range of theories and models. This wide body of research has broadened our understanding of stress. Today, stress is merely defined as a simple stimuli and response phenomenon, rather an adaptive response to the continuous and complex transaction between internal and external factors, including biological factors (e.g., neural, neuroendocrine, neuroendocrine-immune and genetics), psychological factors (e.g., cognitions, emotions, traits, coping style) and structural and social factors (e.g., gender, work, family, culture, ethnicity, socioeconomic).

\section{The impact of biological factors}

Since the beginning of time, humans have been faced with various threats and dangers. Evolution has brought us an intricate system of several parallel running processes, including neural, endocrine and immune responses, with the overall aim of maintaining homeostasis.

When faced with a stressful situation, hypothalamus and the brain stem receives internal and external input that are relayed to the primary components of the stress systems, the neural sympathetic-adrenomedullary (SA) and the parasympathetic systems, and the endocrine hypothalamic-pituitary-adrenal 
(HPA) axis (Charmandari et al., 2005; Chrousos, 2009). These systems are in turn linked to, hippocampus, medial prefrontal cortex and amygdala, structures that are involved with processing, interpretation and regulation of emotions, including stress (Gunnar \& Quevedo, 2007).

The SA system, also known as the rapid or acute stress response, is activated by the hypothalamus following arousal in the sympathetic nervous system. That process stimulates the adrenal medulla to secret hormones such as adrenaline and noradrenaline into the blood system. Within 2-3 seconds, adrenaline and noradrenaline have affected several organs and induced effects such as elevated pulse and heart rate, increased blood flow to the brain and muscles, increased sweating and stimulation of glycogenolysis in the liver to rapidly release large amounts of energy (McEwen, 2007). All activities constitute important functions in mobilizing the fight-or-flight reaction (Cannon, 1915).

In parallel with the SA system, the HPA axis system, is activated. Activation occurs by hypothalamus secreting corticotropic releasing hormone that stimulates the pituitary gland to release adrenocorticotropic hormone (ACTH). ACTH stimulates the adrenal gland to secrete glucocorticoids (e.g., cortisol). The activation of the HPA-axis is a slower process, and the production of these steroids can take up to 25 minutes to reach its peak. Cortisol affects the body in several ways. In addition to increasing blood pressure and metabolism, cortisol also affects the immune system (Gunnar \& Quevedo, 2007).

Whereas the sympathetic branch of the autonomous nervous system triggers arousal, the parasympathetic system restores the organism to a relaxed state (e.g., relaxing muscles, slows the heart rate, lowers blood pressure). This adaptive interplay between the sympathetic and the parasympathetic nervous systems serves to maintain homeostasis and has been termed "allostasis" (Sterling \& Eyer, 1988). Allostasis involves the long-term regulation of the sympathetic and the parasympathetic systems, HPA-axis and the cardiovascular, metabolic and immune systems.

However, when daily stress extends to prolonged or chronic stress that last over weeks and even months, functional changes is seen in the adrenal gland producing relatively higher levels of glucocorticoids. Consequently, we become overexposed to stress hormones, which can lead to a dysregulation in the allostatic system and impairments in bodily functions (McEwen, 1998). Anabolic, restoring activities (e.g., sleep and recovery) are set aside for catabolic, energy consuming, activities. This dysregulation or 'wear and tear' has been term "allostatic load" (Sterling \& Eyer, 1988) and constitutes the fundamental features in the development of stress related disorders and diseases. In addition, chronic activation of the stress-system causes suppression of the gonadal, growth hormone (GH), and thyroid axes. These metabolic disturbances, leads to the metabolic syndrome and cardiometabolic risk factors including obesity, hypertension, dyslipidaemia, and endothelial dysfunction (Kivimäki \& Steptoe, 2018; Tsatsoulis \& Fountoulakis, 2006). 


\section{The impact of psychological factors}

Psychological perspectives and explanatory models take their starting point in the interaction between stressors and the individual traits, cognitions, emotions, and coping strategies.

As previously mentioned, stress is merely a simple stimuli response phenomenon, rather a product of the complex interplay between the individual and the environment. Today, most researchers agree upon the notion that cognitions play an important role in experiences and reactions to stress. According to Lazarus and Folkman (1984, p. 19), "Psychological stress is a particular relationship between the person and the environment that is appraised by the person as taxing or exceeding his or her resources and endangering his or her well-being." According to their definition, stress arises if the individual experiences that the stressor either exceeds her resources or threatens her survival. Lazarus and Folkman's work resulted in the well-known Transactional model of stress (1984). According to the model, the primary assessment is made when the individual becomes aware about what he faces and categorizes the situation as threatening, stimulating, harmless or stressful. The secondary assessment is about how the person should handle the situation.

Contemporary research, using modern brain imaging technology, has suggested a close relation between stress and emotions. For example, studies have shown that the amygdala, medial prefrontal cortex and anterior cingulum regulates stress-responses during emotional stimuli (Wager et al., 2008). During processing of emotional stimuli, activity of the amygdala is down regulated, while areas of the medial prefrontal cortex are upregulated (Golkar et al., 2012). These functional connections appear to change due to chronic stress, with reduced ability to regulate emotions and stress (Golkar et al., 2014).

The association between human resilience and vulnerability to stress and several personality factors has been studied since the early 1970s (Vollrath, 2001). Research has predominantly focused on the relationship between type A personality, characterized by hostility and impatience, stress and increased risk of cardiovascular disease and mortality (Friedman, 1985). Other well-known personality factors, such as neuroticism, locus of control, self-efficacy as well dimensions of the five-factor model/Big five has been linked to stress and other health related risk factors (Vollrath, 2001). Researchers have not only studied the relationship between stress and risk of ill health, but also what traits that manifest resilience to stress. Traits, such as self-efficacy, perseverance, optimism and locus-of-control seems to play an important role as mediators between stress, health and well-being (Vollrath, 2001). A striking example is the personality factor, hardiness. Kob individuals are more resistant or susceptible to stress-related ill health. Hardiness is characterized by the ability to, (a) self-control in stressful events, (b) maintain commitment to activities, and (c) adapt to unexpected changes in life, 
accept them as challenges or temporary interruptions and perceive them as a chance for personal development.

The impact of internal or external stressors is also dependent on individual coping strategies. Coping strategies are the changes in behaviours, thoughts or emotions, individuals make in response to a stressor (Lazarus \& Folkman, 1984). The two main strategies described are problem-focused coping, by changing the situation that causes the stressor or by preventing that the stressful situation will reoccur, and emotion-focused coping, by dealing with the reactions or emotions evoked by a stressor (Carver et al., 1989). Several studies claim that problemfocused coping is more effective than emotion-focused coping in stressful situations (Carr \& Umberson, 2013). Problem-focused strategies have been associated with lower levels of depression and anxiety, whereas emotion-focused strategies have been related to higher levels of stress and hopelessness (Billings \& Moos, 1981). However, emotion-focused coping can be effective when the stressor cannot be changed (Reynolds et al., 2000). Both forms of coping strategies are common components in interventions for stress (Richardson \& Rothstein, 2008).

\section{The impact of social factors}

Social perspectives help us understand how structural, demographic and economic stressors affect both exposure, experiences and reactions to stress (Carr \& Umberson, 2013).

Socio-economic status (SES), whether operationalized as educational, income level or occupational status, is associated with almost all indicators of health, including stress (Carr \& Umberson, 2013). Several studies have documented a link between SES, stress and health problems (Carr \& Umberson, 2013). Low SES increase the risk for stressful life events, such as divorce, unemployment (Turner et al., 1995), financial strain (Kahn \& Pearlin, 2006), stress-related disorders and premature death (Wilkinson, 1992). Even in countries with high level of social and economic welfare, a relative lower SES is a considerable stress factor (Kopp et al., 1998). SES has also been associated with various forms of resources, for example social support (Krause \& Borawski-Clark, 1995), and the use of adaptive coping strategies (Kristenson et al., 2004; Wagmiller et al., 2008) during stressful life events.

Other perspectives have emphasized the impact of social role on stress. Each social role is accompanied by a set of expectations and norms that influence our behaviour (Carr \& Umberson, 2013). Stress can result from holding several roles which exceeds one's resources or coping ability (role overload). Stress can also occur when roles are in conflict, such as a devoted parent, caring son or daughter and a competent and committed employee (role conflict). However, balancing between multiple roles does not always lead to stress or ill health. Self- 
determination (e.g., if you have chosen the role yourself) seems to modulate the effects on stress and health (Carr \& Umberson, 2013).

\section{Stress and disease}

Chronic stress is associated with a range of adverse physiological and psychological outcomes. The following section will give an overview of some of the established clinical correlates.

\section{Cardiovascular disease}

Several studies have reported a strong association between acute and chronic stress and cardiovascular disease (Fransson et al., 2012; Huang et al., 2015; Kivimäki et al., 2006). Accordingly, evidence shows that individuals who experience stress in work or in private life have a 1.1 to 1.6-fold increased risk of stroke and coronary heart disease (Kivimäki \& Steptoe, 2018).

\section{Mortality}

Most studies on the association between stress and mortality have been conducted within the occupational health area. Estimates from the Swedish Work Environment Authority, suggest that 700-800 work-related deaths are caused by stress each year (Arbetsmiljöverket, 2019). Further, work-related stress, specified as work-related exhaustion, has been found to predict all-cause mortality among industrial employees (Ahola et al., 2010).

\section{Metabolic syndrome}

As described in the section on biological factors on stress, chronic activation of the stress-system causes suppression of the gonadal, growth hormone and thyroid axes, which leads to metabolic disturbances, causing the metabolic syndrome, obesity and type 2 diabetes (Kuo et al., 2019; Tsatsoulis \& Fountoulakis, 2006). Notably, the indices of stress in OECD countries correlate with the increasing incidence of both obesity and the metabolic syndrome (Kuo et al., 2019; Tsatsoulis \& Fountoulakis, 2006). Studies have also suggested a bidirectional relationship between stress and obesity, implicating that the chronic hyperactivation of the HPA axis under prolonged stress favours accumulation of visceral fat, and, obesity may cause HPA axis dysfunction (Tsatsoulis \& Fountoulakis, 2006).

A systematic review and meta-analysis examined the impact of different types of stress, stressor(s) and association with the metabolic syndrome (Kuo et al., 2019). For instance, adults in the high-stress groups had $45 \%$ higher chance of having metabolic syndrome than adults in the low-stress groups and based on cross-sectional studies suggested that occupational stress showed the strongest effect, while perceived general stress showed the weakest effect (Kuo et al., 2019). 


\section{Neurobiological correlates and cognitive impairments}

Contemporary research using modern brain imaging technology have found that chronic stress affects the volume in several cortical structures (Ansell et al., 2012; Arnsten, 2009, 2015; Grossi et al., 2015; Lupien et al., 2007; McEwen \& Morrison, 2013). For instance, in an fMRI study by Savic et al. (2017) of patients with chronic stress, reduced cortical volume in the prefrontal cortex, (e.g., attention, working memory, decision-making) and the hippocampus (e.g., memory formation, learning, and spatial cognition) were found. They also reported increased cortical volume in the amygdala, compared to healthy controls. Further, the size of changes in cortical volume correlated with selfestimates of perceived stress and burnout (Grossi et al., 2015; Savic et al., 2017). Repeated fMRI, after 1.5-2 years, showed remission of volume in the prefrontal cortex and partial remission in the amygdala. The aforementioned areas account for the integration of emotional, cognitive and physiological function, and functional changes in these areas are believed to constitute several of the symptoms that appear in burnout and exhaustion (Grossi et al., 2015).

Systematic reviews have reported significant differences in performance on neuropsychological tests amongst patients with chronic stress and burnout on cognitive functioning regarding attention, executive functions, learning and memory (Deligkaris et al., 2014; Jonsdottir et al., 2013). Long term follow-up studies indicate that cognitive impairments in these patients may be long-lasting (Jonsdottir et al., 2017). Fortunately, studies suggest improvement in cognitive functioning can be obtained or at least accelerated with cognitive behaviour therapy (CBT; Van Dam et al., 2012).

\section{Immune system}

Whereas short-term stress, strengthened the immune system and the risk of inflammation decreases. Chronic stress, however, inhibits the immune system with increase in susceptibility to infections, inflammation and autoimmune disease (Kiecolt-Glaser et al., 2002; Mommersteeg et al., 2006; Song et al., 2018, 2019). Studies also indicate that inflammatory processes may account for the symptoms of fatigue reported by individuals with burnout (Vollmer-Conna et al., 2004).

\section{Absenteeism, presentism and long-term sick leave}

In addition to the well-known health implications mentioned above, chronic stress and stress-related disorders have been associated with impaired work functioning and problems in work participation such as sickness absence, presentism, coupled with increased staff turnover, extended usage of healthcare and long-term sick leave (Joyce et al., 2016; Kalia, 2002; Kessler et al., 2006; Sanderson \& Andrews, 2006). In addition, poor self-assessed work ability has 
been associated with increases risk of sickness absence and long-term sick leave over 10 years (Palmlöf et al., 2019).

Decreased work participation is problematic as it has direct effects on people's well-being and leads to immense costs for employers and for society as a whole (Goetzel et al., 2003; Hassard et al., 2014, 2018). For instance, the total estimated annual costs for work-related stress observed in the OECD countries is considerable, ranging from US $\$ 221$ million to $\$ 187$ billion annually (Hassard et al., 2018). Except for direct costs related to sick-leave, medical and health-care, presentism (i.e., being present at work while being physically or mentally ill) and productivity loss have been found to be the largest contributors to the total costs (Hassard et al., 2018). Given these rising costs, it is not surprising that many policy makers view chronic stress as a major public health issue and are seeking advice on the types of interventions that may be effective (World Health Organization, 2008).

\section{Stress-related disorders}

\section{Diagnostic features}

As mentioned above, chronic stress can lead to a wide range of disorders and clinical outcomes, including stress-related disorders (Chrousos, 2009; Cohen et al., 2007; Hammen, 2015). Although, the high prevalence and the serious health implications of chronic stress, we still lack specific diagnostic criteria and adequate diagnostic interview schedules for stress-related disorders (Bianchi et al., 2016; Casey, 2014; Fava et al., 2019; Grossi et al., 2015). Accordingly, scholars have emphasized on the difficult to distinguish stress-related disorders from normal stress reactions and from other health conditions, especially mental health disorders (Bianchi et al., 2016; Casey, 2014; Fava et al., 2019; Grossi et al., 2015). Nevertheless, the major diagnostic systems Diagnostic and Statistical Manual of Mental Disorders (DSM-5) and International Statistical Classification of Diseases and Related Health Problems (ICD-10 and 11) include sections regarding stress-related disorders.

The section regarding stress-related disorders in Swedish version of ICD-10 (F43) contains of seven subtypes that varies in symptomatology, duration and severity. The ICD-10 (and the DSM-5) distinguish between reactions to traumatic (e.g., post-traumatic stress disorder, PTSD) and non-traumatic stressors (e.g., adjustment disorders):

- Acute stress reaction (F43.0)

- Post-traumatic stress disorder (F43.1)

- Adjustment disorder (F43.2)

- Other specified reactions to severe stress (F43.8), which includes:

○ Exhaustion disorder (F43.8) 
- Other specified reactions to severe stress than Exhaustion disorder (F43.8W)

- $\quad$ Reaction to severe stress, unspecified (F43.9).

\section{From stress to stress-related disorders}

Scholars have proposed a continuous overlap between the non-traumatic stressrelated disorders, i.e., from Adjustment to Exhaustion disorder (Åsberg et al., 2010; Bianchi et al., 2016; Casey, 2014; Fava et al., 2019; Grossi et al., 2015). The first is manifested by maladaptiv stress and the latter by chronic fatigue and exhaustion. Åsberg et al. (2010) suggested that stress-related disorders typically follow a development in three phases consisting of a prodromal phase, an acute phase and a recovery phase.

The prodromal phase is characterized by episodic stress symptoms, both physical and mental, for example in the form of tension pain in the neck or back, palpitations, gastrointestinal problems, sleep disturbance, irritability, panic attacks and concentration difficulties. If these episodic stress symptoms continue over the course of months and sometimes even years, the stress symptoms usually exacerbate into the acute phase, marked by physical and mental fatigue, resistant to rest and recovery.

Åsberg et al. (2010) described that the acute phase comes suddenly, often in connection with a stressful or upsetting situation. The acute phase is also characterized by cognitive deficits (short term/working memory, attention and spatial/orientation), increased light and sound sensitivity, emotionality and irritability, pain and aches and stomach and intestinal problems. It is also common with sleep problems, depression and anxiety.

In the recovery phase, which is the final stage, symptoms gradually return to a normal state. Usually, the stress sensitivity and cognitive symptoms remains for a longer period of time (1-2 years) and can affect return to work and to normal functioning (Åsberg et al., 2010).

\section{Burnout}

Before we continue to the diagnostic features of the Adjustment and Exhaustion disorders and comorbidities, we should discuss the term "burnout", often used in the international literature (Freudenberger, 1974; Maslach, 1979, 1987; Schaufeli et al., 2001).

During the last decades, occupational stress and high workload have been increasingly recognized as significant contributors to the global burden of disorders and disease (Atroszko et al., 2020). Accordingly, a more detailed definition of burnout was recently included in the current update of ICD-11. Burnout is defined as an occupational phenomenon, a result of chronic workplace stress that has not been successfully managed, but is not classified as a medical 
condition (Atroszko et al., 2020). Burnout is characterized by constant feelings of helplessness, fatigue and emotional exhaustion (Schaufeli \& Enzmann, 1998). Burnout has been defined in slightly different ways by different research groups over the years (Maslach \& Leiter, 2016). However, the focus on occupational stressors and emotional exhaustion has remained as core factors for the condition (Maslach \& Leiter, 2016). For employees experience chronic occupational stress, the QD85 Burnout in ICD-11 could be applicable. However, for most individuals experiencing chronic stress, stressors are typically not restricted to the workplace (Hasselberg et al., 2014). Hence, in the present thesis, diagnostic description and criteria for Adjustment and Exhaustion disorder, and have been used.

\section{Adjustment disorder}

The new revision of the International Classification of Diseases 11th edition (World Health Organization, 2020), efforts have been made to improve the clinical utility of adjustment disorder (AD). The new diagnostic features of $\mathrm{AD}$ capture the core clinical manifestations of $\mathrm{AD}$, namely: 1) preoccupation (e.g., constant rumination about the stressor and its consequences), and 2) failure to adapt (e.g., impairment in functioning in educational, vocational, interpersonal or other contexts). According to the ICD-11, adjustment disorder (AD) is;

"a maladaptive reaction to an identifiable psychosocial stressor or multiple stressors (e.g., divorce, illness or disability, socio-economic problems, conflicts at home or work) that usually emerges within a month of the stressor. The disorder is characterised by preoccupation with the stressor or its consequences, including excessive worry, recurrent and distressing thoughts about the stressor, or constant rumination about its implications, as well as by failure to adapt to the stressor that causes significant impairment in personal, family, social, educational, occupational or other important areas of functioning. The symptoms are not better explained by another mental disorder (e.g., Mood Disorder, another disorder specifically associated with stress) and typically resolve within 6 months, unless the stressor persists for a longer duration." (World Health Organization, 2020, p. 11)

As the diagnostic features suggest, empirical studies has advocated that $\mathrm{AD}$ is a transient and accumulative disorder, with a typical onset 6 to 24 months prior assessment (Maercker et al., 2012), and from which most people remit spontaneously (Andreasen \& Hoenk, 1982; Diefenbacher \& Strain, 2002). For example, O'Donnell et al. (2016) found that the prevalence of adjustment disorder was $19 \%$ at 3 months and $16 \%$ at 12 months after onset. For some individuals with $\mathrm{AD}$, estimates show that about $20 \%$ develop more severe disorders, most commonly chronic stress, depression and alcoholism (Lorenz et al., 2018; O’Donnell et al., 2016). 


\section{Exhaustion disorder}

As mentioned, in the case of the adjustment disorder, given that the stressor(s) no longer are active, symptoms typically resolve within six months. However, some stressors are recurring, and others are chronic in nature, and as a consequence, symptoms may develop and worsen over the course of months and even years, leading to increasing fatigue, cognitive deficits and disturbed sleep clinical manifests of the exhaustion disorder.

The exhaustion disorder (ED) diagnosis is unique to the Swedish version of ICD and diagnostic criteria is adapted from the Swedish National Board of Health and Welfare (2003). ED is characterized by symptoms of mental and physical fatigue (present for a minimum of two weeks) due to psychosocial stressors that have been present for at least six months before diagnosis. Core symptoms include markedly reduced mental energy, which is manifested by reduced initiative, lack of endurance, or an increase in time needed for recovery after mental effort. At least four of the additional symptoms (e.g., insomnia, cognitive deficits, pain, palpitations, gastroenteric problems, sound and light sensitivity) must be present nearly every day for at least two weeks, and lead to clinically significant distress or impairment (Socialstyrelsen, 2003).

\section{Differential diagnostics}

Symptoms of anxiety and depression are common in individuals with stressrelated disorders. For instance, in a study of 232 clinically referred patients with ED, 67\% also meet criteria for both depression and anxiety disorder (Glise et al., 2012). In terms of differential diagnostics and comorbid disorders there is a great overlap between stress-related disorders and symptoms of depression and anxiety. This is particularly the case when a depressive or anxiety disorder is triggered by a stressful life event. With this overlap, determining diagnosis and which disorder should be the primary target of intervention can be difficult.

However, there are some features that differentiate stress-related disorders from comorbid disorders (Kristiansen et al., 2019). For instance, individuals with ED normally experience residual stress sensitivity, fatigue and cognitive impairment, even after remission of depressive symptoms (Åsberg et al., 2013). In the case of depression, the course is usually more episodic, with a chance of full recovery between episodes (Åsberg et al., 2013). Moreover, the neurotransmitters also differ between states (Åsberg et al., 2013). For instance, the main transmitter involved in depression is serotonin, while chronic stress is foremost associated with cortisol. Finally, the effect of antidepressant drug treatment uncertain in stress-related disorders (Åsberg et al., 2013). Anxiety, worry, and bodily tension are common symptoms after a stressful life event. However, if the symptoms of anxiety recede as an effect of fewer stressors, and if symptoms are not specific enough to meet criteria for an anxiety disorder, a stress-disorder should be diagnosed. 


\section{Prevalence}

In recent years, stress and stress related disorders have received more attention, with higher prevalence among women and within the working population (Eurofound, 2017). For example, every fourth employee have experienced stress during most of their working day (Eurofound, 2017), and according to the Swedish Work Environment Authority (2016), 15\% of women and 8\% of men report problems at work due to stress and other mental health related complaints. In Sweden has the prevalence of burnout in the working population proved to be between 10 and 16\% (Lindblom et al., 2006; Norlund et al., 2010).

Population based studies on the prevalence of stress-related disorders are scarce, due to differences in study methodology, diagnostic criteria and assessment tools. However, in two studies of representative samples of the German general population, $1-2 \%$ were diagnosed with $\mathrm{AD}$ according to the ICD10 and 11 criteria (Glaesmer et al., 2015; Maercker et al., 2012). In clinical settings (primary and psychiatric care), $\mathrm{AD}$ is one of the most commonly used diagnosis, with prevalence ranging between 9 and 35\% (Casey, 2014; Koopmans et al., 2011; Reed \& Buck, 2009; Sundquist et al., 2017; Yaseen, 2017).

As previously mentioned, ED is a Swedish diagnosis, and consequently population-based studies on the prevalence of ED are limited. A recent crosssectional study, based on physician diagnosis of 3406 participants, $4.2 \%$ fulfilled ED (Höglund et al., 2020). Previous studies, based on clinical assessment amongst patients in primary care has found a prevalence of $9 \%$ (Glise, 2014), and a study based on self-rated questionnaires of ED among healthcare and social insurance workers found a prevalence of $16 \%$ (Glise et al., 2010).

\section{Demographic differences}

The prevalence, incidence and morbidity rates of stress and stress related disorders are higher in women than in men, and amongst employees working in female dominated sectors, e.g., education, healthcare, elderly care and social services (Arbetsmiljöverket, 2018; Ayuso-Mateos et al., 2001; Hilton et al., 2008; Kessler et al., 2006; Norlund et al., 2010). Managers frequently report high job demands and work intensity, which may result in chronic stress and even burnout (Cavanaugh et al., 2000; Eurofound, 2016). Managers, in both private and public sectors, displayed high prevalence of insomnia (woman $=23 \%$; men $=15 \%$ ), exhaustion (woman $=10 \% ; \operatorname{men}=5 \%$ ) and depression (woman $=5 \%$; $\operatorname{men}=3 \%$ ) in a report by (Nyberg et al., 2015).

According to statistics from the Swedish Social Insurance Agency, stressrelated disorders were approximately four times more common among women than in men (Försäkringskassan, 2015). (Höglund et al., 2020; Norlund et al., 2010) found that burnout was higher among women aged 35-44 years and among men aged 25-34 years and that the degree of burnout decreased with age. Accordingly, individuals between the ages of 30 and 39 years are at higher risk of 
being on sick leave due to stress-related disorders (Försäkringskassan, 2015), and the incidence of stress is higher among people with post-secondary education, compared to people with lower level of education (Swedish Work Environment Authority, 2016).

There are many possible explanations for the demographic differences mentioned above. For instance, women report more stress due to work-family conflict, still having greater responsibility for home and family (Clays et al., 2009). Further, a report suggested that general practitioners may overestimate work ability and fail to assess mental health in men, and which subsequently results in higher frequency of sick-leave among women (Riksrevisionen, 2019). The higher prevalence of stress and burnout in female-dominated occupations, such as school, care and social services, might be due to the fact that female dominated sectors receive less resources in terms of personnel, managerial and administrative support etcetera (Arbetsmiljöverket, 2016). For instance, in maledominated industries, such as construction, workgroups are generally smaller. Finally, it is not surprising that the age groups 25-44 years, are perceived as most stressful. In these years, most people are set off finding a partner, starting a family and at the same time succeed in making a career (Norlund et al., 2010).

\section{Potential risk- and protective factors}

Many factors interact and constitute potential risk- and protective factors in the development of chronic stress, including genetic, personality, work-related, and a range of lifestyle and behavioural factors.

\section{Genetic factors}

Chronic stress affect the genetic expressions and the formation and development of neurons in both humans and animals (Gunnar \& Quevedo, 2007). Secretion of cortisol during infancy may affect the development of the synaptic connections of neurons and determine the individual ability to regulate stress in adulthood (Gunnar \& Quevedo, 2007). For example, a study on rats found that cubs that are groomed regularly by their mothers are less afraid and has a better ability to regulate stress reactions as adults (Caldji et al., 1998). Another study reported that the first weeks, are extra sensitive to the mother's caring and grooming, and for the expression of receptors for corticosterone (equivalent to cortisol in humans), constituted in the hippocampus (Weaver et al., 2005). High presence of hippocampal corticosterone receptors are determinant for effective control of the HPA stress response (Weaver et al., 2005).

\section{Personality factors}

The association between human resilience and vulnerability to stress and several personality factors has been studied since the early 1970s (Vollrath, 2001). Research has predominantly focused on the relationship between type A 
personality, characterized by hostility and impatience, stress and increased risk of cardiovascular disease and mortality (Friedman, 1985). Other well-known personality factors, such as neuroticism, locus of control, self-efficacy as well dimensions of the five-factor model/Big five have been linked to stress and other health related risk factors (Vollrath, 2001).

Researchers have not only studied the relationship between stress and risk of ill health, but also what traits that manifest resilience to stress. Traits, such as self-efficacy, perseverance, optimism and locus-of-control seem to play an important role as mediators between stress, health and well-being (Vollrath, 2001). A striking example is the personality factor, hardiness. Kobasa and Puccetti (1983) found that hardy individuals were more resistant or susceptible to stress-related ill health. Hardiness is characterized by the ability to, (a) selfcontrol in stressful events, (b) maintain commitment to activities, and (c) adapt to unexpected changes in life, accept them as challenges or temporary interruptions and perceive them as a chance for personal development.

\section{Work-related factors}

Work-related stressors and their association to stress and other health implications have received much attention, especially in the last decades. Two influential models have described the relation between job demand, control and support, and job effort and reward (Karasek \& Theorell, 1992; Siegrist, 1996).

According to the Demand-control model, high demands at work in combination with low control, are associated with high job strain (stress), which in turn poses a potential risk for various health issues, including, cardiovascular disease and burnout (Häusser et al., 2010; Lourel et al., 2008; Statens beredning för medicinsk och social utvärdering, 2014; van der Doef \& Maes, 1999). Demand relates to workload in terms of volume and pace, as well as emotionally demanding work. Control has been operationalized as autonomy or influence at work (e.g., what tasks, when and in what order these should be performed). According to the model, high demands can be balanced by control. On the contrary, low demands as well as low control seems to lead to under stimulation and even passivity (Karasek \& Theorell, 1992).

The demand-control model was later supplemented with a third dimension, social support (Johnson \& Hall, 1988). Social support, e.g., from a superior or a colleague, involves practical and empathic support. There is today a consensus among researchers that high demands combined with low degree of control and lack of social support is a risk factor for cardiovascular disease, mental illness, musculoskeletal and gastrointestinal diseases (Johnson \& Hall, 1988; Karasek \& Theorell, 1992). Population studies and systematic reviews have also found associations between social support in the workplace and risk of burnout (Temam et al., 2019) and symptoms of ED and depression (Statens beredning för medicinsk och social utvärdering, 2014). A mediating role of social support 
between stressors and perceived stress has also been suggested (Viswesvaran et al., 1999).

The Effort and reward model was introduced by Johannes Siegrist in 1990 s (Siegrist, 1996). Siegrist and colleagues suggested that individual efforts must be rewarded materially, socially and/or psychologically, or as a consequence, will lead to stress and in some cases even severe health problems, such as cardiovascular disease (Dragano et al., 2017; Häusser et al., 2010; Siegrist, 1996), burnout (Bakker et al., 2000; Lourel et al., 2008) and symptoms of ED (Statens beredning för medicinsk och social utvärdering, 2014). In this model effort is operationalized as internal and external driving forces. Internal driving forces constitute the individual's own motivation to make an effort (e.g., long-term development, goals, own interests). The external driving forces corresponds to expectations from demands within the work-context. The counterbalancing part, reward, has been described as 1) material, such as salary and benefits, 2) social, including promotion or development opportunities and 3) psychological, such as appreciation and positive feedback.

In addition to these well-established models, a large body of research has pointed to the relationship between work-environment conditions and stressrelated disorders. For instance, employees who experience bullying or conflict, violence, uncertainty in their employment and who are treated unfairly at work, develops more stress-related symptoms than others (Nyberg et al., 2020; Statens beredning för medicinsk och social utvärdering, 2014).

\section{Leadership}

With regard to health and well-being at the work, the impact of leadership is a commonly studied factor. Fair, supportive and clarifying leadership has been associated with a wide range of positive implications including health (LohelaKarlsson et al., 2009), well-being (Stansfeld et al., 2013; Tuomi et al., 2004), job satisfaction (Munir et al., 2012) and reduced production loss and sick leave (Munir et al., 2011; Schmid et al., 2017). Conversely, poor and non-supportive managerial leadership can affect the health (e.g., ischaemic heart disease) of subordinates (Nyberg, 2009; Nyberg et al., 2008), and leads to higher prevalence of absenteeism and presenteeism among employees (Schmid et al., 2017).

\section{Recovery}

Evidence suggests that recovery from work is important for reducing the negative effects of stress and strain, and for individuals well-being and even performance at work (Binnewies et al., 2009; Geurts \& Sonnentag, 2006; Westman \& Eden, 1997). Recovery refers to the restoration processes during which a person's stresslevel returns to its prestress level (Sonnentag et al., 2017). Sonnentag et al. (2017) proposed a distinction between recovery as an activity (e.g., lunch break, spending time with family and friends) and as an experience (e.g., mentally 
detach after work), and between recovery as a process and recovery as an outcome. Recovery as a process refers to the activities and experiences that bring about change in stress and strain indicators. Recovery as an outcome captures a person's psychological or physiological state that is reached after a recovery period (e.g., at the end of a workday). Confirmatory factor analysis has proposed four distinct experiences in the recovery from work process, namely psychological detachment, relaxation, mastery, and control (Sonnentag \& Fritz, 2007). Studies confirm that these experiences are positively related to well-being indicators (Fritz et al., 2010; Siltaloppi et al., 2009). Consequently, Sonnentag and Fritz (2007) developed and validated a questionnaire corresponding to these experiences, the Recovery Experience Questionnaire.

\section{Sleep}

A large body of empirical research indicates that deficiency in sleep is a risk factor for the development of chronic stress and mental ill health (e.g., Åkerstedt, 2006; Åkerstedt et al., 2012; Söderström et al., 2012). Insufficient sleep predicts clinical burnout, and even modest reductions in sleep predict consequential daytime increases in stress and anxiety (Ben Simon et al., 2020; Söderström et al., 2012). Insomnia has been suggested as a maintaining factor in chronic stress and improvement in insomnia has been found to have a significant impact on improvements in fatigue and the ability to recover from a stressful situation (Kallestad et al., 2015). Further, stress, sleep, recovery and excessive worry seem to have a bidirectional relationship. Stress has been negatively related to impaired sleep and recovery (Maghout Juratli et al., 2011; Van Laethem et al., 2015). Excessive worry, and work-related rumination seems to impede recovery and sleep quality by prolonging the effect of stressors, and thereby increase the risk of exhaustion and fatigue (Querstret et al., 2017; Vandevala et al., 2017). Moreover, the baseline level of burnout seems to have a moderating effect on outcomes of insomnia symptoms in treatment of employees with perceived sleep problems (Schiller et al., 2018).

\section{Physical activity}

Several studies have studied the role of physical activity in stress and in the development of chronic stress (Stults-Kolehmainen \& Sinha, 2014). Studies suggest a bidirectional association between stress and physical activity, i.e. high stress inhibits physical activity, and physical activity seems to prevent and reduce stress (Stults-Kolehmainen \& Sinha, 2014). For instance, cross-sectional data from over 3000 employees working in health care and social insurance in Western Sweden showed that individuals reporting physical activity (light to moderate activity) were less likely to report high levels of perceived stress, burnout and symptoms of depression and anxiety, as compared to individuals reporting a sedentary lifestyle (Jonsdottir et al., 2010). The risks of symptoms of high stress and burnout, at follow-up, were significantly lower for those reporting 
physical activity at baseline (Jonsdottir et al., 2010). In addition, studies indicate that physical training improved episodic memory performance in participants with ED compared with controls (Eskilsson et al., 2017; Malmberg Gavelin et al., 2018).

\section{Interventions for stress}

During the last decades, psychological interventions have been developed in order to increase the individual's, organisation's and entire communities resources and resilience to stress (Murphy, 1996). Several reviews and metaanalyses have examined the efficacy of interventions for stress.

Bhui et al. (2012) conducted an umbrella review, including 23 systematic reviews, 499 primary studies, 11 meta-analyses and 12 narrative reviews, and found greater effect sizes of individual interventions on individual outcomes, compared to organisational level interventions (see Classifications of interventions below). Cognitive-behavioural interventions yielded larger effects at the individual level, compared with other interventions. Richardson and Rothstein (2008) conducted a meta-analysis, reviewing the efficacy of stressmanagement interventions in occupational settings, including 36 controlled studies, representing 55 interventions and a total sample of 2847 participants. The overall weighted effect size (Cohen's d) for all studies was $d=0.53$. Subgroup analyses suggested that intervention type played a moderating role. Cognitivebehavioural programs consistently produced larger effects $(d=1.16)$, followed by, relaxation $(d=0.50)$, organizational, $(d=0.14)$, and multimodal $(d=0.24)$ interventions.

However, as pointed out by the authors of these meta-analyses, there are several gaps in the existing literature. For instance, most studies have been conducted within the working population, focusing on sub-clinical or general stress, and it is uncertain whether these results extend to clinical samples. In addition, we still have limited knowledge regarding what factors mediate change, and the literature concerning the efficacy on work-related outcomes (e.g., absenteeism) and the preventive level interventions is scarce. This clarifies the need for further development and evaluation of both preventive and reactive interventions that are accessible among various samples and within different contexts.

\section{Classifications of interventions}

Classifications have been developed (e.g., Quick, 1999) in order to clarify distinctions between various interventions and levels of prevention for stress. Interventions could target the individual, the organization or entire communities, and be delivered at a primary, secondary, or tertiary level (see Table 1). Individual 
interventions include interventions aimed at preventing and/or reducing psychological and emotional stress. Organisational interventions focus on groups or whole populations and include workplace adjustments or conflict management approaches. Some interventions target both the individual and the organisation, for example work-focused individual interventions that also involve workplace adjustments or return-to-work training. Primary interventions aim to prevent stress from occurring by removing the sources of stress (stressors) and enhancing well-being (e.g., by recovery). Secondary interventions aim to reduce the severity or duration of symptoms (e.g., fatigue). Tertiary or reactive interventions aim to provide rehabilitation among those with chronic stress (e.g., return-to-work). The interventions studied in the present thesis aimed at covering all three intervention and prevention levels, (primary) the recovery training evaluated in study IV and the positive management training included in Study I, (secondary) the cognitive behavioural intervention for stress-related disorders tested in study I, II and III, and (tertiary) and the work-focused intervention included in Study III (see section, Empirical studies, for detailed description).

Table 1. Classification of stress-management interventions (adapted from Quick, 1999) with examples.

\begin{tabular}{|c|c|c|c|}
\hline Level & $\begin{array}{l}\text { Primary } \\
\text { interventions }\end{array}$ & $\begin{array}{l}\text { Secondary } \\
\text { interventions }\end{array}$ & $\begin{array}{l}\text { Tertiary } \\
\text { interventions }\end{array}$ \\
\hline Organisational & $\begin{array}{l}\text { Improving work } \\
\text { content, managerial } \\
\text { positive feedback and } \\
\text { peer social support }\end{array}$ & $\begin{array}{l}\text { Improving } \\
\text { communication, decision } \\
\text { making and conflict } \\
\text { management }\end{array}$ & $\begin{array}{l}\text { Return-to-work } \\
\text { training, vocational } \\
\text { rehabilitation and } \\
\text { outplacement }\end{array}$ \\
\hline Individual & $\begin{array}{l}\text { Recovery training, } \\
\text { physical activity or } \\
\text { didactic stress } \\
\text { management }\end{array}$ & $\begin{array}{l}\text { Cognitive behavioural } \\
\text { stress interventions and } \\
\text { relaxation }\end{array}$ & $\begin{array}{l}\text { Rehabilitation after } \\
\text { sick leave, disability } \\
\text { management }\end{array}$ \\
\hline
\end{tabular}

Joyce et al. (2016) conducted an umbrella-review of 20 reviews and meta-analysis on the evidence regarding the efficacy of primary, secondary and tertiary workplace mental health interventions, according to the classification mentioned 
above (see Table 1). A broad definition of 'workplace' mental health interventions was used, including interventions that were either initiated or facilitated by the workplace, and with the aim to either prevent, treat or rehabilitate employees with a mental health diagnosis (mainly stress, depression and anxiety). Joyce and colleges (2016) only identified two primary prevention interventions (e.g., enhancing employee control and promoting physical activity) with moderate evidence. Stronger evidence was found for secondary, CBT-based stress management interventions. Tertiary interventions, such as CBT-based or problem-focused return-to-work programmes, had a strong evidence base for improving symptomology and a moderate evidence base for improving occupational outcomes.

\section{Cognitive behavioural interventions}

Cognitive behavioural interventions (CBT) is a term that describes a family of psychological treatments that are based on learning and/or cognitive theories (Hofmann et al., 2012). CBT usually focus on patterns of unhelpful behaviours and cognitions and aims at achieving symptom reduction and improving functioning and well-being by altering dysfunctional cognitions and maladaptive behaviours (Hofmann et al., 2012). In addition to the core learning and cognitive theory-based components constituting CBT interventions, CBT includes a range of practical approaches, composed of and associated with a broad spectrum of methods and techniques, including relaxation, mindfulness, behavioural activation, physical activity and third wave acceptance and commitment therapy (Hofmann et al., 2012). To date, CBT is the most comprehensively and rigorously researched psychological treatment method for a range of mental and somatic disorders, yielding large effect sizes in the treatment of anxiety disorders, depression, and insomnia (Hofmann et al., 2012), but also several other problems within mental and somatic health care.

Although meta-analyses indicate that CBT is an effective method in reducing symptoms of general stress, and comorbid anxiety, depression and insomnia (Bhui et al., 2012; Joyce et al., 2016; Richardson \& Rothstein, 2008), there are knowledge gaps regarding the efficacy in clinical populations and what factors mediate changes.

Considering clinical populations and individuals suffering from chronic stress or stress-related disorders, interventions have been less successful, showing mixed results (Ahola et al., 2017; Arends et al., 2012; Maricuțoiu et al., 2016; O'Donnell et al., 2018). Maricuțoiu et al. (2016) conducted a meta-analysis evaluating the effect of interventions (mainly CBT) for burnout and exhaustion and found small effect sizes (burnout $d=0.22$ and exhaustion $d=0.17$ ). Further, O'Donnell et al. (2018) found no significant effects of psychological and pharmacological treatments for AD. The same authors reported low confidence in results due to limitations in methodological quality, and heterogeneity of 
studies with regard to treatment content, length, extent, and type of interventions.

To date, we have limited knowledge regarding what factors mediate changes in CBT-based interventions for stress. Acceptance and psychological flexibility of undesirable thoughts and emotions (Bond \& Bunce, 2000; Lloyd et al., 2013), emotion regulation (Ebert, Lehr, et al., 2016), improved recovery (Ebert et al., 2015), insomnia severity (Lindsäter et al., 2020) and sleep quality (Querstret \& Cropley, 2012; Santoft et al., 2019), have been indicated as potential mediators of change in outcomes of symptom reduction (e.g., perceived stress, burnout, exhaustion, insomnia) following stress interventions.

\section{Work and return-to-work focused interventions}

Notwithstanding the extensive support for psychological treatments for common mental disorders (Hofmann et al., 2012) and stress (Bhui et al., 2012), studies on interventions focusing on work-related aspects and outcomes, such as reducing sickness absence (SA), are still inconsistent. The field of research is fairly new and the insurance system and return-to-work processes are complex and influenced by contradictory incentives (Alexanderson \& Norlund, 2004). Nonetheless, there are some indications that interventions which integrate work-related aspects early in the treatment have the potential to accelerate return-to-work (RTW) for persons with common mental health problems including stress-related disorders (Arends et al., 2012; Blonk et al., 2006; de Weerd et al., 2016; Finnes et al., 2019; Kröger et al., 2015; Lagerveld et al., 2012; Rebergen et al., 2009; Schene et al., 2007; van der Klink et al., 2003).

For instance, Arends et al. (2012) found that a problem-solving intervention for adults with stress-related disorders (AD) enhanced partial RTW, but not full RTW, at 1-year follow-up. In the same systematic review, CBT did not reduce time to either partial or full RTW (Arends et al., 2012). For depressed workers, combining CBT with occupational care reduced SA compared to usual care (Nieuwenhuijsen et al., 2014). Recent evidence from a meta-analysis suggested that psychological interventions for common mental disorders (including stress) and musculoskeletal pain are slightly more effective than treatment-as-usual in reducing sickness absence. Overall effect sizes (Hedges' $g$ ) for AD was $g=0.20$, for CBT $g=0.12$ and work-focused CBT $g=0.22$ (Finnes et al., 2019).

In Studies I and III in the present thesis, a work-focused CBT format was evaluated. Work-focused CBT is built on the same conceptual framework as regular CBT (Lagerveld et al., 2012). For example, CBT principles are used to change the appraisal of work stressors (e.g., "it is ok although the task is not 100\% complete or perfect”), change the dysfunctional behaviour (e.g., working late close to bedtime, accept more work despite heavy workload), or increase health promoting behaviours (e.g., recreational activities, assertive behaviour, returnto-work activates). The CBT principal, exposure, is given special attention. 
Gradual exposure can help individuals develop more effective coping skills when dealing with work-related stressors (e.g., assertiveness) and stimulate gradual return to the work setting for individuals on a long-term sick leave (Blonk et al., 2006).

\section{Preventive interventions}

Although extensive research has been devoted to treatments reducing stress symptoms, fewer studies have evaluated interventions with the aim of enhancing protective well-being factors (e.g., relaxation, recovery, off-work recuperation, physical exercise) or preventing stress from occurring by managing or/and removing job stressors (e.g., mobilising social support, problems solving, decision making, time-management, supervisory support). One systematic review (Ruotsalainen et al., 2015) and one meta-analysis (Martin et al., 2009) found positive effects of health-promotive and preventive interventions for stress, burnout and common mental problems. However, most studies included were secondary rather than primary or preventive interventions.

Nevertheless, some promising results have been observed from recovery training programs and positive management.

Recovery training programs focus on enhancing well-being/protective factors and preventing individuals from developing chronic stress (Almén et al., 2020; Ebert et al., 2015; Hahn et al., 2011). For example, a study by Hahn et al. (2011) reported positive effects from a recovery training program on outcomes related to the recovery experiences of self-efficacy, sleep quality, perceived stress, and well-being. No effects were found on a measure of emotional exhaustion.

Positive management, also known as positive feedback or positive reinforcement as a managerial skill (Komaki, 1998), aims to on enhance important protective work-environmental factors, such as control, support and reward, trough positive managerial feedback, and thereby preventing employees from developing chronic stress. The use of positive feedback in occupational settings has been associated with improved employee performance (Skakon et al., 2010), lower levels of stress and, increased well-being in employees (Kelloway \& Barling, 2010).

\section{Internet-based stress interventions}

Despite the well-documented efficacy of stress-management interventions, and some promising results of work-focused and preventive interventions, only a small percentage of distressed individuals actually receive interventions from health professionals (Hilton et al., 2008). This clarifies the need to further develop and evaluate work directed interventions that are accessible to the working population. 
van der Hek and Plomp (1997) early addressed the need for the development of effective interventions for stress that are comprehensive, coordinated, accessible, user-friendly, non-stigmatising, safe and cost-effective. Since the late 1990s, a growing body of literature supports the efficacy of internet-based cognitive behavioural interventions (iCBT), for depression, anxiety and insomnia and other health-related issues (Andersson, Titov, et al., 2019). A major advantage of iCBT is that it is accessible, and it has also been shown to be costeffective (Andersson, 2014).

Since the first randomised controlled trial (RCT) on an internet-based stress management intervention (Zetterqvist et al., 2003), a growing body of studies have evaluated the efficacy of interventions for individuals with elevated symptoms of stress. Similar to studies on face-to-face interventions, most studies have been focusing on general stress or distress and the working population. To date, two meta-analyses and two systematic reviews have been conducted of internet- and computer-based interventions for stress (Heber et al., 2017; Ryan et al., 2017; Stratton et al., 2017; Wingerden \& Derks, 2018).

In the meta-analysis by Heber et al. (2017), 26 controlled studies including 4226 participants were analysed, showing small to moderate effects on outcomes on stress (Cohen's $d=0.43$ ), depression (Cohen's $d=0.34$ ) and anxiety (Cohen's $d=0.32$ ) compared with waitlist control conditions. Subgroup analyses revealed larger effect sizes in favour of guided interventions (Cohen's $d=0.64$ ) and interventions ranging between $5^{-8}$ weeks.

Whereas the meta-analysis conducted by Heber et al. (2017) specifically investigated the effect of interventions aimed at reducing stress, Stratton et al. (2017) conducted a meta-analysis evaluating the evidence for the efficacy of internet-based interventions for a broad range of mental health problems including stress among employees. 23 controlled trials were included, suggesting a small overall positive effect at both post-intervention (Hedge's $g=0.24$ ) and follow-up $(g=0.23)$. Mindfulness based interventions $(g=0.60)$ yielded larger effects than the CBT-based $(g=0.15)$ and stress-management based $(g=0.17)$ interventions.

Ryan et al. (2017) conducted a systematic review of 48 web-based stressmanagement interventions in the workplace. A majority were individual-focused and utilized cognitive-behavioural techniques, relaxation exercises, or mindfulness, and few internet interventions targeted organizational or individual/organization interface factors. Ryan et al. (2017) found low-tomoderate quality evidence that individual-focused interventions were effective for supporting employee well-being and managing their work-related stress, and limited support for the efficacy of internet interventions focusing on organizational or individual/organization interface factors. The same author stressed that there is an existing gap between work-stress theory and the application in the development of internet interventions for work-related stress. 
In addition to the findings from for-mentioned systematic reviews and metaanalyses, studies also suggest that internet interventions for stress can have sustained effects on stress reduction up to 12-months post intervention (Ebert, Lehr, et al., 2016; Heber et al., 2016; Lindsäter et al., 2018) and be cost-effective (Ebert et al., 2018; Kählke et al., 2019; Lindsäter et al., 2019).

\section{Experiences of internet-based interventions}

Although a growing body of literature has evolved supporting the efficacy internet interventions for stress, we still have a fairly limited knowledge about of how participants experience these treatment formats (Fleischmann et al., 2018; Halmetoja et al., 2014). Previous qualitative studies have predominantly been conducted on internet-based treatments for anxiety, depression and insomnia, and participants have reported both positive and negative experiences of these treatment formats.

Positive statements have concerned the availability, flexibility and anonymity of the interventions (Alberts et al., 2018; Bendelin et al., 2011; Halmetoja et al., 2014; O'Mahen et al., 2015; Pugh et al., 2015). Participants have requested more individualized interventions and express the importance of customizing both the amount and the type of feedback and therapist support, to their specific needs and preferences (Gerhards et al., 2011; Ly et al., 2015; Macdonald et al., 2007; O’Mahen et al., 2015; Rozental, Forsström, et al., 2015; Svartvatten et al., 2015).

One previous study examined participants' experiences of internet-based interventions for stress. Fleischmann et al. (2018) evaluated an app-based stress management intervention used by distressed college students. The students expressed the need for more individualized content, background information, content-related support and a better understanding of their situation. Aligned with previous research (Rozental et al., 2014), participants also described that session length and frequency of reminders were demanding and constituted a possible stressor. Hence, experiences of stress caused by the intervention should be taken under special consideration in the development of internet interventions addressing distressed and exhausted individuals. 


\section{AIMS}

The overall aim of the thesis was to bring further evidence to the field on the experiences and efficacy of internet-based and work-focused interventions for employees with stress-related disorders.

\section{STUDY I}

The aim of Study I was to evaluate the efficacy of an internet-based stress management intervention (iSMI) in a self-referred sample of distressed managers. The primary objective was to test whether participating in the iSMI programme would lead to significant improvements on stress, and secondary mental health- and work-related outcomes, compared with an attention control (AC). We hypothesized that, compared with the AC, the iSMI would generate greater improvement on stress, mental health and work-related outcomes.

\section{STUDY II}

The aim of Study II was to examine the experiences of an internet-delivered and work-focused CBT treatment for a stress-related disorder, addressing both mental health and the work situation. Information about participants experiences of advantages and disadvantages with regard to utilization, content and effects on mental health and well-being in both life and at work, was collected using semi structured interviews. The main purpose was to extract information on how the intervention could be improved to further enhance the efficacy and feasibility in the target population.

\section{STUDY III}

The aim of Study III was to evaluate the effectiveness of a work-focused and iCBT intervention for stress-related disorders (W-iCBT). The W-iCBT was compared with a generic iCBT intervention, excluding the work-focused content, and a waitlist control (WLC). We hypothesized that the work-focused and the generic intervention would be equally effective in reducing perceived stress, exhaustion, burnout and other mental health-related outcomes. We also hypothesized that the initially achieved changes would remain stable at a 12-month follow up. In the secondary explorative analyses, we examined whether the work-focused intervention would differ with regard to important work-related outcomes, e.g., work ability and absenteeism.

\section{STUDY IV}

In Study IV we aimed to examine the efficacy of a brief, five-week, internet-based recovery training program (iRTP) for employees, experiencing elevated symptoms of stress and burnout, in a randomised controlled pilot trial. We 
hypothesised that the iRTP would produce greater improvements in recovery experiences (primary outcome) compared to a waitlist control group (WLC). And that the intervention group would differ with regard to perceived stress, burnout, exhaustion and other important mental health and work-related outcomes. The purpose was also to explored whether the initially achieved changes in the iRTP would remain stable at a 6 and 12-month follow-up. 


\section{EMPIRICAL STUDIES}

\section{Study I: Internet-based stress management for distressed managers: results from a randomised controlled trial}

\section{Methods}

\section{Procedure}

Study I was a controlled trial in which 117 managers (first and mid-level) with a stress-related disorder were randomized to either an internet-based stress management intervention (iSMI $n=59)$ or an attention control $(A C n=58)$. Selfreported measures were collected at pre- and post-intervention (eight weeks) and at a 6- and 12-month follow-up. Participants were recruited via an open recruitment strategy (e.g., national newspapers and social media). To be eligible for the study, participants had to fulfil the criteria for a stress-related disorder described in the International Statistical Classification of Diseases and Related Health Problems (ICD-10; (World Health Organization, 1992). Diagnosis was established by a licenced psychologist via telephone interviews using the Mini International Neuropsychiatric Interview (Sheehan et al., 1998) and additional criteria from ICD-10 and national diagnostic guidelines (Socialstyrelsen, 2003). Of the total sample, 117 managers, 63\% were diagnosed with F43.2 Adjustment disorder, 21\% with F43.8 Exhaustion disorder and 15\% with F43.9 Reaction to severe stress, unspecified.

In addition to a stress-related disorder, participants had to fulfil the following criteria: (i) a minimum age of 18 years, (ii) mastering Swedish, (iii) have access to a computer or a tablet computer with internet access, (iv) currently working as a first-line or middle manager, (v) not be on full-time sick leave. Participants on medication for common mental disorders (e.g., antidepressants or sleep medication) were not excluded from the study but were requested to keep their medication constant during the study period.

Participants were excluded from the study if they (i) recently had participated in a stress management programme, (ii) were CEO/top management, (iii) currently were suffering from bipolar disorder, psychosis, post-traumatic stress syndrome (PTSD), eating disorder, substance abuse, severe forms of depression, an anxiety disorder or a DSM axis-II personality disorders and (v) were showing suicidal ideation based on item 9 (>3) of the Montgomery Åsberg Depression Scale-Self Rated (MADRS-S; Montgomery \& Asberg, 1979). 


\section{Outcomes measures}

The primary outcome measure was the 14-item version of Perceived Stress Scale (Cohen et al., 1983). Secondary outcome measures included the 22-item ShiromMelamed Burnout Questionnaire (SMBQ; Lundgren-Nilsson et al., 2012), which was used to assess symptoms of burnout and exhaustion, and a range of other outcome variables, including depressive symptoms, anxiety, insomnia severity, and quality-of-life. In addition to the health-related outcomes, we assessed work experience, absenteeism, presenteeism, and healthcare consumption. All outcome measures were self-reported online questionnaires and were collected pre, post, six months after the intervention. We did not include any data on outcomes regarding managerial feedback performance (will be presented elsewhere).

\section{Intervention}

The iSMI consisted of 8 weekly modules and was delivered via a secure web platform, iterapy (Vlaescu et al., 2016). Each module contained text (about 1015 regular pages), exercises, worksheets, images, examples, audio- and video-files and homework exercises. Participants received weekly online support from an assigned coach (psychology graduates) who gave gradual access to modules. The treatment protocol in the iSMI was based on contemporary CBT techniques (including third wave CBT) such as behaviour activation, exposure, emotion regulation, acceptance, and methods applied from other perspectives including recovery from work training, boundary tactics. See published article Study 1 , for a detailed description.

The iSMI was designed to facilitate change in three dimensions; the individual, the work-environment and the work family interface. This was translated into five consecutive areas: (i) psychoeducation, for example, stress responses, stress physiology, (ii) stressors, for example, action plan to reduce work-environmental stressors, (iii) balance, for example, applied relaxation, physical exercises, boundaries in the work-home interface, (iv) exposure, for example, assertiveness, perfectionism and worry and (v) positive management. In addition to the main areas of the intervention, optional modules were included with the aim of individualising the programme. As an example, participants with insomnia were encouraged to work on sleep management.

In modules 5-8, participants learned how to apply positive reinforcement as a managerial skill (Komaki, 1998). The modules on positive management were distributed over three modules/weeks, positive feedback (week five), corrective feedback (week six), and negative feedback (week seven).

During the final week (week 8), participants summarised their work on both stress management and positive management in a maintenance plan. 


\section{Attention control}

In study 1, an attention control group was designed to limit the risk of attentional effects, which has been debated in the use of wait-list control groups (Safer \& Hugo, 2006). The AC group was developed to provide a similar attentional focus (e.g., weekly mail contact, homework assignment) as to the iSMI group. Participants assigned to the $\mathrm{AC}$ group were given a brief weekly text module (half a regular page), about a stress-related topic (e.g., stressors, recuperation or feedback). They were then invited to discuss each topic, anonymously, with other participants in a moderated web forum. Compared with the iSMI, the AC was a passive learning experience and did not involve any behavioural modification, worksheets or exercises. Equivalent to the participants in the iSMI, the AC group received weekly homework assignments, and received minimal and standardised feedback from their coach. AC group had full access to treatment-as usual.

\section{Statistical analyses}

Statistical analyses were conducted following the intention-to-treat principle and missing data was handled with multiple imputation (MI). We used all, pre, post and the six-month follow-up values of all outcome measures as well as age, gender and educational level as predictors. The interaction effect of time (pre- to post, follow-up) and study group (iSMI vs. AC) were analysed using analysis of covariance (ANCOVA), with the pre-assessment values as covariate. Within- and between-group effect sizes were calculated using Cohen's $d$.

\section{Results}

The study attrition rate was moderate. Out of 117 participants, 93 (79\%; iSMI $\mathrm{n}=42 ; \mathrm{AC} \mathrm{n}=51$ ) responded to the post assessment questionnaires and 82 participants (70\%; iSMI $\mathrm{n}=38$; $\mathrm{AC} \mathrm{n}=44)$ completed data in the six-months follow-up. Participants completed on average 5.83 (iSMI $=5.69$ and $\mathrm{AC}=5.93$ ) out of 8 weeks and in all, $13 \%$ of the participants (iSMI $=6$ and $\mathrm{AC}=9$ ) dropped out early ( $<2$ weeks) in the study. Coaches spent significantly more time $t(90)=-7.28$, $\mathrm{p}<0.001$ on support with the iSMI group ( $\mathrm{M}=16.65 \mathrm{~min} ; \mathrm{SD}=11.96)$, compared to the AC-group ( $\mathrm{M}=3.98 \mathrm{~min}, \mathrm{SD}=1.76)$.

Compared with the AC, the iSMI group showed significant and medium to large improvement in the primary outcome perceived stress at post assessment (Cohen's $d=0.74$ ) and at the six-months follow-up (see Figure 1). Similar pattern of medium to large, between-group, effect sizes seen on the secondary mental health and work-related outcomes at post treatment (e.g., Burnout, SMBQ, $d=$ 0.95; Work satisfaction, WEMS, $d=0.59$ ) and the six-months follow-up (e.g., Insomnia severity, ISI, $d=0.39$ ). 




Figure 1. Development on the primary outcome measure PSS-14 (Mean scores). iSMI, Internetbased stress-management intervention; AC, Attention control; Pre, before treatment; Post, after treatment; 6FU, six-months follow-up.

\section{Conclusions}

Results from Study 1 indicated that an internet-based stress management intervention can be an effective, accessible and potentially time-effective approach of reducing stress and other mental-related and work-related health symptoms among distressed managers. Long-term effects were seen on several of the mental health-related outcomes. However, we did not collect any data from subordinates and their perception of managerial feedback. Thus, future studies are needed to address the potential effects of positive management tactics on employee stress and satisfaction at work. 


\section{Study II: Experiences of internet-delivered and work- focused cognitive behavioural therapy for stress: $A$ qualitative study}

\section{Methods}

\section{Procedure}

Study II was conducted as a follow-up to a randomized controlled pilot trial examining the efficacy of work-focused and internet-based cognitive behavioural treatment (iCBT) for stress among employees. In the original study, 54 participants were randomized to either a guided iCBT $(n=27)$ or a waitlist control group $(n=27)$ who received unguided self-help after three months. For the randomized controlled pilot trial, we used the same recruitment, inclusion and exclusion criteria's as in Study 1.

In Study II, 24 participants were selected from the iCBT group of the original study using a criterion-based sampling approach, selecting those participants who had completed all treatment modules. Initially, eleven participants reported an interest in participating in interviews. Nine participants participated in a semistructured interview. The material was analysed using Thematic Analysis.

All participants in Study II were female, in comparison to $92 \%$ female participants in the original study. Age ranged from 28 to 61 years with a mean of 48.50 years $(S D=10.38)$, being representative of the original study $(M=47.67$, $\mathrm{SD}=8.42$ ). All participants fulfilled the criteria for a stress-related disorder (e.g., $\mathrm{AD}$ ) and all participants had additional diagnoses (e.g., depression, anxiety and/or insomnia). Most participants were working in healthcare or social services, manufacturing or education. Three out of nine participants were on benefits for long-term sick leave.

\section{Interviews}

The interview aimed at capturing the participants' experiences (advantages and disadvantages) of the intervention regarding usability, user-friendliness, feedback and support, motivation, session length, extent, work effort and effects on mental health and wellbeing. Questions were selected based on previous research (Bendelin et al., 2011; Fleischmann et al., 2018; Rozental, Forsström, et al., 2015; Svartvatten et al., 2015). After completion of the three-month followup, the selected participants were contacted for an interview. Interviews were recorded and anonymized during transcription. Interviewers and coders were not blinded to the participants' treatment outcomes. The average interview was 52 min (range, $38 \mathrm{~min}$ to $1 \mathrm{~h} 17 \mathrm{~min}$ ). 


\section{Analysis and coding procedure}

The interviews were analysed through thematic analysis according to recommendations from Braun and Clarke (2006). The keywords were encoded and processed via NVivo Software (version 11.4.1.). We used a combination of deductive and inductive thematic analyses and the analysis process, followed Braun and Clarke's (2006) six-step coding procedure, including:

(1) Transcription and repeated reading of all material

(2) Coding of keywords

(3) Organizing keywords in themes and sub-themes

(4) Reviewing and revising themes

(5) Defining, analysing and naming each theme and sub-themes

(6) Compiling of results and implementing the final analysis

\section{Results}

The thematic analysis generated six themes and 13 sub-themes, described in Table 2.

Table 2. Themes, sub-themes and participants experiences.

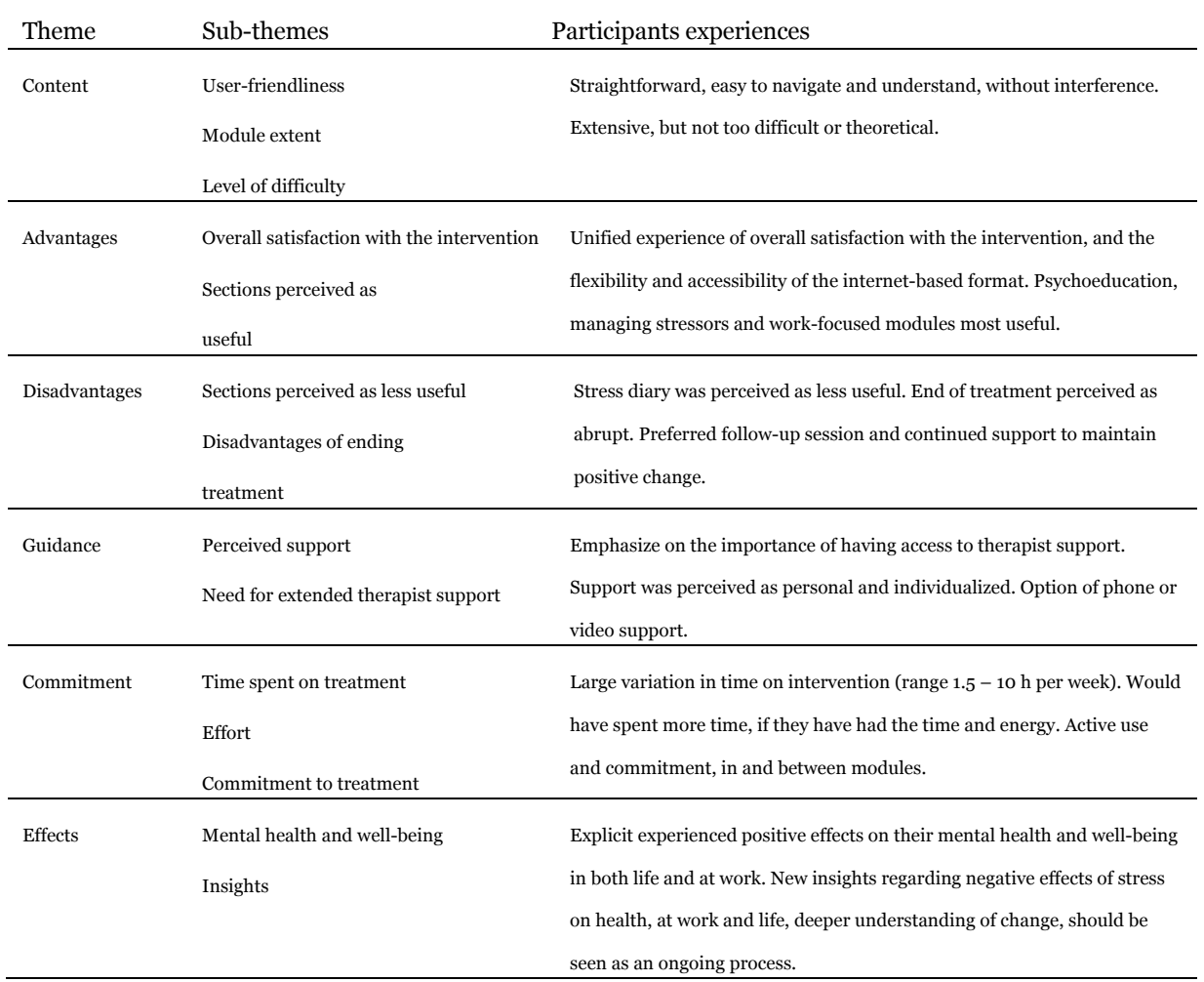




\section{Conclusions}

To our knowledge, Study II was the first study examining participants experience of a work-focused iCBT intervention for stress-related disorders. The results indicated that most of the participants experienced positive effects on their mental health and well-being in both life and at work. All participants emphasized the importance of having access to therapist support. In line with previous research, participants found the intervention to be extensive and demanding and expressed the need for extended treatment time and therapist support. The participants' experience of combined effects in their personal- and work life was promising, since the efficacy of iCBT and CBT usually are limited to mental health and well-being (Andersson et al., 2019). 


\section{Study III: Work-focused versus generic internet- based interventions for employees with stress- related disorders: a randomized controlled trial}

\section{Methods}

\section{Procedure}

Study III was a controlled trial in which 182 employees were randomized to a work-focused and internet-based cognitive-behavioural intervention for stressrelated disorders $(\mathrm{W}$-iCBT, $\mathrm{n}=61)$ or a generic iCBT $(\mathrm{n}=61$; excluding the workfocused content) or a waitlist control (WLC, $n=60$ ). Self-reported measures were collected at pre- and post-treatment (ten weeks) and at a six and 12-months follow-up. As described in previous studies, I and II, participants were recruited via an open recruitment strategy and to be eligible for the study, participants had to fulfil the criteria for a stress-related disorder established via diagnostic interviews, and additional inclusion and exclusion criteria. For detailed description, see Study I and attached manuscripts Study 1-4. In total, 489 individuals were screened and 307 were excluded according to the inclusion and exclusion criteria.

Of the total sample, 182 employees, $80.8 \%$ were female, with an average age of $46.4(\mathrm{SD}=8.6)$ years. A majority, 112 participants $(61.6 \%)$ were working in the social, healthcare or educational sector and 51 participants were on sick leave. 76.9\% fulfilled the ICD-10 diagnosis F43.8 Exhaustion disorder, 15.9\% F43.2 Adjustment disorder and $66.7 \%$ were diagnosed with F51.0 Non-organic insomnia.

\section{Outcomes measures}

The primary outcome measure was the 22-item Shirom-Melamed Burnout Questionnaire (SMBQ; Lundgren-Nilsson et al., 2012). Secondary outcome measures included the 10-item version of Perceived Stress Scale (Cohen et al., 1983) and the 9-item Karolinska Exhaustion Disorder Scale (KEDS-9; (Beser et al., 2014), which was used to assess symptoms of stress and exhaustion. Since one of the main purposes of Study III was to evaluate the efficacy of the work-focused modules, work-related outcomes (e.g., work ability, sickness absence and longterm sick leave) was of special interest. Work ability was measured with the Work ability index (de Zwart et al., 2002) and sickness absence according to the TiC-P (Bouwmans et al., 2013). All outcome measures were self-reported online except for the data on participants receiving benefits due to long-term sick leave. Data 
on long-term sick leave was retrieved between the pre-assessment and the six months follow-up, from the Swedish Social Insurance Agency.

\section{Intervention}

The generic iCBT program, represented in iCBT and W-iCBT, were based on protocols tested in our previous trials, Study I and II, including contemporary CBT techniques adapted for stress-related disorders, and recovery from work training inspired by Hahn et al. (2011). The iCBT and W-iCBT were delivered via a secure web platform, iterapy (Vlaescu et al., 2016). Both the iCBT and W-iCBT programs consisted of ten modules distributed over ten weeks, with modules lasting 60-120 min per week (Table 3). Each module contained information, exercises, worksheets, images, examples, audio- and video files and homework exercises. Both interventions included three fictional participants, representing different ages, genders and ethnicities, serving as examples throughout the intervention. Participants received weekly online support from an assigned coach (psychology graduates) who gave gradual access to modules.

Table 3. CBT and Work-focused content.

\begin{tabular}{|c|c|c|c|}
\hline Module & Name & CBT content & Work-focused content \\
\hline 1 & Introduction & Psychoeducation and aims & $\begin{array}{l}\text { Work content, tasks, demands and } \\
\text { workload }\end{array}$ \\
\hline 2 & Balance & $\begin{array}{l}\text { Recovery through psychological detachment, } \\
\text { mindfulness, life/work balance and values }\end{array}$ & $\begin{array}{l}\text { Work conditions, employment status and } \\
\text { security }\end{array}$ \\
\hline 3 & $\begin{array}{l}\text { Stressful thoughts, feelings } \\
\text { \& behaviours }\end{array}$ & $\begin{array}{l}\text { Recovery through applied relaxation (step 1) } \\
\text { stress diary, stress, appraisals, emotions and } \\
\text { behaviour }\end{array}$ & $\begin{array}{l}\text { Work relations, cooperation, leadership, } \\
\text { organizational justice, feedback, social } \\
\text { support, conflicts, harassment and bullying }\end{array}$ \\
\hline 4 & Recovery in everyday life & $\begin{array}{l}\text { Work/life balance, applied relaxation (step 2) } \\
\text { stress diary, coping with stressors, sleep } \\
\text { management (step 1) and values }\end{array}$ & Job satisfaction and meaningfulness \\
\hline 5 & Challenges & $\begin{array}{l}\text { Gradual exposure in a stress-related area, } \\
\text { continued recovery training, applied relaxation } \\
\text { (step 3) and sleep management (step 2) }\end{array}$ & $\begin{array}{l}\text { Summary of the entire work situation, plan } \\
\text { for workplace adjustments, gradual return- } \\
\text { to-work plan (only for participants on sick } \\
\text { leave) }\end{array}$ \\
\hline 6 & Challenges, continued & $\begin{array}{l}\text { Continued exposure, values, recovery training, } \\
\text { applied relaxation (step 4) and sleep } \\
\text { management (step 3) }\end{array}$ & $\begin{array}{l}\text { Effort, appreciation and reward and } \\
\text { continued plan for workplace adjustments } \\
\text { and gradual return-to-work }\end{array}$ \\
\hline 7 & Physical exercise & $\begin{array}{l}\text { Recovery through physical exercise, applied } \\
\text { relaxation (step 5) and sleep management } \\
\text { (step 4) }\end{array}$ & $\begin{array}{l}\text { Control, responsibility and autonomy and } \\
\text { continued plan for workplace adjustments } \\
\text { and gradual return-to-work }\end{array}$ \\
\hline 8 & Planning & $\begin{array}{l}\text { Time management, values, recovery training, } \\
\text { applied relaxation (step 6) and sleep } \\
\text { management (step 5) }\end{array}$ & $\begin{array}{l}\text { Social support and continued plan for } \\
\text { workplace adjustments and gradual return- } \\
\text { to-work }\end{array}$ \\
\hline 9 & Cognitive functioning & $\begin{array}{l}\text { Exhaustion and temporary cognitive problems } \\
\text { (e.g., how to manage distractions and } \\
\text { temporary memory problems) and applied } \\
\text { relaxation (step 7). }\end{array}$ & $\begin{array}{l}\text { Recovery in the workplace and continued } \\
\text { plan for workplace adjustments and gradual } \\
\text { return-to-work }\end{array}$ \\
\hline 10 & $\begin{array}{l}\text { Action and relapse } \\
\text { prevention plan }\end{array}$ & $\begin{array}{l}\text { Evaluation of training, early warning signs, } \\
\text { values, summary and prevention plan }\end{array}$ & Summary and prevention plan \\
\hline
\end{tabular}


In the first module (introduction), of the generic iCBT, participants received information about the outline of the program, and they defined their individual treatment goals (e.g., "I would like to be more assertive"). The first week also contained information and exercises on stress physiology, consequences of longterm stress, exhaustion and burnout and how to manage stressors (e.g., workload, pace, social support). During the second week (balance) participants were introduced to different recovery techniques (Sonnentag et al., 2017) and applied relaxation . These components reoccurred throughout the entire program. The third and fourth week contained exercises related to behavioural activation (Martell et al., 2001), work-home balance, and values-based action skills derived from Acceptance Commitment Therapy (Flaxman \& Bond, 2010). Between weeks five and ten, participants were able to choose between different exposure-based exercises regarding assertiveness perfectionism, procrastination or worry. The final three weeks also comprised of physical activity and time management. In addition, participants with insomnia could choose to focus on sleep management between week 5-9, including well established CBT techniques, such as sleep restriction, stimulus control, sleep hygiene and cognitive interventions (Cheng \& Dizon, 2012; Thiart et al., 2015). In the last module, ten, a summary and prevention plan, including an evaluation of the individual treatment goals and early warning/stress signs, was made.

The internet-based and work-focused cognitive-behavioural therapy (W-iCBT) consisted of the generic treatment for stress-related disorders (iCBT), plus components focusing on work and return-to-work. These sections were adapted for the present trial with permission from Lagerveld et al. (2012) and were integrated and represented in each of the ten modules.

In the first four modules, a work-related perspective on symptoms of chronic stress was given and a problem analysis of the work situation was made (including job content, job conditions, work relations and work satisfaction). In module five, participants who were on sick leave made a first draft of a gradual (stepwise) return-to-work plan and participants who were working made an elaborative work-adjustment-plan. The participants were encouraged to communicate their problem analysis, return-to-work and/or work-adjustmentplan through dialog with their employer (e.g., manager, HR). These plans were continually updated by the participants throughout the remaining modules. In modules six to ten, participants were taught how to take action and get involved in health-promoting behaviours at work, including: (i) Effort, appreciation and reward, (ii) Control, responsibility and autonomy, (iii) Social, instrumental, emotional and informative support and (iv) Recovery in the workplace. In the last tenth module an integrated summary and prevention plan was drafted for both the work-focused and the generic CBT-program. 


\section{Statistical analyses}

Statistical analyses were conducted according to the intention-to-treat principle and missing data was handled with multiple imputation. The effects of group on primary and secondary outcome measures were analysed using repeated measures ANOVAs with time (pre, post and six-months follow-up) as a withinsubject factor. Pooled F-values were calculated using RStudio (RStudio, Inc., Boston, MA). Cohen's d was reported for the between-group effect sizes and corresponding $95 \%$ confidence intervals (95\% CI). Sickness absence and longterm sick leave were analysed using Kruskal-Wallis, non-parametric test. To evaluate clinically significant change, we used the guidelines by Jacobson and Truax (1991). Clinically significant change was based on the completer's analysis.

\section{Results}

The study attrition rate was moderate, $19.2 \%$ at post-treatment $(\mathrm{W}-\mathrm{iCBT}=43$, $\mathrm{iCBT}=52$ and $\mathrm{WLC}=52), 24.2 \%$ at the six-months follow-up ( $\mathrm{W}$-iCBT $=39$, $\mathrm{iCBT}=5 \mathrm{O}$ and $\mathrm{WLC}=49$ ) and $34.4 \%$ at the 12 -month follow-up questionnaires (W$\mathrm{iCBT}=33$ and $\mathrm{iCBT}=47$ ).

As depicted in figure 2, both interventions presented lower scores and large effect sizes compared to the WLC on the primary outcome SMBQ, at postassessment (W-iCBT, $d=1.00$; CBT, $d=0.83$ ) and the six months follow-up (WiCBT, $d=0.74$; iCBT, $d=0.74$ ). No significant differences were found between the two interventions at any timepoint.



Figure 2. Development on the primary outcome measure SMBQ (Mean scores). W-iCBT, workfocused internet-based cognitive behavioural therapy; iCBT, generic internet-based cognitive behavioural therapy; WLC, waitlist control; Pre, before treatment; Post, after treatment; 6FU, sixmonths follow-up, $12 \mathrm{FU}$, twelve-month follow-up. 
For the secondary outcomes, significant overall effects (all P's <0.05) and medium to large effect sizes were found in favour of the two intervention groups. In the following analyses of simple effects, we found significant improvement in the W-iCBT, when compared with the WLC, on work ability and sickness absence (Figure 3). At the six-months follow-up, sickness absence was 324 days lower ( $M=5.31$ days per participant) in the $\mathrm{W}$-iCBT compared to the iCBT and 445 days ( $M=7.29$ days per participant) compared to the WLC. However, no significant differences were found on long-term sick leave $(H(2)=-0.82, P=0.663)$. Total net days on benefits due to long-term sick leave were, 1932 days in the $\mathrm{W}$-iCBT, 2328 days in the iCBT, and 2435 days in the WLC group.

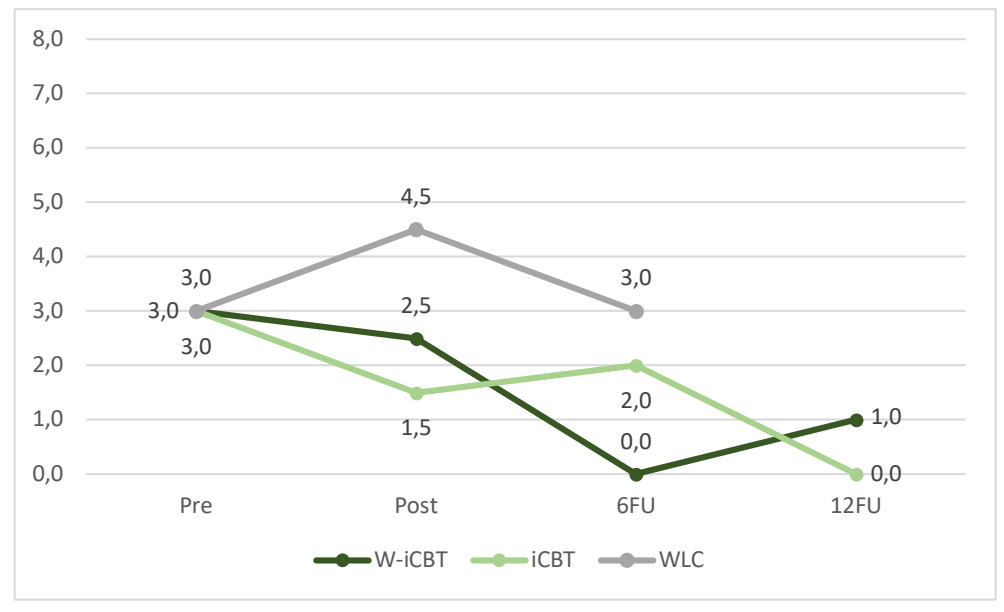

Figure 3. Development on the TiC-P sickness absence (Median days). W-iCBT, work-focused internet-based cognitive behavioural therapy; iCBT, generic internet-based cognitive behavioural therapy; WLC, waitlist control; Pre, before treatment; Post, after treatment; 6FU, six-months follow-up, 12FU, twelve-months follow-up.

\section{Conclusions}

Study III confirms that internet-based interventions can be as effective as faceto-face interventions targeting clinical samples, within the working population. To the best of our knowledge, this was the first internet-based trial integrating a work-focused format, with effects on important work-related outcomes, e.g., sickness absence and work ability. These results are promising, as they provide further evidence that treatments that integrate work-aspects has great potential in accelerating both recovery and return-to-work due to stress-related disorders. Nonetheless, more research is needed to investigate the potential of internetbased and work-focused interventions. 


\section{Study IV: Learning how to recover from stress: results from an Internet-based, randomized, controlled pilot trial}

\section{Methods}

\section{Procedure}

In Study IV we evaluated the efficacy of a brief internet-based recovery training intervention that targeted distressed employees. In a sample, 69 employees with elevated symptoms of perceived stress were assigned randomly to a five-week recovery training intervention (iRTP, $\mathrm{n}=35$ ) or a wait-list control condition (WLC, $n=34$ ). Self-report data were collected pre- and post-intervention, then six and 12-months after the intervention. Participants were recruited from the general public through ads, articles in regional and national newspapers, and social media.

To be eligible for the study, participants had to match the cut-off score for elevated symptoms of perceived stress (PSS $\geq 14$ points) and burnout (SMBQ $<5$ points) and fulfil the criteria for a stress-related disorder established via diagnostic interviews. Additional inclusion and exclusion criteria were applied. For detailed description, see attached manuscript for Study IV. In total, 156 individuals were screened, and 87 were excluded, according to the inclusion and exclusion criteria, mostly because of sub or above threshold scores on one or several of the outcome measures.

The sample comprised of 69 employees, most of whom were female (85.5\%) with an average age of $44.4(\mathrm{SD}=10.1)$. A majority of the participants $(71.0 \%)$ were working in the social, healthcare, or educational sectors. The average participant was working full-time, with 4.2 hours $(\mathrm{SD}=3.8)$ of overtime per week.

\section{Outcomes measures}

The primary outcome measure was the Recovery Experience Questionnaire (REQ), which included the subdimensions (i) psychological detachment; (ii) relaxation; (iii) mastery; and (iv) control (Sonnentag \& Fritz, 2007). The secondary outcome measures gauged other relevant mental and work-related health outcomes (e.g., Perceived stress scale, Work ability Index, Brunnsviken Brief Quality of Life Inventory). All outcome measures were self-reported online. 


\section{Intervention}

The iRTP was based on recovery experiences (psychological detachment, relaxation, mastery, and control), converted into an internet-based recovery training intervention, and inspired by Hahn et al. (2011). The iRTP comprised five modules distributed over five weeks, with modules lasting 60-120 minutes per week. Each module contained psychoeducation, worksheets, images, cases, audio and video files, and homework assignments. The intervention included two fictional participants, representing different ages, genders and ethnicities, serving as examples throughout the intervention. The intervention was delivered via a secure web platform, iterapy (Vlaescu et al., 2016). Participants received weekly online support from an assigned coach (psychology graduates) who gave gradual access to modules.

The first module included an introduction, aim formulation, and psychoeducation about stress and the association between recovery and work-life balance. It also focused on the recovery experience psychological detachment, and strategies for detachment from stressors at work and in private life (e.g., mindfulness, activities that facilitate psychological detachment). The first module also included transitional rituals (Ashforth et al., 2000), with the aim of separating stressors in the work/home interface. In the second module, participants focused on the recovery experience relaxation and sleep management. Participants were asked to identify relaxing activities, practise applied relaxation (Öst, 1987), along with sleep hygiene and sleep strategies (Åkerstedt et al., 2012; Cheng \& Dizon, 2012). The third module concentrated on the recovery experience mastery, and the role of physical exercise in recovery. This module began with rationale about the concept of mastery and ways to develop and build self-confidence and skills in other areas outside of work. The participants also examined and practiced boundary tactics at work (Kreiner et al., 2009). The fourth module focused on the recovery experience control and continued training of applied relaxation and boundary-setting tactics. Participants were introduced to the concept of control and why selfdetermination is important in recovery from stress and strain. In the final module, maintenance, key lessons learned were summarized in an action and relapse plan.

\section{Statistical analyses}

Missing data was handled with multiple imputation, following the intention-totreat principle. The effects of group on primary and secondary outcome measures were analysed using analysis of covariance (ANCOVA), with pre-assessment values as covariates and time (pre, post and six-months follow-up) as a withinsubject factor. Pooled F-values were calculated using RStudio (RStudio, Inc., Boston, MA). Cohen's d was reported for the between-group effect sizes. 


\section{Results}

The study attrition rate was moderate, $15.8 \%$ at post-treatment (iRTP $=9$ and $\mathrm{WLC}=2$ ); $25.9 \%$ at the six-month follow-up (iRTP $=15$ and $\mathrm{WLC}=3$ ); and $37.1 \%$ at the 12-month follow-up (iRTP=13) questionnaires. Participants of the iRTP completed on average 4.32 modules $(\mathrm{SD}=0.80$ ), which equals $86.4 \%$ of the intervention.

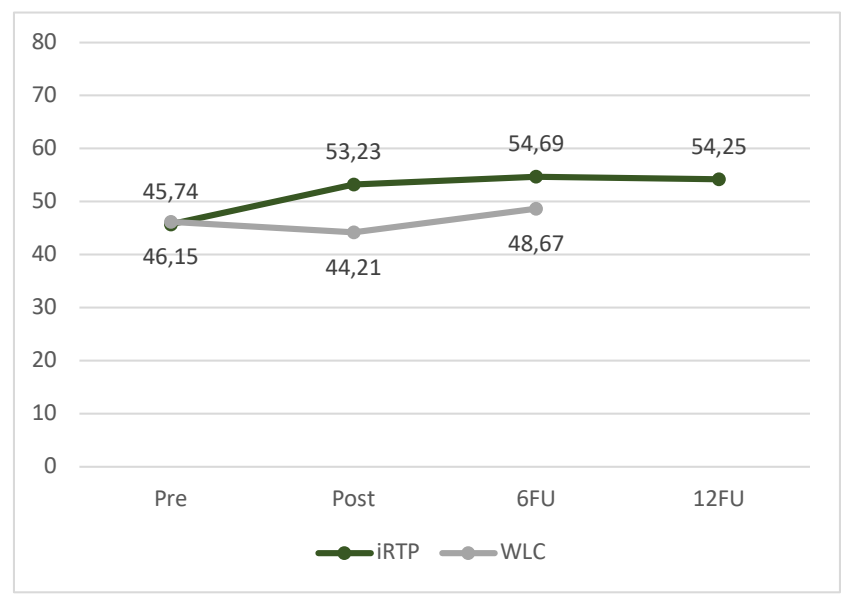

Figure 4. Development on the REQ (Mean scores). iRTP, internet-based recovery training; WLC, waitlist control; Pre, before treatment; Post, after treatment; 6FU, six-month follow-up, 12FU, twelve-month follow-up.

As depicted in figure 4, intervention group improved significantly more than the control group on the primary outcome measure, REQ, at post-test $(d=0.91)$ and at the six-months follow-up $(d=0.51)$. In the following analysis of the recovery experience subscales, participants in the intervention group registered significantly higher scores on psychological detachment $(d=0.69)$, relaxation ( $d=0.58)$, and mastery $(d=0.97)$. No significant differences were found on the recovery experience control at any timepoint.

In the secondary outcome analysis, participants in the intervention group reported significant and small to moderate effects on perceived stress $(d=0.48)$, anxiety $(d=0.49)$, quality-of-life $(d=0.47)$, and work ability $(d=0.47)$ at postassessment. Both the iRTP and WLC groups continued to improve during the sixand 12-months follow-up periods, however there were no significant difference between the two groups. No significant differences were found on any timepoint regarding burnout, exhaustion, depression, physical exercise, work experience, or sickness absences. 


\section{Conclusions}

The preliminary results of Study IV suggest that employees from various professions could learn how to recover from elevated symptoms from stress via a brief Internet-based recovery training intervention. Study IV also indicates that the initially gained improvements could be sustained over time. Hopefully, these kinds of accessible and brief recovery interventions could shape the future of stress prevention. However, more research is needed with larger samples before further conclusions can be drawn. 


\section{DISCUSSION}

\section{MAIN FINDINGS}

In the present thesis, three internet-based interventions were evaluated. Studies I and III indicated that iCBT can be efficacious in reducing symptoms of chronic stress and comorbid health problems in samples of managers and employees diagnosed with a stress-related disorder, when compared with controls. In addition to effects on stress- and mental health-related symptom, the workfocused intervention in Study III, was found to be more efficacious, compared to a generic iCBT and WLC, in increasing work ability and reducing sickness absence. Study II indicated positive experiences among participant of a W-iCBT intervention on measures of mental health and well-being in both life and at work. However, in line with previous research, participants found the intervention to be extensive and demanding and expressed a need for extended treatment time and therapist support. Finally, Study IV showed that recovery experiences, an important protective factor, could be improved by a brief recovery training intervention.

\section{Effects of internet-based cognitive behavioural stress management interventions}

The iCBT interventions evaluated in Study I and III consistently produced larger between-group effects sizes on stress- and mental-health-related outcomes, compared to pooled effects found in meta-analyses on internet-based interventions for stress.

In Study I and III, effect sizes on perceived stress $(d=0.85$ and $d=0.74$ respectively), were larger compared to the effects $(d=0.45)$ found in a metaanalysis on internet-based stress interventions (Heber et al., 2017), and in line with regular face-to-face CBT-based interventions for stress $(d=0.68-1.16$ : Richardson \& Rothstein, 2008). The fact that internet-based interventions might generate effects in line with face-to-face, is supported by a growing body of evidence (Carlbring et al., 2018). It is also important to bear in mind that face-toface interventions are delivered with substantial support from health professionals, about $60 \mathrm{~min}$ in face-to-face compared with a mean of 12.1 and 16.7 $\mathrm{min} /$ week in in Study I and III.

In addition to the main effects, medium to large effects were found on secondary mental-health-related outcomes in Studies I and III, depression ( $d=0.86-0.87$ vs. 0.34 ), anxiety ( $d=0.70$ vs. 0.32$)$ and insomnia $(d=0.34-0.87$ vs. o.86), compared to effect sizes found in the meta-analysis on iCBT for stress (Heber et al., 2017) and insomnia (Cheng \& Dizon, 2012). When comparing effect sizes, it should be noted that the treatment of choice for common mental disorders is pharmacological treatment (e.g., SSRI), with small mean effect sizes 
$(d=0.30)$ reported in a large meta-analysis comparing the efficacy of 21 antidepressants for the treatment of adults with major depressive disorder (Cipriani et al., 2018). However, comparing effect sizes should be made with caution, as there is a large heterogeneity between studies in terms of study design, target populations, and treatment outcomes.

As emphasized in previous sections, most studies on internet-based and faceto-face interventions for stress have been conducted within sub-clinical samples and in the occupational context, and it is uncertain whether these results extend to clinical samples. Interestingly both study I and III produced larger effect sizes on outcomes of burnout $\left(d=0.95^{-1.00}\right)$ and exhaustion $(d=0.87)$ at post assessment, compared to the meta-analysis on face-to-face interventions for chronic stress by Maricuțoiu et al. (2016), in which the effect size for burnout was 0.22 and exhaustion 0.17 .

Compared to the previously referred meta-analyses, greater initial symptom severity could be one possible explanation for the relativity large effect sizes found in Study I and III. Recent studies suggests that greater baseline scores, moderates the effect of iCBT and predict larger reductions, compared with participants with lower initial symptom severity (Andersson, Carlbring, et al., 2019; Weisel et al., 2018). Another reason may be that early iCBT interventions, for instance Zetterqvist et al. (2003), were based on protocols adapted for anxiety rather than stress-related disorders. Perhaps more recently evaluated interventions have been more tailored for the specific needs and preferences of the target population. This possible explanation is supported by the larger effects found in subsequent trials (e.g., Ebert, Heber, et al., 2016; Ebert, Lehr, et al., 2016; Lindsäter et al., 2018).

Notably, the effect sizes on insomnia severity varied between Study I $(d=0.34)$ and III $(d=0.87)$. Both studies comprised of modules regarding sleepmanagement. However, modules in Study I were more elementary, as compared to the iCBT in Study III, and did not include any sleep restriction or sleep strategies, found to be efficacious (e.g., Cheng \& Dizon, 2012; Thiart et al., 2015). In addition, Study III focused on recovery techniques to a larger extent, and perhaps increased daytime recovery partially could explain the relativity large differences in effects between the studies on insomnia severity. A lack of recovery during the day has been found to increase the risk of disturbed sleep and selfreported sleep quality (Tucker et al., 2008).

Finally, a majority of the participants in the intervention groups of Study III (67-69\%) fulfilled the criteria for clinically significant change on the primary outcome on burnout. The proportion of clinically significant change was comparable to previous trials (Lindsäter et al., 2018; van de Leur et al., 2020). However, there was a considerable discrepancy in the number of participants achieving clinically significant change between measures of burnout (SMBQ) and exhaustion (KEDS). This probably reflects that SMBQ and KEDS measure 
different underlying constructs, which has been noted in previous research (Saboonchi et al., 2013).

\section{Effects of internet-based and work-focused stress interventions}

Stress-related disorders are a common cause for sickness absence, often resulting in long-term sick leave sizable costs (Hassard et al., 2018; Koopmans et al., 2011). Hence, it is not surprising that policy makers seek advice on how sickness absence can be prevented. Accordingly, the work-focused, W-iCBT, intervention evaluated in Study III, aimed at improving work-related factors (e.g., demand, support, clarity) and reduce sickness absence among employees with a stressrelated disorder (i.e., tertiary reactive interventions). As hypothesised, effects on work-related outcomes, work ability $(d=0.40)$ and sickness absence $(d=0.20-$ o.25), were only seen in work-focused intervention, compared to the WLC condition of Study III. Effects on sickness absence were however small and comparable to the effect sizes (Hedges' $g=0.22$ ) found in a meta-analysis (Finnes et al., 2019) on work-focused CBT interventions targeting individuals with sickness absence due to common mental disorders. The effects on sickness absence and work ability are promising, as poor work ability has been associated with increases risk of sickness absence over 10 years (Palmlöf et al., 2019). It should be noted that the interventions, iCBT and W-iCBT included in study III, were only compared separately in term of superiority and in relation to the WLC. Study III was not a non-inferiority trial.

No significant effects on either sickness absence or presenteeism were found in Study I. Accordingly, no significant differences were observed in Study III on long-term sick leave. This may be due to differences in measurement between Studies I and III. Sickness absence was conceptualized as the self-rated number of days absent from work while being physically or mentally ill, during the past month in Study I and past three months in Study III. Sickness absence was assessed at three time-points, pre, post and at a six-months follow-up. Long-term sick leave, however, was based on data from the Swedish Social Insurance Agency on the number of net days on sickness benefit between the pre- and six-months follow-up assessment. In Sweden, sickness benefit from the Swedish Social Insurance Agency is due from day 15 on sick leave.

Interestingly, in Study I, participants improved significantly compared to controls on the work-related outcome, Work Experience Measurement Scale (WEMS), with small to medium effect sizes on the subscales perceived support, leadership, process of change and work satisfaction. However, effects were not sustained at the six-months follow-up. Accordingly, they were not seen in study III and IV, including the WEMS. It is probable that the temporary results of Study I were indirect effects, mediated by the general reduction on the stress and mental health related outcomes. 


\section{Effects of internet-based preventive stress interventions}

The main purpose of Study IV was to improve recovery experiences in a sample of employees with elevated symptoms of stress (i.e., primary prevention intervention). Recovery has been found to be an important preventive and protective factor against the development of chronic stress (Sonnentag et al., 2017). Compared to controls, the iRTP produced larger effect sizes on recovery experiences and medium effects on perceived stress, anxiety, quality-of-life, and work ability. In addition, the results on the primary and secondary outcomes remained stable in the intervention group at the six- and 12-months follow-ups, indicating that effects can be maintained over time and even prevent employees from developing chronic stress.

Few studies have investigated the efficacy of recovery intervention and only one previous trial has been reported on an internet-based, eight-week, sleep and recovery program targeting distressed teachers, for comparison (Ebert et al., 2015). The mean effect size $(d=0.91)$ found in Study IV on the main outcome, recovery experiences, corresponds with the mean effects $(d=1.03)$ reported in the study by Ebert et al. (2015). However, the same authors found very large effect sizes $(d=1.72)$ on the subscale measuring psychological detachment compared to $d=0.69$ in Study IV. One possible explanation could be that we did not include any metacognitive techniques, shown to be effective in the management of perseverative cognitions, such as stressful thoughts and ruminations (Wells et al., 2009). This might explain the relativity large effect sizes on the recovery experience psychological detachment in the study by Ebert et al. (2015). Future studies could benefit from including metacognitive techniques with the aim of facilitating further change in detachment from stressful thoughts and ruminations. It should be noted that the present study differed from the aforementioned study. For example, we included employees from various occupations, i.e., more heterogenous sample, and we performed the posttreatment assessment after five weeks, compared to eight weeks in the referred study.

No significant differences were found at any timepoint regarding burnout, exhaustion, depression, insomnia, alcohol consumption, physical exercise, work experience, or sickness absences. These insignificant results might be explained by the fact that we did not include any specific interventions or techniques, that target these problems or outcomes. However, in the case of burnout, exhaustion, insomnia, and depression, we expected that the focus on recovery experiences, relaxation, sleep management and physical exercise, would reduce the negative effects from stress and, consequently, burnout, exhaustion, depression, and insomnia. It is possible that brief interventions, like Study IV, with a timeframe of five weeks, are too short to generate effects on disorders such as burnout, exhaustion and depression. A recent study suggested that around eight sessions/modules are needed for $50 \%$ of the participants to achieve reliable change, and that around 14 sessions are needed for $50 \%$ of the participants to 
achieve clinically significant change (Levy et al., 2020). Accordingly, with lower symptom severity at baseline there is a risk of floor effects (Andersson, Carlbring, et al., 2019; Weisel et al., 2018). Another plausible explanation is that we failed to address or had to leave out relevant components due to space constraints, which would have affected these outcomes. For example, we did not include any behavioural activation or sleep restrictions, which have been shown to be effective in reducing depression and insomnia, respectively (Cheng \& Dizon, 2012; Martell et al., 2001). Corresponding with this reasoning, moderate-to-large effects on burnout, depression, and insomnia were found in the aforementioned Studies I and III, following an eight- or ten-week iCBT, including both behavioural activation and sleep restriction.

Modules regarding positive management were integrated in the main iCBT stress intervention of Study I. As mentioned in the introduction of this thesis, positive management (Komaki, 1998) aims to on enhance important protective work-environmental factors, such as control, support and reward, trough positive managerial feedback. And thereby preventing employees from developing chronic stress (Kelloway \& Barling, 2010), and improve well-being and performance (Skakon et al., 2010). Unfortunately, we did not collect any data from subordinates on stress, well-being and work-performance, and their perception of managerial feedback. Since recruitment was carried out through an open self-referral process, there was no secure way of collecting data from subordinates. Presumably, future studies using different recruitment approaches (e.g., worksite) could gain some insights on employee perception of managerial feedback and possible effects on health and work-related outcomes.

\section{Experiences of internet-based stress interventions}

Study II is one of the first studies examining participants' experiences of having completed an iCBT for stress, including a work-focused content.

All participants found that the intervention was useful, relevant and userfriendly. Most useful were the sections regarding psychoeducation on stress, managing stress factors in both work and private life, and the work-focused components. All participants emphasized the importance of having access to therapist support, which is in line with previous research suggesting better outcome when guidance is included (Baumeister et al., 2014). Aligned with previous research, participants found the intervention to be extensive and demanding, and session length and deadlines constituting stress factors (Bendelin et al., 2011; Fleischmann et al., 2018; Halmetoja et al., 2014; Rozental, Forsström, et al., 2015). Nevertheless, none of the participants wished to reduce the extent of the program. The present iCBT program contained both CBT- and work-focused material represented each module, covering between five and 16 regular pages of information. To our knowledge, five and 16 regular pages of information per module are comparable to other iCBT programs. However, given the challenge of developing iCBT interventions for stress and burnout that neither 
drain the participants' resources nor compromise the quality of the program, it could be feasible to test different iCBT formats for stressed participants. We have previous positive experiences of reducing content to $2 / 3$ of the original format with sustained efficacy in a trial on social anxiety disorder (Dagöö et al., 2014).

A majority expressed a need for extended treatment time, more frequent therapist support (when needed) and a follow-up or booster session. However, themes expressed in previous research regarding the need for more individualized feedback and support were not emphasized by the participants in the present study (Fleischmann et al., 2018; Gerhards et al., 2011; Ly et al., 2015; Rozental, Boettcher, et al., 2015). On the contrary, most of the participants perceived the treatment and the support as authentic and tailored to their needs, situation and preferences.

\section{Limitations}

The present study has several limitations in terms of selection, representativeness, attrition, adherence and compliance, blinding, power and moderating and mediating mechanisms.

\section{Selection and representativeness}

In all studies included in the present thesis, I-IV, an open recruitment strategy was applied, meaning that all participants were recruited by a self-referral process. We used a self-referral process to increase access to the interventions. We also considered that the participants would be more interested in participating, given the anonymity of the intervention. The use of self-referral recruitment has been criticized for being vulnerable to selection bias, recruiting those participants most inclined to participate (Murray et al., 2009). These circumstances could constitute a threat to the generalisability of the results. The issue was confirmed by the fact that most participants were women, middle aged, and $89-96 \%$ of the participants in Studies I-IV had a university-level educational background, compared to $28 \%$ in the general population (Statistics Sweden, 2020). Future studies are therefore needed, including participants that are more representative for the general working population. Perhaps providing W-iCBT integrated in the workplace, could lower thresholds and be a successful approach in including a broader spectrum of employees.

Selection could also influence the representativeness of Study II, where participants were selected using a criterion-based sampling approach, selecting those participants who had completed all treatment modules and the threemonth follow-up. Including dropouts could potentially have contributed to a lager variety of different experiences and suggestions for improvements of the intervention. 


\section{Attrition, adherence and compliance}

There was moderate attrition and non-adherence in studies I, III and IV. Between $16 \%$ and $21 \%$ did not complete the post-assessment questionnaires and $24-30 \%$ did not provide data on the six-months follow-up. Additionally, participants completed on average $71-87 \%$ of the intervention. However, the attrition and adherence rates in the current trial are in line with previous iCBT trials for stress (Heber et al., 2017), and within limits of acceptable drop-out rate (20\% for shortterm and $30 \%$ for long-term follow-up) according to Cochrane guidelines for systematic reviews (Furlan et al., 2009). Considering these observations on attrition and adherence, together with the use of multiple imputation, which is a recommended approach for handling missing data (Schafer \& Graham, 2002), the results seem nevertheless reliable.

Another limitation is that we did not collect any reliable data on treatment compliance (such as degree of homework completion or active use of the iSMI). We did store information about the number of logins and login time. However, we could not discriminate between active and passive users (e.g., signed in but not active). In future studies, we suggest inclusion of knowledge tests or qualitative analysis of homework assignments, to assess active use and treatment compliance.

\section{Control conditions}

The use of passive, wait-list control, conditions has been debated (e.g., risk of attentional bias), and the inclusion of active control groups is often regarded to be a more conservative approach (Safer \& Hugo, 2006). In Study I we developed an active control condition, attention control, designed to provide similar attention as the intervention in terms of communication, support, homework assignments etcetera. This type of passive learning experience and attention control could be utilized to ensure blinding among participants in RCT for internet-based interventions, and thereby limiting the risk of detection and performance bias and overestimated treatment effects. Nevertheless, we did not include active control conditions in Studies III and IV, since most internet-based interventions trials are compared to waitlist controls. In order to be able to compare with previous results, the choice was to use waitlist control conditions.

\section{Power}

Sample size was estimated on the basis of previous controlled trials on iCBT for chronic stress and recovery training (Ebert et al., 2015; Lindsäter et al., 2018; Zetterqvist et al., 2003), with the aim of detecting an effect size of Cohens' $d=0.40-0.50$ on the primary outcome, at post assessment, based on a power of 0.80 in a two-tailed test with 0.05 significant level. For sub-group analysis, the sample sizes in Studies I, III and IV, were however insufficient. For instance, in Study III, 51 participants (28\%) or 17 participants per group, were on 
long-term sick leave receiving sickness benefit. For sufficient power, a much larger sample size would have been needed. Similarly, subgroup analysis of differences on the basis of disorder, gender, occupation etcetera, were also not possible due to insufficient power. Future studies could include larger sample sizes to enable sub-group analyses. In the case of including participants on longterm sick leave due to stress-related disorder, another recruitment and delivering approach would be applicable, for example, directly via primary and occupational health care, where most sick leave is initiated.

\section{Objective measures}

All outcomes represented in the present thesis, except for long-term sick leave included in Study III, were subjective self-rated questionnaires. Objective measures could improve the validity and reliability of the study and objective measures, e.g., biological markers, has successfully been used in previous trials


objective measures, e.g., biological markers collected via blood samples, could be resource-intensive and impractical (e.g., participants cannot eat or drink prior sampling and samples must be administered at a specific time and place), posing a potential threat to the validity of the study. Future studies could include objective measure parameters in order to objectively measure the efficacy of internet-based stress interventions, thus practical issues must be taken under special consideration.

\section{Moderating and mediating mechanisms}

In the studies of the present thesis, we did not design for or include any mediator or moderator analyses. As mentioned in the introduction, recovery and psychological detachment might have bidirectional relationship with workrelated rumination and sleep quality, which in turn have been shown to be antecedents for burnout, depression, and even long-term sick leave (Grossi et al., 2015; Vahle-Hinz et al., 2014). Accordingly, an emphasis on the preoccupation and constant rumination about stressor(s) and its consequences, have been added to the criteria for $\mathrm{AD}$ in latest update of ICD (ICD-11).

Perhaps, day- and night-time recovery (sleep) and psychological detachment from rumination about stressor(s) and its consequences, are core mediating factors, explaining much of the effects seen in psychological interventions for stress and stress-related disorders. Including corresponding modules possibly this could explain the relatively large effect sizes found in study III, on outcomes regarding insomnia (ISI, $d=0.87$ ), psychological detachment (REQ, $d=0.93)$ and anxiety/worry (GAD-7, $d=0.70)$. 


\section{Health economic analysis}

The present thesis would have benefited from including health economic analysis. Even though few studies have investigated the cost-effectiveness of internetbased interventions for stress or stress-related disorders, there is some indications of promising results (Ebert et al., 2018; Kählke et al., 2019; Lindsäter et al., 2019). Interestingly, in the aforementioned studies, the cost-effectiveness was largely driven by a reduction in costs for presenteeism. This is promising since presenteeism and production loss tend to be high in samples with chronic stress (Hassard et al., 2014, 2018; Kigozi et al., 2017).

\section{Future directions}

\section{Efficacy within different samples and formats}

Even though the studies in the $t$ thesis have provided further evidence on the efficacy of internet-based interventions for stress, more controlled trials are needed, using lager sample sizes, different recruitment strategies, control conditions, and treatment formats. For instance, future studies could test the efficacy within different samples within regular care or by applying on site workplace requitement approaches. Future studies could also blend internetbased and face-to-face group formats, and compare interventions to active controls.

The present thesis found positive results of the work-focused intervention (Study III) on outcomes of work ability and sickness absence. Considering the relative limited evidence regarding the efficacy on work-related outcomes, such as improved work ability, reduced presenteeism, and reduced sickness absence due to stress-related disorders, these findings needs to be replicated, and tested in larger samples of participants on long-term sick leave due to stress-related disorder. Accordingly, the preliminary results in Study IV of a brief internetbased recovery intervention needs to be replicated. Preferably in a robust RCT with sufficient power and sample size.

\section{Preventive interventions}

Although we have a great deal of knowledge about the etiology, prevalence and treatment of stress, the range of prevention is not at all proportionate to the needs of the public. However, as previously mentioned, the evidence for the efficacy of individual and organizational level primary preventive interventions at a scarce (Bhui et al., 2012; Martin et al., 2009; Naghieh et al., 2015). More studies are therefore needed focusing on prevention.

Early detection of signs of chronic stress are pivotal in the process of prevention. And perhaps future studies should include on-site (e.g., workplace, 
school) and repeated internet-based screening procedures, identifying those individuals with high risk of developing chronic stress, and providing direct access to preventive interventions, e.g., internet-based recovery training.

Moreover, a comprehensive body of literature has been pointing to the impact of work-environmental factors in the development of chronic stress (e.g., Statens beredning för medicinsk och social utvärdering, 2014). Future studies could focus on how to organize and enhance important protective workenvironmental factors, such as control, support and reward. For instance, trough supportive leadership (e.g., Schmid et al., 2017) and peer support groups (e.g., Peterson et al., 2008), and thereby preventing employees from developing chronic stress and subsequent sick leave. Accordingly, workplace involvement has been found to be important factor in return-to-work process (Hoefsmit et al., 2012; Joyce et al., 2016). Hence, it would be interesting to evaluate an internetbased and work-focused interventions for employees suffering from stressrelated disorders with a parallel program targeting managers/HR focusing on workplace support and involvement in the return-to-work process.

\section{Dismantling what works and for whom}

As mentioned previously, studying moderators and mediators of treatment effect could help to dismantling what works and for whom, to further improve and streamlining of interventions in the target population. In addition to the aforementioned mediators (see limitations), future studies on moderators could gain further insight on the impact of initial disorder, symptom severity, gender, work sector, age, previous treatment etcetera. Moreover, the use of dismantling or factorial designs, in which the effects of different components can be compared, could be applicable approaches (Andersson, Titov, et al., 2019).

\section{Dissemination and implementation}

While the benefits of internet-based interventions have been firmly established in controlled research, these efforts have rarely been evaluated in real-world settings or documented from an implementation science perspective (Andersson, Titov, et al., 2019). One potential obstacle when implementing internet-based interventions is that they rarely fit traditional healthcare systems, and give raise to legal, ethical, and professional issues (Childress, 2000). Moreover, negative attitudes among clients, patients, practitioners and other stakeholders might affect and slow down the dissemination and implementation of internet-based treatment in routine practice. For example, negative attitudes were found in a stakeholder study conducted in eight European countries on internet-based interventions reporting that blended treatment approaches, i.e., combining internet-based with face-to-face within the same treatment, were preferred over internet-based as a stand-alone intervention (Topooco et al., 2017). 
Even so, some interventions have been evaluated and published on the effectiveness of internet-based interventions for common mental-health disorders within routine practice, including chronic stress (Andersson, Titov, et al., 2019; Niles et al., 2020). For example, an uncontrolled trial of 470 general practitioner referred patients treated at a Dutch online mental health clinic for burnout, found positive and large within-group effects of a therapist-assisted iCBT intervention (Ruwaard et al., 2012). However, as the authors pointed out further effectiveness studies are needed before large-scale dissemination of internet-based interventions for chronic stress can be recommended.

Moreover, we have recently conducted an evaluation on the effectiveness and implementation process of a work-focused and internet-based intervention in primary and occupational care. The implementation process was evaluated with regard to the perspectives of different stakeholders (e.g., organization, practitioners, patient) concerning the effectiveness, acceptability, utility and feasibility of the intervention. Results are currently being processed and analysed.

Given the revolution in digitalization, especially during the last year accelerated by a global pandemic, future studies could bring further light into the implementation process and the potential obstacles to facilitate further access to evidence-based interventions for stress-related disorders. 


\section{CONCLUSIONS}

The studies in the thesis bring further evidence to the growing body of literature, suggesting that internet-based interventions could be an effective and accessible approach of reducing chronic stress and other mental- and work-related health symptoms among distressed managers and employees. In line with recent studies, we found evidence that these interventions could produce effects within in range of face-to-face interventions, and that the effects can be sustained over time.

We provide new evidence regarding the experience and the efficacy of a workfocused and internet-based intervention for stress, indicating positive experiences on the acceptance and feasibility of this relatively new treatment format, and preliminary and promising results regarding work-related outcomes, including work ability and sickness absence. Finally, we bring new evidence on the efficacy of brief internet interventions on recovery, a potential protective factor in the prevention of stress.

The results motivate further evaluation within different populations, including mediating treatment mechanisms and further integration within the workplace. If implemented, this kind of accessible and brief interventions could shape the future of stress prevention, learning employees and others how to recover from chronic stress. 


\section{REFERENCES}

Ahola, K., Toppinen-Tanner, S., \& Seppänen, J. (2017). Interventions to alleviate burnout symptoms and to support return to work among employees with burnout: Systematic review and meta-analysis. Burnout Research, 4, 1-11. https://doi.org/10.1016/j.burn.2017.02.001

Ahola, K., Väänänen, A., Koskinen, A., Kouvonen, A., \& Shirom, A. (2010). Burnout as a predictor of all-cause mortality among industrial employees: A 10-year prospective register-linkage study. Journal of Psychosomatic Research, 69(1), 51-57. https://doi.org/10.1016/j.jpsychores.2010.01.002

Åkerstedt, T. (2006). Psychosocial stress and impaired sleep. Scandinavian Journal of Work, Environment \& Health, 32(6), 493-501.

Åkerstedt, T., Nordin, M., Alfredsson, L., Westerholm, P., \& Kecklund, G. (2012). Predicting changes in sleep complaints from baseline values and changes in work demands, work control, and work preoccupation - The WOLF-project. Sleep Medicine, 13(1), 73-80. https://doi.org/10.1016/j.sleep.2011.04.015

Alberts, N. M., Hadjistavropoulos, H. D., Titov, N., \& Dear, B. F. (2018). Patient and provider perceptions of Internet-delivered cognitive behavior therapy for recent cancer survivors. Supportive Care in Cancer, 26(2), 597-603. https://doi.org/10.1007/s00520-017-3872-8

Alexanderson, K., \& Norlund, A. (2004). Swedish Council on Technology Assessment in Health Care (SBU). Chapter 1. Aim, background, key concepts, regulations, and current statistics. Scandinavian Journal of Public Health. Supplement, 63, 12-30. https://doi.org/10.1080/14034950410021808

Almén, N., Lisspers, J., \& Öst, L.-G. (2020). Stress-Recovery Management: A Pilot Study Using a Single-Subject Experimental Design. Behavior Modification, 44(3), 449-466. https://doi.org/10.1177/0145445518825363

Andersson, G. (2014). The Internet and CBT: A Clinical Guide (1 edition). Boca 
Raton: CRC Press.

Andersson, G., Carlbring, P., \& Rozental, A. (2019). Response and Remission

Rates in Internet-Based Cognitive Behavior Therapy: An Individual

Patient Data Meta-Analysis. Frontiers in Psychiatry, 10.

https://doi.org/10.3389/fpsyt.2019.00749

Andersson, G., Titov, N., Dear, B. F., Rozental, A., \& Carlbring, P. (2019).

Internet-delivered psychological treatments: From innovation to

implementation. World Psychiatry, 18(1), 20-28.

https://doi.org/10.1002/wps.20610

Andreasen, N. C., \& Hoenk, P. R. (1982). The predictive value of adjustment

disorders: A follow-up study. The American Journal of Psychiatry, 139(5), 584-590. https://doi.org/10.1176/ajp.139.5.584

Ansell, E. B., Rando, K., Tuit, K., Guarnaccia, J., \& Sinha, R. (2012). Cumulative adversity and smaller gray matter volume in medial prefrontal, anterior cingulate, and insula regions. Biological Psychiatry, 72(1), 57-64. https://doi.org/10.1016/j.biopsych.2011.11.022

Arbetsmiljöverket. (2018). Arbetsorsakade besvär 2018. https://www.av.se/arbetsmiljoarbete-ochinspektioner/arbetsmiljostatistik-officiellarbetsskadestatstik/arbetsorsakade-besvar-2018/

Arbetsmiljöverket. (2019). Arbetsrelaterad dödlighet-Delrapport 1 (2019:1; p. 74).

Arends, I., Bruinvels, D. J., Rebergen, D. S., Nieuwenhuijsen, K., Madan, I., Neumeyer-Gromen, A., Bültmann, U., \& Verbeek, J. H. (2012). Interventions to facilitate return to work in adults with adjustment disorders. The Cochrane Database of Systematic Reviews, 12, CDo06389. https://doi.org/10.1002/14651858.CDoo6389.pub2

Arnsten, A. F. T. (2009). Stress signalling pathways that impair prefrontal cortex structure and function. Nature Reviews. Neuroscience, 1O(6), 410-422. https://doi.org/10.1038/nrn2648

Arnsten, A. F. T. (2015). Stress weakens prefrontal networks: Molecular insults to higher cognition. Nature Neuroscience, 18(10), 1376-1385. https://doi.org/10.1038/nn.4087

Åsberg, M., Grape, T., Krakau, I., Nygren, Å., Rohde, M., Wahlberg, A., \& 
Währborg, P. (2010). Stress som orsak till psykisk ohälsa.

Läkartidningen, 107(19-20), 1307-1310.

Åsberg, M., Nygren, Å., \& Nager, A. (2013). Att skilja mellan depression och utmattningssyndrom. Läkartidningen, 110(9/10), 484-486.

Ashforth, B. E., Kreiner, G. E., \& Fugate, M. (2000). All in a day's work: Boundaries and micro role transitions. The Academy of Management Review, 25(3), 472-491. https://doi.org/10.2307/259305

Atroszko, P. A., Demetrovics, Z., \& Griffiths, M. D. (2020). Work Addiction, Obsessive-Compulsive Personality Disorder, Burn-Out, and Global Burden of Disease: Implications from the ICD-11. International Journal of Environmental Research and Public Health, 17(2). https://doi.org/10.3390/ijerph17020660

Ayuso-Mateos, J. L., Vázquez-Barquero, J. L., Dowrick, C., Lehtinen, V., Dalgard, O. S., Casey, P., Wilkinson, C., Lasa, L., Page, H., Dunn, G., \& Wilkinson, G. (2001). Depressive disorders in Europe: Prevalence figures from the ODIN study. The British Journal of Psychiatry, 179(4), 308316. https://doi.org/10.1192/bjp.179.4.308

Bakker, A. B., Killmer, C. H., Siegrist, J., \& Schaufeli, W. B. (2000). Effortreward imbalance and burnout among nurses. Journal of Advanced Nursing, 31(4), 884-891. https://doi.org/10.1046/j.13652648.2000.01361.x

Baumeister, H., Reichler, L., Munzinger, M., \& Lin, J. (2014). The impact of guidance on Internet-based mental health interventions-A systematic review. Internet Interventions, 1(4), 205-215. https://doi.org/10.1016/j.invent.2014.08.003

Ben Simon, E., Rossi, A., Harvey, A. G., \& Walker, M. P. (2020). Overanxious and underslept. Nature Human Behaviour, 4(1), 100-110. https://doi.org/10.1038/s41562-019-0754-8

Bendelin, N., Hesser, H., Dahl, J., Carlbring, P., Nelson, K. Z., \& Andersson, G. (2011). Experiences of guided Internet-based cognitive-behavioural treatment for depression: A qualitative study. BMC Psychiatry, 11, 107. https://doi.org/10.1186/1471-244X-11-107

Beser, A., Sorjonen, K., Wahlberg, K., Peterson, U., Nygren, A., \& Asberg, M. (2014). Construction and evaluation of a self rating scale for stress- 
induced Exhaustion Disorder, the Karolinska Exhaustion Disorder Scale. Scandinavian Journal of Psychology, 55(1), 72-82.

Bhui, K. S., Dinos, S., Stansfeld, S. A., \& White, P. D. (2012). A synthesis of the evidence for managing stress at work: A review of the reviews reporting on anxiety, depression, and absenteeism. Journal of Environmental and Public Health, 2012, 515874. https://doi.org/10.1155/2012/515874

Bianchi, R., Verkuilen, J., Brisson, R., Schonfeld, I. S., \& Laurent, E. (2016). Burnout and depression: Label-related stigma, help-seeking, and syndrome overlap. Psychiatry Research, 245, 91-98. https://doi.org/10.1016/j.psychres.2016.08.025

Billings, A. G., \& Moos, R. H. (1981). The role of coping responses and social resources in attenuating the stress of life events. Journal of Behavioral Medicine, 4(2), 139-157.

Binnewies, C., Sonnentag, S., \& Mojza, E. J. (2009). Daily performance at work: Feeling recovered in the morning as a predictor of day-level job performance. Journal of Organizational Behavior, 3o(1), 67-93. https://doi.org/10.1002/job.541

Blonk, R. W. B., Brenninkmeijer, V., Lagerveld, S. E., \& Houtman, I. L. D. (2006). Return to work: A comparison of two cognitive behavioural interventions in cases of work-related psychological complaints among the self-employed. Work \& Stress, 2O(2), 129-144. https://doi.org/10.1080/02678370600856615

Bond, F. W., \& Bunce, D. (2000). Mediators of change in emotion-focused and problem-focused worksite stress management interventions. Journal of Occupational Health Psychology, 5(1), 156-163. https://doi.org/10.1037/1076-8998.5.1.156

Bouwmans, C., De Jong, K., Timman, R., Zijlstra-Vlasveld, M., Van der FeltzCornelis, C., Tan Swan, S., \& Hakkaart-van Roijen, L. (2013). Feasibility, reliability and validity of a questionnaire on healthcare consumption and productivity loss in patients with a psychiatric disorder (TiC-P). BMC Health Services Research, 13, 217. https://doi.org/10.1186/1472-6963$13-217$

Cannon, W. B. (Walter B. (1915). Bodily changes in pain, hunger, fear, and rage; an account of recent researches into the function of emotional 
excitement. New York: D. Appleton and Company.

http://archive.org/details/bodilychangesinpoocannrich

Carlbring, P., Andersson, G., Cuijpers, P., Riper, H., \& Hedman-Lagerlöf, E.

(2018). Internet-based vs. face-to-face cognitive behavior therapy for psychiatric and somatic disorders: An updated systematic review and meta-analysis. Cognitive Behaviour Therapy, 47(1), 1-18.

https://doi.org/10.1080/16506073.2017.1401115

Carr, D., \& Umberson, D. (2013). The social psychology of stress, health, and coping. In J. DeLamater \& A. Ward (Eds.), Handbook of Social Psychology (pp. 465-487). Dordrecht: Springer Netherlands. https://doi.org/10.1007/978-94-007-6772-0_16

Carver, C. S., Scheier, M. F., \& Weintraub, J. K. (1989). Assessing coping strategies: A theoretically based approach. Journal of Personality and Social Psychology, 56(2), 267-283.

Casey, P. (2014). Adjustment disorder: New developments. Current Psychiatry Reports, 16(6), 451. https://doi.org/10.1007/s11920-014-0451-2

Cavanaugh, M. A., Boswell, W. R., Roehling, M. V., \& Boudreau, J. W. (2000). An empirical examination of self-reported work stress among U.S. managers. The Journal of Applied Psychology, 85(1), 65-74.

Charmandari, E., Tsigos, C., \& Chrousos, G. (2005). Endocrinology of the stress response. Annual Review of Physiology, 67, 259-284. https://doi.org/10.1146/annurev.physiol.67.040403.120816

Cheng, S. K., \& Dizon, J. (2012). Computerised cognitive behavioural therapy for insomnia: A systematic review and meta-analysis. Psychotherapy and Psychosomatics, 81(4), 206-216. https://doi.org/10.1159/ooo335379 Childress, C. A. (2000). Ethical issues in providing online psychotherapeutic interventions. Journal of Medical Internet Research, 2(1), E5. https://doi.org/10.2196/jmir.2.1.e5

Chrousos, G. P. (2009). Stress and disorders of the stress system. Nature Reviews. Endocrinology, 5(7), 374-381. https://doi.org/10.1038/nrendo.2009.106

Cipriani, A., Furukawa, T. A., Salanti, G., Chaimani, A., Atkinson, L. Z., Ogawa, Y., Leucht, S., Ruhe, H. G., Turner, E. H., Higgins, J. P. T., Egger, M., Takeshima, N., Hayasaka, Y., Imai, H., Shinohara, K., Tajika, A., 
Ioannidis, J. P. A., \& Geddes, J. R. (2018). Comparative efficacy and acceptability of 21 antidepressant drugs for the acute treatment of adults with major depressive disorder: A systematic review and network metaanalysis. The Lancet, 391(10128), 1357-1366.

https://doi.org/10.1016/So140-6736(17)32802-7

Clays, E., Kittel, F., Godin, I., Bacquer, D. D., \& Backer, G. D. (2009). Measures of work-family conflict predict sickness absence from work. Journal of Occupational and Environmental Medicine, 51(8), 879-886. https://doi.org/10.1097/JOM.obo13e3181aa5070

Cohen, S., Janicki-Deverts, D., \& Miller, G. E. (2007). Psychological stress and disease. JAMA, 298(14), 1685-1687. https://doi.org/10.1001/jama.298.14.1685

Cohen, S., Kamarck, T., \& Mermelstein, R. (1983). A global measure of perceived stress. Journal of Health and Social Behavior, 24(4), 385396.

Dagöö, J., Persson Asplund, R., Bsenko, H. A., Hjerling, S., Holmberg, A., Westh, S., Öberg, L., Ljótsson, B., Carlbring, P., Furmark, T., \& Andersson, G. (2014). Cognitive behavior therapy versus interpersonal psychotherapy for social anxiety disorder delivered via smartphone and computer: A randomized controlled trial. Journal of Anxiety Disorders, 28(4), 410-417. https://doi.org/10.1016/j.janxdis.2014.02.003

de Weerd, B. J., van Dijk, M. K., van der Linden, J. N., Roelen, C. A. M., \& Verbraak, M. J. P. M. (2016). The effectiveness of a convergence dialogue meeting with the employer in promoting return to work as part of the cognitive-behavioural treatment of common mental disorders:

A randomized controlled trial. Work, 54(3), 647-655.

https://doi.org/10.3233/WOR-162307

de Zwart, B. C. H., Frings-Dresen, M. H. W., \& van Duivenbooden, J. C. (2002). Test-retest reliability of the Work Ability Index questionnaire. Occupational Medicine, 52(4), 177-181.

Deligkaris, P., Panagopoulou, E., Montgomery, A. J., \& Masoura, E. (2014). Job burnout and cognitive functioning: A systematic review. Work \& Stress, 28(2), 107-123.

Diefenbacher, A., \& Strain, J. J. (2002). Consultation-liaison psychiatry: 
Stability and change over a 10-year-period. General Hospital Psychiatry, 24(4), 249-256. https://doi.org/10.1016/so163-8343(02)oo182-2

Dragano, N., Siegrist, J., Nyberg, S. T., Lunau, T., Fransson, E. I., Alfredsson, L., Bjorner, J. B., Borritz, M., Burr, H., Erbel, R., Fahlén, G., Goldberg, M., Hamer, M., Heikkilä, K., Jöckel, K.-H., Knutsson, A., Madsen, I. E. H., Nielsen, M. L., Nordin, M., ... IPD-Work consortium. (2017). EffortReward Imbalance at Work and Incident Coronary Heart Disease: A Multicohort Study of 90,164 Individuals. Epidemiology, 28(4), 619-626. https://doi.org/10.1097/EDE.0000000000000666

Ebert, D., Berking, M., Thiart, H., Riper, H., Laferton, J. A. C., Cuijpers, P., Sieland, B., \& Lehr, D. (2015). Restoring depleted resources: Efficacy and mechanisms of change of an internet-based unguided recovery training for better sleep and psychological detachment from work. Health Psychology, 34S, 1240-1251. https://doi.org/10.1037/heaoooo277 Ebert, D., Heber, E., Berking, M., Riper, H., Cuijpers, P., Funk, B., \& Lehr, D. (2016). Self-guided internet-based and mobile-based stress management for employees: Results of a randomised controlled trial. Occupational and Environmental Medicine, 73(5), 315-323. https://doi.org/10.1136/oemed-2015-103269

Ebert, D., Kählke, F., Buntrock, C., Berking, M., Smit, F., Heber, E., Baumeister, H., Funk, B., Riper, H., \& Lehr, D. (2018). A health economic outcome evaluation of an internet-based mobile-supported stress management intervention for employees. Scandinavian Journal of Work, Environment \& Health, 44(2), 171-182. https://doi.org/10.5271/sjweh.3691

Ebert, D., Lehr, D., Heber, E., Riper, H., Cuijpers, P., \& Berking, M. (2016). Internet- and mobile-based stress management for employees with adherence-focused guidance: Efficacy and mechanism of change. Scandinavian Journal of Work, Environment \& Health, 42(5), 382-394. https://doi.org/10.5271/sjweh.3573

Eskilsson, T., Slunga Järvholm, L., Malmberg Gavelin, H., Stigsdotter Neely, A., \& Boraxbekk, C.-J. (2017). Aerobic training for improved memory in patients with stress-related exhaustion: A randomized controlled trial. BMC Psychiatry, 17(1), 322. https://doi.org/10.1186/s12888-017-1457-1 
Eurofound. (2016). Fifth European Working Conditions Survey. Luxembourg: Publications Office of the European Union.

Eurofound. (2017). Sixth European Working Conditions Survey - Overview report (2017 update). Luxembourg: Publications Office of the European Union.

Fava, G. A., McEwen, B. S., Guidi, J., Gostoli, S., Offidani, E., \& Sonino, N. (2019). Clinical characterization of allostatic overload.

Psychoneuroendocrinology, 108, 94-101.

https://doi.org/10.1016/j.psyneuen.2019.05.028

Finnes, A., Enebrink, P., Ghaderi, A., Dahl, J., Nager, A., \& Öst, L.-G. (2019). Psychological treatments for return to work in individuals on sickness absence due to common mental disorders or musculoskeletal disorders: A systematic review and meta-analysis of randomized-controlled trials. International Archives of Occupational and Environmental Health, 92(3), 273. https://doi.org/10.1007/s00420-018-1380-x

Flaxman, P. E., \& Bond, F. W. (2010). Worksite stress management training: Moderated effects and clinical significance. Journal of Occupational Health Psychology, 15(4), 347-358. https://doi.org/10.1037/a0020522 Fleischmann, R. J., Harrer, M., Zarski, A.-C., Baumeister, H., Lehr, D., \& Ebert, D. (2018). Patients' experiences in a guided Internet- and App-based stress intervention for college students: A qualitative study. Internet Interventions, 12, 130-140. https://doi.org/10.1016/j.invent.2017.12.001

Försäkringskassan. (2015). Stress vanligaste orsaken till sjukskrivning. https://www.forsakringskassan.se/wps/portal/press/pressmeddelanden /stress_vanligaste_orsaken_till_sjukskrivning

Fransson, E. I., Heikkila, K., Nyberg, S. T., Zins, M., Westerlund, H., Westerholm, P., Vaananen, A., Virtanen, M., Vahtera, J., Theorell, T., Suominen, S., Singh-Manoux, A., Siegrist, J., Sabia, S., Rugulies, R., Pentti, J., Oksanen, T., Nordin, M., Nielsen, M. L., ... Kivimaki, M. (2012). Job strain as a risk factor for leisure-time physical inactivity: An individual-participant meta-analysis of up to 170,000 men and women. American Journal of Epidemiology, 176(12), 1078-1089. https://doi.org/10.1093/aje/kws336

Freudenberger, H. J. (1974). Staff Burn-Out. Journal of Social Issues, 3o(1), 
159-165. https://doi.org/10.1111/j.1540-4560.1974.tboo706.x

Friedman, R. (1985). Treating Type A Behavior-And Your Heart. Meyer Friedman Diane Ulmer. The Quarterly Review of Biology, 3, 402.

Fritz, C., Sonnentag, S., Spector, P. E., \& McInroe, J. A. (2010). The weekend matters: Relationships between stress recovery and affective experiences. Journal of Organizational Behavior, 31(8), 1137-1162. https://doi.org/10.1002/job.672

Furlan, A., Pennick, V., Bombardier, C., \& van Tulder, M. (2009). 2009 updated method guidelines for systematic reviews in the cochrane back review group. SPINE, 34(18), 1929-1941.

Gerhards, S. A. H., Abma, T. A., Arntz, A., de Graaf, L. E., Evers, S. M. A. A., Huibers, M. J. H., \& Widdershoven, G. A. M. (2011). Improving adherence and effectiveness of computerised cognitive behavioural therapy without support for depression: A qualitative study on patient experiences. Journal of Affective Disorders, 129(1), 117-125. https://doi.org/10.1016/j.jad.2010.09.012

Geurts, S. A. E., \& Sonnentag, S. (2006). Recovery as an explanatory mechanism in the relation between acute stress reactions and chronic health impairment. Scandinavian Journal of Work, Environment \& Health, 32(6), 482-492. https://doi.org/10.5271/sjweh.1053

Glaesmer, H., Romppel, M., Brähler, E., Hinz, A., \& Maercker, A. (2015). Adjustment disorder as proposed for ICD-11: Dimensionality and symptom differentiation. Psychiatry Research, 229(3), 940-948. https://doi.org/10.1016/j.psychres.2015.07.010

Glise, K. (2014). Utmattningssyndrom, identifikation, karakteristika och förlopp (avhandling). Göteborgs universitet.

Glise, K., Ahlborg, G., \& Jonsdottir, I. (2012). Course of mental symptoms in patients with stress-related exhaustion: Does sex or age make a difference? BMC Psychiatry, 12, 18. https://doi.org/10.1186/1471-244X12-18

Glise, K., Hadzibajramovic, E., Jonsdottir, I., \& Ahlborg, G. (2010). Selfreported exhaustion: A possible indicator of reduced work ability and increased risk of sickness absence among human service workers. International Archives of Occupational and Environmental Health, 
83(5), 511-520. https://doi.org/10.1007/s00420-009-0490-X

Goetzel, R. Z., Hawkins, K., Ozminkowski, R. J., \& Wang, S. (2003). The health and productivity cost burden of the "top 10" physical and mental health conditions affecting six large U.S. employers in 1999. Journal of Occupational and Environmental Medicine, 45(1), 5-14.

Golkar, A., Johansson, E., Kasahara, M., Osika, W., Perski, A., \& Savic, I. (2014). The influence of work-related chronic stress on the regulation of emotion and on functional connectivity in the brain. PLOS ONE, 9(9). https://doi.org/10.1371/journal.pone.0104550

Golkar, A., Lonsdorf, T. B., Olsson, A., Lindstrom, K. M., Berrebi, J., Fransson, P., Schalling, M., Ingvar, M., \& Öhman, A. (2012). Distinct contributions of the dorsolateral prefrontal and orbitofrontal cortex during emotion regulation. PloS One, $7(11)$, e48107. https://doi.org/10.1371/journal.pone.0048107

Grossi, G., Perski, A., Osika, W., \& Savic, I. (2015). Stress-related exhaustion disorder--clinical manifestation of burnout? A review of assessment methods, sleep impairments, cognitive disturbances, and neurobiological and physiological changes in clinical burnout. Scandinavian Journal of Psychology, 56(6), 626-636. https://doi.org/10.1111/sjop.12251

Gunnar, M., \& Quevedo, K. (2007). The neurobiology of stress and development. Annual Review of Psychology, 58, 145-173. https://doi.org/10.1146/annurev.psych.58.110405.085605

Hahn, V. C., Binnewies, C., Sonnentag, S., \& Mojza, E. J. (2011). Learning how to recover from job stress: Effects of a recovery training program on recovery, recovery-related self-efficacy, and well-being. Journal of Occupational Health Psychology, 16(2), 202-216.

https://doi.org/10.1037/a0022169

Halmetoja, C. O., Malmquist, A., Carlbring, P., \& Andersson, G. (2014). Experiences of internet-delivered cognitive behavior therapy for social anxiety disorder four years later: A qualitative study. Internet Interventions, 1 (3), 158-163. https://doi.org/10.1016/j.invent.2014.08.001

Hammen, C. (2015). Stress sensitivity in psychopathology: Mechanisms and 
consequences. Journal of Abnormal Psychology, 124(1), 152-154. https://doi.org/10.1037/abnooooo40

Hassard, J., Teoh, K., Cox, T., Cosmar, M., Gründler, R., Flemming, D., Cosemans, B., \& Broek, K. (2014). Calculating the cost of work-related stress and psychosocial risks. Luxembourg: Publications Office of the European Union.

Hassard, J., Teoh, K. R. H., Visockaite, G., Dewe, P., \& Cox, T. (2018). The cost of work-related stress to society: A systematic review. Journal of Occupational Health Psychology, 23(1), 1-17. https://doi.org/10.1037/ocpooooo69

Hasselberg, K., Jonsdottir, I., Ellbin, S., \& Skagert, K. (2014). Self-reported stressors among patients with exhaustion disorder: An exploratory study of patient records. BMC Psychiatry, 14, 66. https://doi.org/10.1186/1471-244X-14-66

Hasson, D., Anderberg, U. M., Theorell, T., \& Arnetz, B. B. (2005).

Psychophysiological effects of a web-based stress management system: A prospective, randomized controlled intervention study of IT and media workers. BMC Public Health, 5, 78. https://doi.org/10.1186/1471-24585-78

Häusser, J. A., Mojzisch, A., Niesel, M., \& Schulz-Hardt, S. (2010). Ten years on: A review of recent research on the job demand-control (-support) model and psychological well-being. Work \& Stress, 24(1), 1-35. https://doi.org/10.1080/02678371003683747

Heber, E., Ebert, D., Lehr, D., Cuijpers, P., Berking, M., Nobis, S., \& Riper, H. (2017). The Benefit of Web- and Computer-Based Interventions for Stress: A Systematic Review and Meta-Analysis. Journal Of Medical Internet Research, 19(2), e32-e32. https://doi.org/10.2196/jmir.5774 Heber, E., Lehr, D., Ebert, D., Berking, M., \& Riper, H. (2016). Web-Based and Mobile Stress Management Intervention for Employees: A Randomized Controlled Trial. Journal of Medical Internet Research, 18(1), e21. https://doi.org/10.2196/jmir.5112

Hilton, M. F., Whiteford, H. A., Sheridan, J. S., Cleary, C. M., Chant, D. C., Wang, P. S., \& Kessler, R. C. (2008). The prevalence of psychological distress in employees and associated occupational risk factors. Journal of 
Occupational and Environmental Medicine, 5o(7), 746-757.

https://doi.org/10.1097/JOM.obo13e31817e9171

Hoefsmit, N., Houkes, I., \& Nijhuis, F. J. N. (2012). Intervention characteristics that facilitate return to work after sickness absence: A systematic literature review. Journal of Occupational Rehabilitation, 22(4), 462477. https://doi.org/10.1007/s10926-012-9359-z

Hofmann, S. G., Asnaani, A., Vonk, I. J. J., Sawyer, A. T., \& Fang, A. (2012). The Efficacy of Cognitive Behavioral Therapy: A Review of Meta-analyses. Cognitive Therapy and Research, 36(5), 427-440. https://doi.org/10.1007/s10608-012-9476-1

Höglund, P., Hakelind, C., \& Nordin, S. (2020). Severity and prevalence of various types of mental ill-health in a general adult population: Age and sex differences. BMC Psychiatry, $20(1), 209$. https://doi.org/10.1186/s12888-020-02557-5

Huang, Y., Xu, S., Hua, J., Zhu, D., Liu, C., Hu, Y., Liu, T., \& Xu, D. (2015). Association between job strain and risk of incident stroke: A metaanalysis. Neurology, 85(19), 1648-1654. https://doi.org/10.1212/WNL.oooooooooooo2098

Jacobson, N. S., \& Truax, P. (1991). Clinical significance: A statistical approach to defining meaningful change in psychotherapy research. Journal of Consulting and Clinical Psychology, 59(1), 12-19. https://doi.org/10.1037//o022-006x.59.1.12

Jonsdottir, I., Nordlund, A., Bernhardsson, S., Ljung, T., Glise, K., Währborg, P., \& Wallin, A. (2013). Cognitive impairment in patients with stress-related exhaustion. Stress, 16(2), 181-190. https://doi.org/10.3109/10253890.2012.708950

Jonsdottir, I., Nordlund, A., Ellbin, S., Ljung, T., Glise, K., Währborg, P., Sjörs, A., \& Wallin, A. (2017). Working memory and attention are still impaired after three years in patients with stress-related exhaustion. Scandinavian Journal of Psychology, 58(6), 504-509. https://doi.org/10.1111/sjop.12394

Jonsdottir, I., Rödjer, L., Hadzibajramovic, E., Börjesson, M., \& Ahlborg, G. (2010). A prospective study of leisure-time physical activity and mental health in Swedish health care workers and social insurance officers. 
Preventive Medicine, 51(5), 373-377.

https://doi.org/10.1016/j.ypmed.2010.07.019

Joyce, S., Modini, M., Christensen, H., Mykletun, A., Bryant, R., Mitchell, P. B., \& Harvey, S. B. (2016). Workplace interventions for common mental disorders: A systematic meta-review. Psychological Medicine, 46(4), 683-697. https://doi.org/10.1017/Soo33291715002408

Kählke, F., Buntrock, C., Smit, F., Berking, M., Lehr, D., Heber, E., Funk, B., Riper, H., \& Ebert, D. (2019). Economic evaluation of an internet-based stress management intervention alongside a randomized controlled trial. JMIR Mental Health, 6(5). https://doi.org/10.2196/10866

Kahn, J. R., \& Pearlin, L. I. (2006). Financial strain over the life course and health among older adults. Journal of Health and Social Behavior, 47(1), 17-31. https://doi.org/10.1177/002214650604700102

Kalia, M. (2002). Assessing the economic impact of stress-The modern day hidden epidemic. Metabolism: Clinical and Experimental, 51(6 Suppl 1), 49-53.

Kallestad, H., Jacobsen, H. B., Landrø, N. I., Borchgrevink, P. C., \& Stiles, T. C. (2015). The role of insomnia in the treatment of chronic fatigue. Journal of Psychosomatic Research, 78(5), 427-432. https://doi.org/10.1016/j.jpsychores.2014.11.022

Karasek, R., \& Theorell, T. (1992). Healthy Work: Stress, Productivity, and the Reconstruction Of Working Life (Revised ed. edition). New York, NY: Basic Books.

Kelloway, E. K., \& Barling, J. (2010). Leadership development as an intervention in occupational health psychology. Work \& Stress, 24(3), 260-279. https://doi.org/10.1080/02678373.2010.518441

Kessler, R. C., Akiskal, H. S., Ames, M., Birnbaum, H., Greenberg, P., Hirschfeld, R. M. A., Jin, R., Merikangas, K. R., Simon, G. E., \& Wang, P. S. (2006). Prevalence and effects of mood disorders on work performance in a nationally representative sample of U.S. workers. The American Journal of Psychiatry, 163(9), 1561-1568.

https://doi.org/10.1176/appi.ajp.163.9.1561

Kiecolt-Glaser, J. K., McGuire, L., Robles, T. F., \& Glaser, R. (2002).

Psychoneuroimmunology: Psychological influences on immune function 
and health. Journal of Consulting and Clinical Psychology, 7o(3), 537547.

Kigozi, J., Jowett, S., Lewis, M., Barton, P., \& Coast, J. (2017). The estimation and inclusion of presenteeism costs in applied economic evaluation: A systematic review. The Journal of the International Society for Pharmacoeconomics and Outcomes Research, 20(3), 496-506. https://doi.org/10.1016/j.jval.2016.12.006

Kivimäki, M., \& Steptoe, A. (2018). Effects of stress on the development and progression of cardiovascular disease. Nature Reviews. Cardiology, 15(4), 215-229. https://doi.org/10.1038/nrcardio.2017.189

Kivimäki, M., Virtanen, M., Elovainio, M., Kouvonen, A., Väänänen, A., \& Vahtera, J. (2006). Work stress in the etiology of coronary heart disease-A meta-analysis. Scandinavian Journal of Work, Environment \& Health, 32(6), 431-442.

Kobasa, S. C., \& Puccetti, M. C. (1983). Personality and social resources in stress resistance. Journal of Personality and Social Psychology, 45(4), 839850.

Komaki, J. L. (1998). Leadership from an Operant Perspective. London: Routledge.

Koopmans, P. C., Bültmann, U., Roelen, C. A. M., Hoedeman, R., van der Klink, J. J. L., \& Groothoff, J. W. (2011). Recurrence of sickness absence due to common mental disorders. International Archives of Occupational and Environmental Health, 84(2), 193-201. https://doi.org/10.1007/s00420-010-0540-4

Kopp, M. S., Szedmák, S., \& Skrabski, A. (1998). Socioeconomic differences and psychosocial aspects of stress in a changing society. Annals of the New York Academy of Sciences, 851, 538-543. https://doi.org/10.1111/j.17496632.1998.tbogo33.x

Krause, N., \& Borawski-Clark, E. (1995). Social class differences in social support among older adults. The Gerontologist, 35(4), 498-508.

Kreiner, G. E., Hollensbe, E. C., \& Sheep, M. L. (2009). Balancing borders and bridges: Negotiating the work-home interface via boundary work tactics. Academy of Management Journal, 52(4), 704-730.

https://doi.org/10.5465/AMJ.2009.43669916 
Kristenson, M., Eriksen, H. R., Sluiter, J. K., Starke, D., \& Ursin, H. (2004). Psychobiological mechanisms of socioeconomic differences in health. Social Science \& Medicine (1982), 58(8), 1511-1522. https://doi.org/10.1016/So277-9536(03)00353-8

Kristiansen, J., Friborg, M. K., Eller, N., Brandt, L. P. A., Glasscock, D. J., PihlThingvad, J., Persson, R., Besèr, A., Åsberg, M., \& Thorsen, S. V. (2019). Comparison of exhaustion symptoms in patients with stress-related and other psychiatric and somatic diagnoses. BMC Psychiatry, 19(1), 84. https://doi.org/10.1186/s12888-019-2066-y

Kröger, C., Bode, K., Wunsch, E.-M., Kliem, S., Grocholewski, A., \& Finger, F. (2015). Work-related treatment for major depressive disorder and incapacity to work: Preliminary findings of a controlled, matched study. Journal of Occupational Health Psychology, 2O(2), 248-258. https://doi.org/10.1037/aoo38341

Kuo, W.-C., Bratzke, L. C., Oakley, L. D., Kuo, F., Wang, H., \& Brown, R. L. (2019). The association between psychological stress and metabolic syndrome: A systematic review and meta-analysis. Obesity Reviews, 2O(11), 1651-1664. https://doi.org/10.1111/obr.12915

Lagerveld, S. E., Blonk, R. W. B., Brenninkmeijer, V., Wijngaards-de Meij, L., \& Schaufeli, W. B. (2012). Work-focused treatment of common mental disorders and return to work: A comparative outcome study. Journal of Occupational Health Psychology, 17(2), 220-234. https://doi.org/10.1037/ao027049

Lazarus, R. S., \& Folkman, S. (1984). Stress, Appraisal, and Coping. New York: Springer Publishing Company.

Levy, H. C., Worden, B. L., Davies, C. D., Stevens, K., Katz, B. W., Mammo, L., Diefenbach, G. J., \& Tolin, D. F. (2020). The dose-response curve in cognitive-behavioral therapy for anxiety disorders. Cognitive Behaviour Therapy. https://doi.org/10.1080/16506073.2020.1771413

Lindblom, K. M., Linton, S. J., Fedeli, C., \& Bryngelsson, I.-L. (2006). Burnout in the working population: Relations to psychosocial work factors.

International Journal of Behavioral Medicine, 13(1), 51-59. https://doi.org/10.1207/s15327558ijbm1301_7

Lindsäter, E., Axelsson, E., Salomonsson, S., Santoft, F., Ejeby, K., Ljótsson, B., 
Åkerstedt, T., Lekander, M., \& Hedman-Lagerlöf, E. (2018). Internetbased cognitive behavioral therapy for chronic stress: A randomized controlled trial. Psychotherapy and Psychosomatics, 87(5), 296-305. https://doi.org/10.1159/000490742

Lindsäter, E., Axelsson, E., Salomonsson, S., Santoft, F., Ljótsson, B., Åkerstedt, T., Lekander, M., \& Hedman-Lagerlöf, E. (2019). Cost-Effectiveness of Therapist-Guided Internet-Based Cognitive Behavioral Therapy for Stress-Related Disorders: Secondary Analysis of a Randomized Controlled Trial. Journal of Medical Internet Research, 21(9), e14675. https://doi.org/10.2196/14675

Lindsäter, E., Axelsson, E., Salomonsson, S., Santoft, F., Ljótsson, B., Åkerstedt, T., Lekander, M., \& Hedman-Lagerlöf, E. (2020). The mediating role of insomnia severity in internet-based cognitive behavioral therapy for chronic stress: Secondary analysis of a randomized controlled trial. Behaviour Research and Therapy, 136, 103782. https://doi.org/10.1016/j.brat.2020.103782

Lloyd, J., Bond, F., \& Flaxman, P. (2013). The value of psychological flexibility: Examining psychological mechanisms underpinning a cognitive behavioural therapy intervention for burnout. Work \& Stress, 27. https://doi.org/10.1080/02678373.2013.782157

Lohela-Karlsson, Björklund, Vingård, Hagberg, \& Jensen. (2009). Does a change in psychosocial work factors lead to a change in employee health? Journal of Occupational and Environmental Medicine, 51(2), 195-203. https://doi.org/10.1097/JOM.obo13e318192bd2c

Lorenz, L., Perkonigg, A., \& Maercker, A. (2018). The course of adjustment disorder following involuntary job loss and its predictors of latent change. Clinical Psychological Science, 6(5), 647-657. https://doi.org/10.1177/2167702618766290

Lourel, M., Abdellaoui, S., Chevaleyre, S., Paltrier, M., \& Gana, K. (2008). Relationships between psychological job demands, job control and burnout among firefighters. North American Journal of Psychology, 1O(3), 489-495.

Lundgren-Nilsson, Å., Jonsdottir, I., Pallant, J., \& Ahlborg, G. (2012). Internal construct validity of the Shirom-Melamed Burnout Questionnaire 
(SMBQ). BMC Public Health, 12, 1. https://doi.org/10.1186/1471-245812-1

Lupien, S. J., Maheu, F., Tu, M., Fiocco, A., \& Schramek, T. E. (2007). The effects of stress and stress hormones on human cognition: Implications for the field of brain and cognition. Brain and Cognition, 65(3), 209237. https://doi.org/10.1016/j.bandc.2007.02.007

Ly, K. H., Asplund, K., \& Andersson, G. (2015). Stress management for middle managers via an acceptance and commitment-based smartphone application: A randomized controlled trial. Internet Interventions, 1(3), 95-101. https://doi.org/10.1016/j.invent.2014.06.003

Macdonald, W., Mead, N., Bower, P., Richards, D., \& Lovell, K. (2007). A qualitative study of patients' perceptions of a "minimal” psychological therapy. The International Journal of Social Psychiatry, 53(1), 23-35. https://doi.org/10.1177/0020764006066841

Maercker, A., Forstmeier, S., Pielmaier, L., Spangenberg, L., Brähler, E., \& Glaesmer, H. (2012). Adjustment disorders: Prevalence in a representative nationwide survey in Germany. Social Psychiatry and Psychiatric Epidemiology, 47(11), 1745-1752.

https://doi.org/10.1007/s00127-012-0493-X

Maghout Juratli, S., Janisse, J., Schwartz, K., \& Arnetz, B. B. (2011).

Demographic and lifestyle factors associated with perceived stress in the primary care setting: A MetroNet study. Family Practice, 28(2), 156-162. https://doi.org/10.1093/fampra/cmq091

Malmberg Gavelin, H., Eskilsson, T., Boraxbekk, C.-J., Josefsson, M., Stigsdotter Neely, A., \& Slunga Järvholm, L. (2018). Rehabilitation for improved cognition in patients with stress-related exhaustion disorder: RECO - a randomized clinical trial. Stress, 21(4), 279-291. https://doi.org/10.1080/10253890.2018.1461833

Maricuţoiu, L. P., Sava, F. A., \& Butta, O. (2016). The effectiveness of controlled interventions on employees' burnout: A meta-analysis. Journal of Occupational \& Organizational Psychology, 89(1), 1-27. https://doi.org/10.1111/joop.12099

Martell, C. R., Addis, M. E., \& Jacobson, N. S. (2001). Depression in Context: Strategies for Guided Action. New York: W.W. Norton. 
Martin, A., Sanderson, K., \& Cocker, F. (2009). Meta-analysis of the effects of health promotion intervention in the workplace on depression and anxiety symptoms. Scandinavian Journal of Work, Environment \& Health, 35(1), 7-18. https://doi.org/10.5271/sjweh.1295

Maslach, C. (1979). Burned-out. The Canadian Journal of Psychiatric Nursing, $2 O(6), 5-9$.

Maslach, C. (1987). Burnout research in social services: A critique. Journal of Social Service Research, 10(1), 95-105. https://doi.org/10.1300/Jo79v10no1_09

Maslach, \& Leiter. (2016). Understanding the burnout experience: Recent research and its implications for psychiatry. World Psychiatry, 15(2), 103-111. https://doi.org/10.1002/wps.20311

McEwen. (1998). Stress, adaptation, and disease. Allostasis and allostatic load. Annals of the New York Academy of Sciences, 840, 33-44. https://doi.org/10.1111/j.1749-6632.1998.tbo9546.x

McEwen, B. S. (2007). Physiology and neurobiology of stress and adaptation: Central role of the brain. Physiological Reviews, 87(3), 873-904. https://doi.org/10.1152/physrev.00041.2006

McEwen, B. S., \& Morrison, J. H. (2013). The brain on stress: Vulnerability and plasticity of the prefrontal cortex over the life course. Neuron, 79(1), 1629. https://doi.org/10.1016/j.neuron.2013.06.028

Melchior, M., Caspi, A., Milne, B. J., Danese, A., Poulton, R., \& Moffitt, T. E. (2007). Work stress precipitates depression and anxiety in young, working women and men. Psychological Medicine, 37(8), 1119-1129. https://doi.org/10.1017/So033291707000414

Mommersteeg, P. M. C., Heijnen, C. J., Kavelaars, A., \& van Doornen, L. J. P. (2006). Immune and endocrine function in burnout syndrome.

Psychosomatic Medicine, 68(6), 879-886. https://doi.org/10.1097/01.psy.0000239247.47581.0c

Montgomery, S. A., \& Asberg, M. (1979). A new depression scale designed to be sensitive to change. The British Journal of Psychiatry, 134, 382-389.

Munir, F., Burr, H., Hansen, J. V., Rugulies, R., \& Nielsen, K. (2011). Do positive psychosocial work factors protect against 2-year incidence of long-term sickness absence among employees with and those without depressive 
symptoms? A prospective study. Journal of Psychosomatic Research, 7O(1), 3-9. https://doi.org/10.1016/j.jpsychores.2010.09.014

Munir, F., Nielsen, K., Garde, A. H., Albertsen, K., \& Carneiro, I. G. (2012).

Mediating the effects of work-life conflict between transformational leadership and health-care workers' job satisfaction and psychological wellbeing. Journal of Nursing Management, 2O(4), 512-521. https://doi.org/10.1111/j.1365-2834.2011.01308.x

Murphy, L. R. (1996). Stress management in work settings: A critical review of the health effects. American Journal of Health Promotion, 11(2), 112135 .

Murray, E., Khadjesari, Z., White, I. R., Kalaitzaki, E., Godfrey, C., McCambridge, J., Thompson, S. G., \& Wallace, P. (2009). Methodological Challenges in Online Trials. Journal of Medical Internet Research, 11(2). https://doi.org/10.2196/jmir.1052

Naghieh, A., Montgomery, P., Bonell, C. P., Thompson, M., \& Aber, J. L. (2015). Organisational interventions for improving wellbeing and reducing workrelated stress in teachers. The Cochrane Database of Systematic Reviews, 4, CDo10306. https://doi.org/10.1002/14651858.CD010306.pub2

Nieuwenhuijsen, K., Faber, B., Verbeek, J. H., Neumeyer-Gromen, A., Hees, H. L., Verhoeven, A. C., van der Feltz-Cornelis, C. M., \& Bültmann, U. (2014). Interventions to improve return to work in depressed people. The Cochrane Database of Systematic Reviews, 12, CDoo6237. https://doi.org/10.1002/14651858.CDoo6237.pub3

Niles, A. N., Axelsson, E., Andersson, E., Hedman-Lagerlöf, E., Carlbring, P., Andersson, G., Johansson, R., Widén, S., Driessen, J., Santoft, F., \& Ljótsson, B. (2020). Internet-based cognitive behavior therapy for depression, social anxiety disorder, and panic disorder: Effectiveness and predictors of response in a teaching clinic. Behaviour Research and Therapy, 136, 103767. https://doi.org/10.1016/j.brat.2020.103767

Norlund, S., Reuterwall, C., Höög, J., Lindahl, B., Janlert, U., \& Birgander, L. S. (2010). Burnout, working conditions and gender-Results from the northern Sweden MONICA Study. BMC Public Health, 1O, 326. https://doi.org/10.1186/1471-2458-10-326 
Nyberg, A. (2009). The impact of managerial leadership on stress and health among employees. Stockholm: Department of Public Health Sciences. http://publications.ki.se/xmlui/handle/10616/38102

Nyberg, A., Kecklund, g., Hanson Magnusson, l., \& Rajaleid, K. (2020).

Workplace violence and health in human service industries: A systematic review of prospective and longitudinal studies. Occupational and Environmental Medicine. https://doi.org/10.1136/oemed-2020-106450

Nyberg, A., Leineweber, C., \& Magnusson Hanson, L. (2015). Gender differences in psychosocial work factors, work-personal life interface, and well-being among Swedish managers and non-managers. International Archives of Occupational and Environmental Health, 88(8), 1149-1164. https://doi.org/10.1007/s00420-015-1043-0

Nyberg, A., Westerlund, H., Magnusson Hanson, L. L., \& Theorell, T. (2008). Managerial leadership is associated with self-reported sickness absence and sickness presenteeism among Swedish men and women.

Scandinavian Journal of Public Health, 36(8), 803-811. https://doi.org/10.1177/1403494808093329

O’Donnell, M. L., Alkemade, N., Creamer, M., McFarlane, A. C., Silove, D., Bryant, R. A., Felmingham, K., Steel, Z., \& Forbes, D. (2016). A longitudinal study of adjustment disorder after trauma exposure. The American Journal of Psychiatry, 173(12), 1231-1238. https://doi.org/10.1176/appi.ajp.2016.16010071

O’Donnell, M. L., Metcalf, O., Watson, L., Phelps, A., \& Varker, T. (2018). A systematic review of psychological and pharmacological treatments for adjustment disorder in adults. Journal of Traumatic Stress, 31(3), 321331. https://doi.org/10.1002/jts.22295

O’Mahen, H. A., Grieve, H., Jones, J., McGinley, J., Woodford, J., \& Wilkinson, E. L. (2015). Women's experiences of factors affecting treatment engagement and adherence in internet delivered Behavioural Activation for Postnatal Depression. Internet Interventions, 2(1), 84-90. https://doi.org/10.1016/j.invent.2014.11.003

Öst, L. G. (1987). Applied relaxation: Description of a coping technique and review of controlled studies. Behaviour Research and Therapy, 25(5), 397-409. https://doi.org/10.1016/0005-7967(87)90017-9 
Palmlöf, L., Skillgate, E., Talbäck, M., Josephson, M., Vingård, E., \& Holm, L. W. (2019). Poor work ability increases sickness absence over 10 years. Occupational Medicine (Oxford, England), 69(5), 359-365. https://doi.org/10.1093/occmed/kqzo83

Peterson, U., Bergström, G., Samuelsson, M., Asberg, M., \& Nygren, A. (2008). Reflecting peer-support groups in the prevention of stress and burnout: Randomized controlled trial. Journal of Advanced Nursing, 63(5), 506516. https://doi.org/10.1111/j.1365-2648.2008.04743.x

Pugh, N. E., Hadjistavropoulos, H. D., Hampton, A. J. D., Bowen, A., \& Williams, J. (2015). Client experiences of guided internet cognitive behavior therapy for postpartum depression: A qualitative study. Archives of Women's Mental Health, 18(2), 209-219. https://doi.org/10.1007/s00737-014-0449-0

Querstret, D., \& Cropley, M. (2012). Exploring the relationship between workrelated rumination, sleep quality, and work-related fatigue. Journal of Occupational Health Psychology, 17(3), 341-353. https://doi.org/10.1037/aoo28552

Querstret, D., Cropley, M., \& Fife-Schaw, C. (2017). Internet-based instructorled mindfulness for work-related rumination, fatigue, and sleep: Assessing facets of mindfulness as mechanisms of change. A randomized waitlist control trial. Journal of Occupational Health Psychology, 22(2), 153-169. https://doi.org/10.1037/ocpooooo28

Quick, J. C. (1999). Occupational health psychology: The convergence of health and clinical psychology with public health and preventive medicine in an organizational context. Professional Psychology: Research and Practice, 3o(2), 123-128. https://doi.org/10.1037/0735-7028.30.2.123

Rebergen, D. S., Bruinvels, D. J., Bezemer, P. D., van der Beek, A. J., \& van Mechelen, W. (2009). Guideline-based care of common mental disorders by occupational physicians (CO-OP study): A randomized controlled trial. Journal of Occupational and Environmental Medicine, 51(3), 305312. https://doi.org/10.1097/JOM.obo13e3181990d32

Reed, J., \& Buck, S. (2009). The effect of regular aerobic exercise on positiveactivated affect: A meta-analysis. Psychology of Sport and Exercise, 10(6), 581-594. https://doi.org/10.1016/j.psychsport.2009.05.009 
Reynolds, P., Hurley, S., Torres, M., Jackson, J., Boyd, P., \& Chen, V. W. (2000). Use of coping strategies and breast cancer survival: Results from the Black/White Cancer Survival Study. American Journal of Epidemiology, 152(10), 940-949.

Richardson, K. M., \& Rothstein, H. R. (2008). Effects of occupational stress management intervention programs: A meta-analysis. Journal of Occupational Health Psychology, 13(1), 69-93. https://doi.org/10.1037/1076-8998.13.1.69

Riksrevisionen. (2019). Jämställd sjukfrånvaro - bedöms män och kvinnor likvärdigt i sjukskrivningsprocessen? (RiR 2019:19; p. 76).

Rozental, A., Andersson, G., Boettcher, J., Ebert, D., Cuijpers, P., Knaevelsrud, C., Ljótsson, B., Kaldo, V., Titov, N., \& Carlbring, P. (2014). Consensus statement on defining and measuring negative effects of Internet interventions. Internet Interventions, 1(1), 12-19. https://doi.org/10.1016/j.invent.2014.02.001

Rozental, A., Boettcher, J., Andersson, G., Schmidt, B., \& Carlbring, P. (2015). Negative effects of internet interventions: A qualitative content analysis of patients' experiences with treatments delivered online. Cognitive Behaviour Therapy, 44(3), 223-236. https://doi.org/10.1080/16506073.2015.1008033

Rozental, A., Forsström, D., Tangen, J. A., \& Carlbring, P. (2015). Experiences of undergoing Internet-based cognitive behavior therapy for procrastination: A qualitative study. Internet Interventions, 2(3), 314322. https://doi.org/10.1016/j.invent.2015.05.001

Ruotsalainen, J. H., Verbeek, J. H., Mariné, A., \& Serra, C. (2015). Preventing occupational stress in healthcare workers. The Cochrane Database of Systematic Reviews, 4, CDoo2892. https://doi.org/10.1002/14651858.CDoo2892.pub5

Ruwaard, J., Lange, A., Schrieken, B., Dolan, C. V., \& Emmelkamp, P. (2012). The effectiveness of online cognitive behavioral treatment in routine clinical practice. PloS One, 7(7), e40089. https://doi.org/10.1371/journal.pone.0040089

Ryan, C., Bergin, M., Chalder, T., \& Wells, J. S. (2017). Web-based interventions for the management of stress in the workplace: Focus, form, and efficacy. 
Journal of Occupational Health, 59(3), 215-236.

Saboonchi, F., Perski, A., \& Grossi, G. (2013). Validation of Karolinska

Exhaustion Scale: Psychometric properties of a measure of exhaustion syndrome. Scandinavian Journal of Caring Sciences, 27(4), 1010-1017. https://doi.org/10.1111/j.1471-6712.2012.01089.x

Safer, D. L., \& Hugo, E. M. (2006). Designing a control for a behavioral group therapy. Behavior Therapy, 37(2), 120-130. https://doi.org/10.1016/j.beth.2005.06.001

Sanderson, K., \& Andrews, G. (2006). Common mental disorders in the workforce: Recent findings from descriptive and social epidemiology. Canadian Journal of Psychiatry, 51(2), 63-75.

Santoft, F., Salomonsson, S., Hesser, H., Lindsäter, E., Ljótsson, B., Lekander, M., Kecklund, G., Öst, L.-G., \& Hedman-Lagerlöf, E. (2019). Mediators of change in cognitive behavior therapy for clinical burnout. Behavior Therapy, 5O(3), 475-488. https://doi.org/10.1016/j.beth.2018.08.005

Savic, I., Perski, A., \& Osika, W. (2017). MRI Shows that Exhaustion Syndrome Due to Chronic Occupational Stress is Associated with Partially Reversible Cerebral Changes. Cerebral Cortex. https://doi.org/10.1093/cercor/bhw413

Schafer, J. L., \& Graham, J. W. (2002). Missing data: Our view of the state of the art. Psychological Methods, 7(2), 147-177.

Schaufeli, \& Enzmann. (1998). The Burnout Companion To Study And Practice: A Critical Analysis. Boca Raton: CRC Press.

Schaufeli, W. B., Bakker, A. B., Hoogduin, K., Schaap, C., \& Kladler, A. (2001). On the clinical validity of the maslach burnout inventory and the burnout measure. Psychology \& Health, 16(5), 565-582. https://doi.org/10.1080/08870440108405527

Schene, A. H., Koeter, M. W. J., Kikkert, M. J., Swinkels, J. A., \& McCrone, P. (2007). Adjuvant occupational therapy for work-related major depression works: Randomized trial including economic evaluation. Psychological Medicine, 37(3), 351-362. https://doi.org/10.1017/Soo33291706009366

Schiller, H., Söderström, M., Lekander, M., Rajaleid, K., \& Kecklund, G. (2018). A randomized controlled intervention of workplace-based group 
cognitive behavioral therapy for insomnia. International Archives of Occupational and Environmental Health, 91(4), 413-424. https://doi.org/10.1007/s00420-018-1291-x

Schmid, J. A., Sonntag, D., Manfred Herr, R., Fischer, J. E., Jarczok, M. N., \& Schmidt, B. (2017). Associations Between Supportive Leadership Behavior and the Costs of Absenteeism and Presenteeism. Journal of Occupational \& Environmental Medicine, 59(2), 141-147. https://doi.org/10.1097/JOM.ooooooooooooog19

Selye, H. (1936). A syndrome produced by diverse nocuous agents. Nature, 138(3479), 32.

Sheehan, D. V., Lecrubier, Y., Sheehan, K. H., Amorim, P., Janavs, J., Weiller, E., Hergueta, T., Baker, R., \& Dunbar, G. C. (1998). The MiniInternational Neuropsychiatric Interview (M.I.N.I.): The development and validation of a structured diagnostic psychiatric interview for DSMIV and ICD-10. The Journal of Clinical Psychiatry, 59 Suppl 20, 2233;quiz 34-57.

Siegrist, J. (1996). Adverse health effects of high-effort/low-reward conditions. Journal of Occupational Health Psychology, 1(1), 27-41.

Siltaloppi, M., Kinnunen, U., \& Feldt, T. (2009). Recovery experiences as moderators between psychosocial work characteristics and occupational well-being. Work \& Stress, 23(4), 330-348.

https://doi.org/10.1080/02678370903415572

Skakon, J., Nielsen, K., Borg, V., \& Guzman, J. (2010). Are leaders' well-being, behaviours and style associated with the affective well-being of their employees? A systematic review of three decades of research. Work and Stress, 24(2), 107-139. https://doi.org/10.108o/02678373.2010.495262

Socialstyrelsen. (2003). Utmattningssyndrom: Stressrelaterad psykisk ohälsa. Stockholm: Socialstyrelsen.

Söderström, M., Jeding, K., Ekstedt, M., Perski, A., \& Åkerstedt, T. (2012). Insufficient sleep predicts clinical burnout. Journal of Occupational Health Psychology, 17(2), 175-183. https://doi.org/10.1037/aoo27518

Song, H., Fall, K., Fang, F., Erlendsdóttir, H., Lu, D., Mataix-Cols, D., Fernández de la Cruz, L., D’Onofrio, B. M., Lichtenstein, P., Gottfreðsson, M., Almqvist, C., \& Valdimarsdóttir, U. A. (2019). Stress related disorders 
and subsequent risk of life threatening infections: Population based sibling controlled cohort study. BMJ (Clinical Research Ed.), 367, 15784. https://doi.org/10.1136/bmj.l5784

Song, H., Fang, F., Tomasson, G., Arnberg, F. K., Mataix-Cols, D., Fernández de la Cruz, L., Almqvist, C., Fall, K., \& Valdimarsdóttir, U. A. (2018). Association of stress-related disorders with subsequent autoimmune disease. JAMA, 319(23), 2388-2400. https://doi.org/10.1001/jama.2018.7028

Sonnentag, S., \& Fritz, C. (2007). The Recovery Experience Questionnaire: Development and validation of a measure for assessing recuperation and unwinding from work. Journal of Occupational Health Psychology, 12(3), 204-221. https://doi.org/10.1037/1076-8998.12.3.204

Sonnentag, S., Venz, L., \& Casper, A. (2017). Advances in recovery research: What have we learned? What should be done next? Journal of Occupational Health Psychology, 22(3), 365-380. https://doi.org/10.1037/ocpooooo79

Stansfeld, S. A., Shipley, M. J., Head, J., Fuhrer, R., \& Kivimaki, M. (2013). Work characteristics and personal social support as determinants of subjective well-being. PloS One, 8(11), e81115. https://doi.org/10.1371/journal.pone.0o81115

Statens beredning för medicinsk och social utvärdering. (2014). Arbetsmiljöns betydelse för symtom på depression och utmattningssyndrom: En systematisk litteraturöversikt (Medicinska biblioteket - Boksamlingen 613; Vol. 2014). Stockholm : Statens beredning för medicinsk utvärdering (SBU).

Statistics Sweden. (2020). Educational level Sweden. Statistics Sweden. http://www.scb.se/hitta-statistik/sverige-i-siffror/utbildning-jobb-ochpengar/utbildningsnivan-i-sverige/

Sterling, P., \& Eyer, J. (1988). A new paradigm to explain arousal pathology. In S. Fisher \& J. Reason (Eds.), Handbook of life stress, cognition and health (Vol. 1988, pp. xxxiii, 750). Oxford: John Wiley \& Sons.

Stratton, E., Lampit, A., Choi, I., Calvo, R. A., Harvey, S. B., \& Glozier, N. (2017). Effectiveness of eHealth interventions for reducing mental health conditions in employees: A systematic review and meta-analysis. PloS 
One, 12(12), e0189904. https://doi.org/10.1371/journal.pone.0189904

Stults-Kolehmainen, M. A., \& Sinha, R. (2014). The Effects of Stress on Physical

Activity and Exercise. Sports Medicine, 44(1), 81-121.

https://doi.org/10.1007/s40279-013-0090-5

Sundquist, J., Ohlsson, H., Sundquist, K., \& Kendler, K. S. (2017). Common

adult psychiatric disorders in Swedish primary care where most mental

health patients are treated. BMC Psychiatry, 17(1), 235.

https://doi.org/10.1186/s12888-017-1381-4

Svartvatten, N., Segerlund, M., Dennhag, I., Andersson, G., \& Carlbring, P.

(2015). A content analysis of client e-mails in guided internet-based

cognitive behavior therapy for depression. Internet Interventions, 2(2),

121-127. https://doi.org/10.1016/j.invent.2015.02.004

Temam, S., Billaudeau, N., \& Vercambre, M.-N. (2019). Burnout

symptomatology and social support at work independent of the private sphere: A population-based study of French teachers. International Archives of Occupational and Environmental Health, 92(6), 891-900. https://doi.org/10.1007/s00420-019-01431-6

Thiart, H., Lehr, D., Ebert, D., Berking, M., \& Riper, H. (2015). Log in and breathe out: Internet-based recovery training for sleepless employees with work-related strain - results of a randomized controlled trial.

Scandinavian Journal of Work, Environment \& Health, 41(2), 164-174. https://doi.org/10.5271/sjweh.3478

Topooco, N., Riper, H., Araya, R., Berking, M., Brunn, M., Chevreul, K., Cieslak, R., Ebert, D., Etchmendy, E., Herrero, R., Kleiboer, A., Krieger, T., García-Palacios, A., Cerga-Pashoja, A., Smoktunowicz, E., Urech, A., Vis, C., \& Andersson, G. (2017). Attitudes towards digital treatment for depression: A European stakeholder survey. Internet Interventions, 8, 19. https://doi.org/10.1016/j.invent.2017.01.001

Tsatsoulis, A., \& Fountoulakis, S. (2006). The protective role of exercise on stress system dysregulation and comorbidities. Annals of the New York Academy of Sciences, 1083, 196-213.

https://doi.org/10.1196/annals.1367.020

Tucker, P., Dahlgren, A., Akerstedt, T., \& Waterhouse, J. (2008). The impact of free-time activities on sleep, recovery and well-being. Applied 
Ergonomics, 39(5), 653-662.

https://doi.org/10.1016/j.apergo.2007.12.002

Tuomi, K., Vanhala, S., Nykyri, E., \& Janhonen, M. (2004). Organizational practices, work demands and the well-being of employees: A follow-up study in the metal industry and retail trade. Occupational Medicine, 54(2), 115-121. https://doi.org/10.1093/occmed/kqhoo5

Turner, R. J., Wheaton, B., \& Lloyd, D. A. (1995). The epidemiology of social stress. American Sociological Review, 6o(1), 104-125. https://doi.org/10.2307/2096348

Vahle-Hinz, T., Bamberg, E., Dettmers, J., Friedrich, N., \& Keller, M. (2014). Effects of work stress on work-related rumination, restful sleep, and nocturnal heart rate variability experienced on workdays and weekends. Journal of Occupational Health Psychology, 19(2), 217-230. https://doi.org/10.1037/ao036009

Van Dam, A., Keijsers, G. P. j., Eling, P. A. t. m., \& Becker, E. S. (2012). Impaired cognitive performance and responsiveness to reward in burnout patients: Two years later. Work \& Stress, 26(4), 333-346. https://doi.org/10.1080/02678373.2012.737550

van de Leur, J. C., Buhrman, M., Åhs, F., Rozental, A., \& Jansen, G. B. (2020). Standardized multimodal intervention for stress-induced exhaustion disorder: An open trial in a clinical setting. BMC Psychiatry, 2O(1), 526. https://doi.org/10.1186/s12888-020-02907-3

van der Doef, M., \& Maes, S. (1999). The Job Demand-Control (-Support) model and psychological well-being: A review of 20 years of empirical research. Work \& Stress, 13(2), 87-114. https://doi.org/10.1080/026783799296084 van der Hek, H., \& Plomp, H. N. (1997). Occupational stress management programmes: A practical overview of published effect studies. Occupational Medicine (Oxford, England), 47(3), 133-141. van der Klink, Blonk, R. W. B., Schene, A. H., \& van Dijk, F. J. H. (2003). Reducing long term sickness absence by an activating intervention in adjustment disorders: A cluster randomised controlled design. Occupational and Environmental Medicine, 6o(6), 429-437. Van Laethem, M., Beckers, D. G. J., Kompier, M. A. J., Kecklund, G., van den 
Bossche, S. N. J., \& Geurts, S. A. E. (2015). Bidirectional relations between work-related stress, sleep quality and perseverative cognition. Journal of Psychosomatic Research, 79(5), 391-398. https://doi.org/10.1016/j.jpsychores.2015.08.011 Vandevala, T., Pavey, L., Chelidoni, O., Chang, N.-F., Creagh-Brown, B., \& Cox, A. (2017). Psychological rumination and recovery from work in intensive care professionals: Associations with stress, burnout, depression and health. Journal of Intensive Care, 5, 16. https://doi.org/10.1186/s4056o017-0209-0

Viswesvaran, C., Sanchez, J. I., \& Fisher, J. (1999). The role of social support in the process of work stress: A meta-analysis. Journal of Vocational Behavior, 54(2), 314-334. https://doi.org/10.1006/jvbe.1998.1661 Vlaescu, G., Alasjö, A., Miloff, A., Carlbring, P., \& Andersson, G. (2016). Features and functionality of the Iterapi platform for internet-based psychological treatment. Internet Interventions, 6, 107-114. https://doi.org/10.1016/j.invent.2016.09.006

Vollmer-Conna, U., Fazou, C., Cameron, B., Li, H., Brennan, C., Luck, L., Davenport, T., Wakefield, D., Hickie, I., \& Lloyd, A. (2004). Production of pro-inflammatory cytokines correlates with the symptoms of acute sickness behaviour in humans. Psychological Medicine, 34(7), 12891297. https://doi.org/10.1017/so033291704001953

Vollrath, M. (2001). Personality and stress. Scandinavian Journal of Psychology, 42(4), 335.

Wager, T. D., Davidson, M. L., Hughes, B. L., Lindquist, M. A., \& Ochsner, K. N. (2008). Prefrontal-subcortical pathways mediating successful emotion regulation. Neuron, 59(6), 1037-1050. https://doi.org/10.1016/j.neuron.2008.09.006

Wagmiller, R. L., Lennon, M. C., \& Kuang, L. (2008). Parental health and children's economic well-being. Journal of Health and Social Behavior, 49(1), 37-55. https://doi.org/10.1177/002214650804900104

Weisel, K. K., Lehr, D., Heber, E., Zarski, A.-C., Berking, M., Riper, H., \& Ebert, D. (2018). Severely burdened individuals do not need to be excluded from internet-based and mobile-based stress management: Effect modifiers of treatment outcomes from three randomized controlled 
trials. Journal of Medical Internet Research, 2O(6), e211. https://doi.org/10.2196/jmir.9387

Wells, A., Fisher, P., Myers, S., Wheatley, J., Patel, T., \& Brewin, C. R. (2009). Metacognitive therapy in recurrent and persistent depression: A multiple-baseline study of a new treatment. Cognitive Therapy and Research, 33(3), 291-300. https://doi.org/10.1007/s10608-007-9178-2

Westman, M., \& Eden, D. (1997). Effects of a respite from work on burnout: Vacation relief and fade-out. Journal of Applied Psychology, 82(4), 516527. https://doi.org/10.1037/0021-9010.82.4.516

Wilkinson, R. G. (1992). National mortality rates: The impact of inequality? American Journal of Public Health, 82(8), 1082-1084.

Wingerden, J., \& Derks, D. (2018). The effectiveness of online stress management training interventions: A systematic literature review. International Journal of Learning and Development, 8(3), 57-86. https://doi.org/10.5296/ijld.v8i3.13600

World Health Organization. (1992). ICD-10 classification of mental and behavioural disorders (1st ed.). World Health Organization.

World Health Organization. (2008). The global burden of disease: 2004 update. World Health Organization.

World Health Organization. (2020, November 21). ICD-11-World Health Organization. https://icd.who.int/browse11/lm/en\#/http\%3a\%2f\%2fid.who.int\%2ficd\%2fentity\%2f264310751

Yaseen, Y. A. (2017). Adjustment disorder: Prevalence, sociodemographic risk factors, and its subtypes in outpatient psychiatric clinic. Asian Journal of Psychiatry, 28, 82-85. https://doi.org/10.1016/j.ajp.2017.03.012

Zetterqvist, K., Maanmies, J., Ström, L., \& Andersson, G. (2003). Randomized controlled trial of internet-based stress management. Cognitive Behaviour Therapy, 32(3), 151-160. https://doi.org/10.1080/16506070302316 


\section{LINKÖPING STUDIES IN BEHAVIOURAL SCIENCE}

199. ELOFSSON, JESSICA. Children's early mathematics learning and development. Number game interventions and number line estimations. 2017. ISBN: 978-91-7685-517-1

200. ÅHLFELDT, EMANUEL. Hållbart utvecklingsarbete i vård och omsorg. Ett institutionellt perspektiv på projekt i en professionell och byråkratisk kontext. 2017. ISBN: 978-91-7685-445-7

201. VERNMARK, KRISTOFER. Therapeutic alliance and different treatment formats when delivering internet-based CBT for depression. 2017. ISBN: 978-91-7685-436-5

202. FRANKL, MY. Psychotherapy for Substance Use Disorder - the importance of affects. 2017. ISBN: 978-91-7685-429-7

203. ABDULLA, AFRAH. Readiness or resistance? - Newly arrived adult migrants' experiences, meaning making, and learning in Sweden. 2017. ISBN: 978-91-7685-428-0

204. OLSSON, LINDA. "Count on me!”. Mathematical development, developmental dyscalculia and computer-based intervention. 2018. ISBN: 978-91-7685-409-9

205. COLLIANDER, HELENA, Being and Becoming a Teacher in Initial Literacy and Second Language Education for Adults. 2018. ISBN: 978-91-7685-304-7

206. TOPOOCO, NAIRA. Blended Cognitive Behavior Therapy. Efficacy and Acceptability for Treating Depression in the Adult and Adolescent Population. 2018. ISBN: 978-91-7685-297-2

207. SOLÍS MARCOS, IGNACIO. Challenges in Partially Automated Driving: A Human Factors Perspective. 2018. ISBN: 978-91-7685-296-5

208. THORSTEN, ANJA. Berättelseskrivande i skolan. Att studera, beskriva och utveckla ett kunnande. 2018. ISBN: 978-91-7685-258-3

209. ELEONOR, BREDLÖV EKNOR. Shaped for beauty. Vocational and gendered subjectivities in private education for the beauty industry. 2018 ISBN: 978-91-7685-248-4

210. VESTERGREN, SARA. Psychological change as an outcome of participation in collective action. 2018. ISBN:978-91-7685-242-2

211. MÖLLER, CLARA. Mentalizing. Competence and process. 2018. ISBN: 978-91-7685-189-O 
212. SÖDERBERG GIDHAGEN, YLVA. Psychological treatment of outpatients with substance use disorders in routine care - attachment style, alliance, and treatment outcome. 2018. ISBN: 978-91-7685-197-5

213. HAGMAN, WILLIAM. When are nudges acceptable? Influences of beneficiaries, techniques, alternatives and choice architects. 2018. ISBN: 978-91-7685-160-9

214. RAHM, LINA. Educational imaginaries: a genealogy of the digital citizen. 2019. ISBN: 978-91-7685-158-6

215. HALVARSSON LUNDQVIST, AGNETA. Learning Dynamics of Workplace Development Programmes. Studies in Swedish national programmes. 2019. ISBN: 978-91-7685-124-1

216. HOLMQVIST LARSSON, MATTIAS. Rupture and Repair in the Working Alliance: Relation to Psychotherapy Outcome and Within-Session Interaction. 2019. ISBN: 978-91-7685-111-1

217. LINDQVIST, HENRIK. Student teachers' and beginning teachers' coping with emotionally challenging situations. 2019. ISBN: 978-91-7685-078-7

218. GRÖNLUND, AGNETA. Återkoppling i analoga och digitala klassrum. Spänningsfyllda verksamheter i samhällskunskapsundervisning. 2019. ISBN: 978-91-7685-074-9

219. ÅKERBLOM, ERIKA. Utbildning och hälsa i nationens intresse. Styrningsteknologier och formering av en förädlad befolkning. 2019. ISBN: 978-91-7685-053-4220.

220. ÖSTERBORG WIKLUND, SOFIA. Folkbildning i global (o)rättvisa. Makt och motstånd i folkhögskolans internationalisering och transnationella kurser. 2019. ISBN: 978-91-7519-002-O

221. DAHLIN, MATS. Development and evaluation of an internet-based treatment for generalized anxiety disorder. An acceptance-based approach. 2020. ISBN: 978-91-7929-793-0

222. ERIKSSON, ELISABETH. Återkoppling i lågstadieklassrum. 2020. ISBN: 978-91-7929-769-5

223. KÖPSÉN, JOHANNA. Knowledge in VET curricula and power in society and labour market: Policy and practice: demands-based and employer-driven Swedish higher vocational education. 2020. ISBN: 978-91-7929-768-0

224. SJÖGREN, BJÖRN. Bystander behaviors in pree victimization: Associations with moral disengagement, efficacy beliefs, and student-teacher relationship quality 2021. ISBN: 978-91-7929-728-2 


\section{Papers}

The papers associated with this thesis have been removed for copyright reasons. For more details about these see:

http://urn.kb.se/resolve?urn=urn:nbn:se:liu:diva-172685 


\section{FACULTY OF ARTS AND SCIENCES}

Linköping Studies in Arts and Sciences • No 801

Linköping Studies in Behavioural Science • No 225

Department of Behavioural Sciences and Learning

Linköping University

SE-581 83 Linköping, Sweden

www.liu.se 